UNIVERSIDADE DE SÃO PAULO

FFCLRP- DEPARTAMENTO DE PSICOLOGIA E EDUCAÇÃO

PROGRAMA DE PÓS- GRADUAÇÃO EM PSICOBIOLOGIA

\title{
"Percepção visual e háptica de comprimentos de linha apresentados em diferentes formas"
}

Dissertação de Mestrado apresentada ao Departamento de Psicologia e Educação da Faculdade de Filosofia, Ciências e Letras de Ribeirão Preto da Universidade de São Paulo para a obtenção do título de Mestre em Ciências. Área de Concentração: Psicobiologia.

Ribeirão Preto- SP 
UNIVERSIDADE DE SÃO PAULO

FFCLRP- DEPARTAMENTO DE PSICOLOGIA E EDUCAÇÃO

PROGRAMA DE PÓS- GRADUAÇÃO EM PSICOBIOLOGIA

\section{"Percepção visual e háptica de comprimentos de linha} apresentados em diferentes formas"

Ana Paula Tosetto

Orientador

Prof. Dr. José Aparecido da Silva

Dissertação de Mestrado apresentada ao Departamento de Psicologia e Educação da Faculdade de Filosofia, Ciências e Letras de Ribeirão Preto da Universidade de São Paulo para a obtenção do título de Mestre em Ciências. Área de Concentração: Psicobiologia.

Ribeirão Preto- SP 
Tosetto, Ana Paula

Percepção visual e háptica de comprimentos de linha apresentados em diferentes formas. Ribeirão Preto, 2005.

107 p. : il. ; $30 \mathrm{~cm}$

Dissertação, apresentada à Faculdade de Filosofia, Ciências e Letras de Ribeirão Preto / USP - Dep. de Psicologia e Educação. Área de Concentração: Psicobiologia.

Orientador: Da Silva, José Aparecido

1. Percepção Visual. 2. Percepção Háptica.

3. Comprimentos de linha 
À Márcia e Antonio Carlos, meus pais, pelo amor, compreensão e encorajamento que me permitiram desenvolver meus estudos com perseverança e tranqüilidade. 


\section{AGRADECIMENTOS}

Ao Prof. Dr. José Aparecido da Silva, meu orientador, quem me dedicou a oportunidade, o conhecimento e a experiência para a realização deste Mestrado, bem como discussões e orientações acadêmicas que aguçaram e ampliaram meus interesses pela pesquisa.

Ao Prof. Dr. Nilton Pinto Ribeiro Filho, por prestar toda a assistência necessária para que eu pudesse analisar e refletir sobre minhas idéias e resultados relacionados à percepção e à psicofísica, cuja paciência e atenção o tornam um cientista muito especial.

Aos meus colegas de laboratório e pós- graduação, Waldemar Júnior, Luciana, Nice, Catarina, José Ricardo, Joseane, Elisângela e Veridiana pelas discussões de idéias, orientações técnicas, compartilhamento de artigos e, principalmente, pela amizade e momentos de descontração.

Aos funcionários da Faculdade de Filosofia, Ciências e Letras de Ribeirão Preto, em especial, à Denise A. S. dos Santos da Seção de Pós- Graduação, à Igor O. Douchkin, técnico do Laboratório de Percepção e Psicofísica, à Regina Teles Gonçalves, secretária do Prof. Dr. José Aparecido da Silva e à Renata B. Vicentini, secretária da Psicobiologia, por sua prontidão em resolver quaisquer problemas que ocorreram no decorrer desta PósGraduação. 


\section{PREFÁCIO}

O interesse pela área de Psicofísica e Percepção surgiu quando freqüentei o Curso de Aperfeiçoamento de Psicobiologia, ministrado na Faculdade de Filosofia, Ciências e Letras de Ribeirão Preto, USP/ SP, no segundo semestre de 2002. Na ocasião, tive a oportunidade de assistir a uma aula sobre Psicofísica, com o Prof. Dr. José Aparecido da Silva, e, desde então, iniciei os estudos nesta área. Minha experiência prévia com a Psicologia Cognitiva durante a Graduação e, em particular, com a Terapia Cognitiva através do Curso de Especialização em Terapia Cognitiva (Instituto de Terapia Cognitiva, Dra. Ana Maria Serra), suscitou um interesse maior em aprofundar meus conhecimentos em Psicofísica e Percepção, visto que os processos sensoriais, bem como sua mensuração, são fundamentais para o entendimento do funcionamento integral de um indivíduo. E este conhecimento advém da Psicofísica, ciência que investiga a relação entre estímulos e as respostas dadas a eles e suas proporções. No início de 2003, participei da disciplina "Inteligência emocional" e de alguns cursos de extensão ministrados pelo Prof. Dr. José Aparecido da Silva, ingressando no Programa de Pós- Graduação em Psicobiologia como sua orientanda, no segundo semestre deste mesmo ano. A partir de inúmeras discussões junto ao Prof. José Aparecido e alguns professores e alunos do programa e, através das disciplinas cursadas ao longo de todo o mestrado, tive a oportunidade de ampliar meus conhecimentos e acrescentar importantes considerações e promover modificações no meu projeto sob sua orientação e dedicação. O resultado de toda esta experiência resultou na dissertação que ora estamos apresentando para a obtenção do Título de Mestre em Ciências. 


\section{SUMÁRIO}

RESUMO

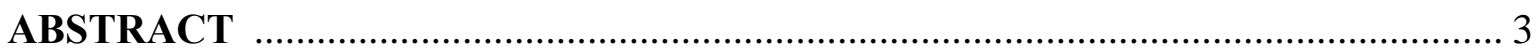

I. INTRODUÇÃ

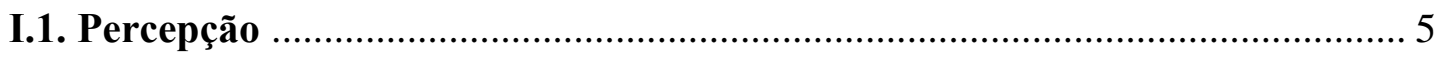

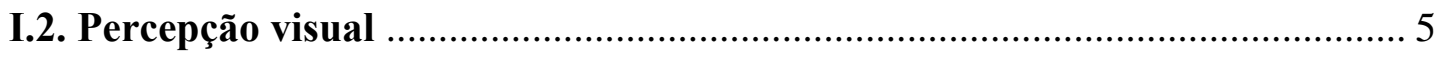

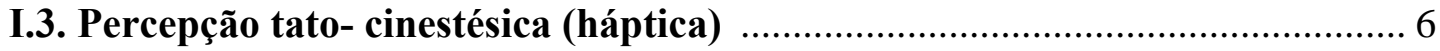

I.4. Ilusões visuais e hápticas geométricas …................................................ 9

I.5. Estudos sobre percepção de comprimento de linha ................................... 11

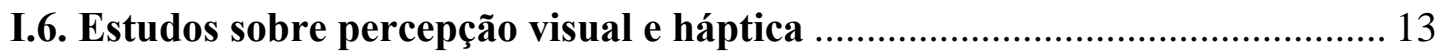

I.7. Algumas evidências neuropsicológicas sobre percepção visual e háptica .... 22

I.8. Diferenças de gênero na percepção e cognição espacial ................................ 23

I.8.1. Teorias biológicas ........................................................................ 24

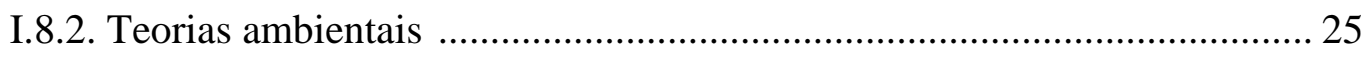

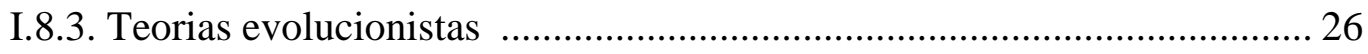

I.9. Julgamentos perceptivos em função do gênero …....................................... 27

I.10. Julgamentos perceptivos em função da idade .......................................... 28

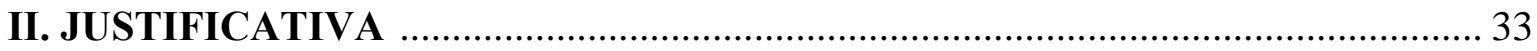

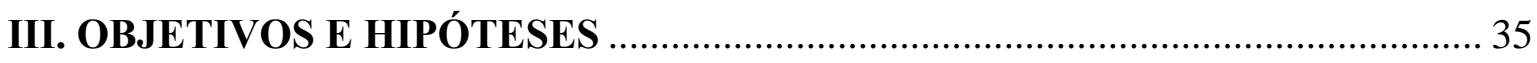

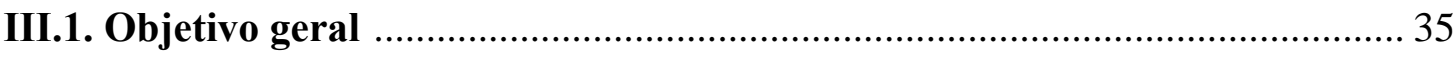

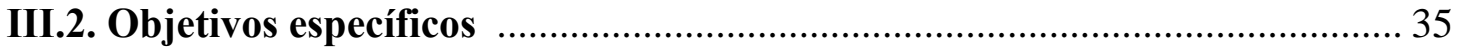

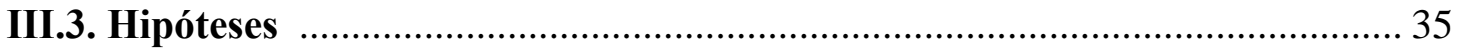

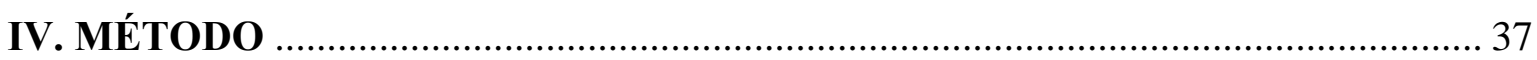

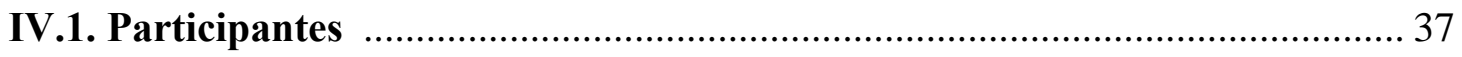




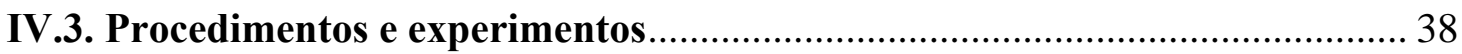

IV.3.1.Experimento 1 - Estimação de magnitude visual (EMV) ..................... 40

IV.3.2. Experimento 2 - Estimação de magnitude não visual (EMNV) .............. 40

IV.3.3. Experimento 3 - Estimação de categoria visual (ECV) ......................... 41

IV.3.4.Experimento 4 - Estimação de categoria não visual (ECNV) ................ 42

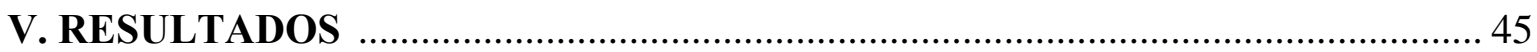

V.1. Análise das estimativas de magnitude numérica ........................................ 45

V.1.1. Análise dos expoentes da função de potência ........................................ 50

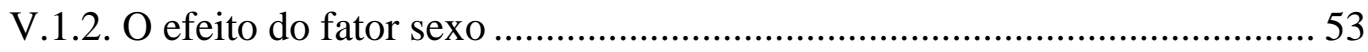

V.2. Análise das estimativas de categoria numérica .......................................... 53

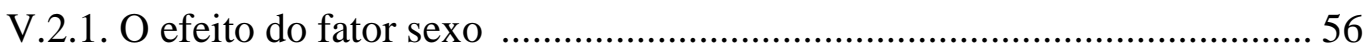

V.3. Comparação entre os métodos psicofísicos: estimativas de magnitude numérica e estimativas de categoria numérica ............................................... 57

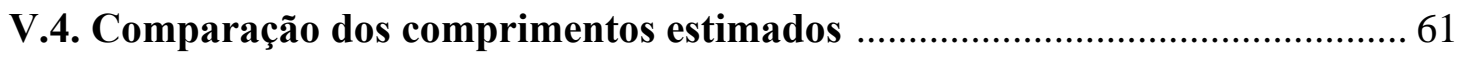

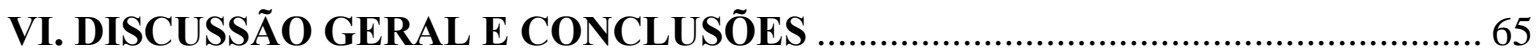

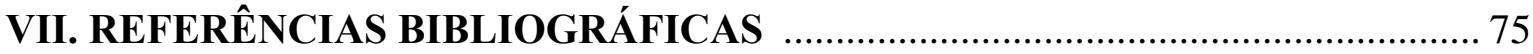

\section{ANEXOS}

Anexo 1- Termo de Consentimento Livre e Esclarecido para o Sujeito ...................... 85

Anexo 2- Instruções - Tipo de Experimento: Estimação de Magnitude Visual .......... 86

Anexo 3- Instruções - Tipo de Experimento: Estimação de Magnitude Não-

Visual

Anexo 4- Instruções - Tipo de Experimento: Estimação de Categoria Visual ........... 88

Anexo 5- Instruções - Tipo de Experimento: Estimação de Categoria Não-

Visual 
Anexo 6- Modelo de Folha de resposta. Tipo de experimento: Estimação de

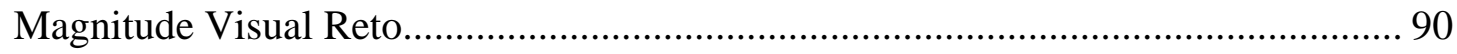

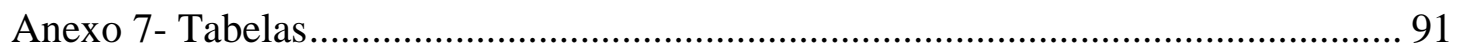

Anexo 8 - Declaração do Comitê de Ética em Pesquisa ............................................. 95 


\section{ÍNDICE DAS FIGURAS}

Figura 1- Representação dos 39 estímulos, peças retangulares de acrílico fumê, com $6 \mathrm{~mm}$ de espessura e 13 comprimentos diferentes $(2,5,4,5,7,0,12,0,20,0,31,0$, 45,0, 55,0, 63,0, 70,0, 83,0, 95,0, 118,0 cm), utilizados em cada situação experimental: forma reta (painel superior à esquerda), forma em L (painel superior à direita) e forma curva (painel inferior).

Figura 2- Representação do ambiente experimental. O observador está sentado em uma cadeira fixa, situada à $68 \mathrm{~cm}$ do estímulo apresentado em um quadro (90 x 120 $\mathrm{cm}$ ) posicionado à sua frente, podendo mover a cabeça livremente. O estímulo foi posicionado à altura dos olhos do observador. Tipo de experimento: Visual Reto (painel à esquerda), Visual em L (painel à direita) .

Figura 3- Representação do ambiente experimental. O observador está sentado em uma cadeira fixa, situada à $68 \mathrm{~cm}$ do estímulo apresentado em um quadro (90 x 120 $\mathrm{cm}$ ) posicionado à sua frente, podendo deslizar a ponta de dois dedos até três vezes pelo estímulo. Se necessário, o observador podia deslocar ombros e braços livremente. O estímulo foi posicionado de acordo com a posição do braço estendido horizontalmente do observador ao atingir o quadro. Tipo de experimento: Não Visual Reto (painel à esquerda), Não Visual Curvo (painel à direita).

Figura 4- Médias geométricas e seus desvios padrão das estimativas de magnitude numérica para modalidade sensorial não vidente em função do comprimento físico das estimativas para a situação forma, reta x em L x curva. As barras verticais representam o desvio padrão da média geométrica e estão em uma direção por motivos estéticos. As barras com chapéus menores indicam a situação de forma reta, as de chapéu médio, as de forma em L e as de maior chapéu, as de forma curva.

Figura 5- Médias geométricas e seus desvios padrão das estimativas de magnitude numérica para modalidade sensorial vidente em função do comprimento físico das estimativas para a situação forma, reta x em $\mathrm{L}$ x curva. As barras verticais representam o desvio padrão da média geométrica. As barras com chapéus menores indicam a situação de forma reta, as de chapéu médio, as de forma em $\mathrm{L}$ e as de maior chapéu, as de forma curva.

Figura 6- Logaritmo das médias geométricas das estimativas de magnitude numéricas em função do logaritmo dos comprimentos físicos para os níveis do fator forma para a modalidade não vidente.

Figura 7- Logaritmo das médias geométricas das estimativas de magnitude numéricas em função do logaritmo dos comprimentos físicos para os níveis do fator forma para modalidade vidente.

Figura 8- Ilustração dos expoentes médios da função de potência das estimativas de magnitude numérica para os fatores forma e modalidade sensorial. 
Figura 9- Expoentes médios da função de potência das estimativas de magnitude numérica para os níveis dos fatores modalidade e forma. As barras verticais indicam o desvio padrão da média aritmética e o asterisco $(*)$ indica que o valor do teste t de Student para medidas repetidas do pareamento dos expoentes empíricos e o preditor $(1,0)$ foi significativo para $\mathbf{p} \leq 0,05$

Figura 10- Médias aritméticas e seus desvios padrão das estimativas de categoria numérica em função do comprimento físico $(\mathrm{cm})$ para a modalidade sensorial não vidente e os níveis do fator forma. As barras verticais representam o desvio padrão da média aritmética. As barras com chapéus menores indicam a situação de forma reta, as de chapéu médio, as de forma em L e as de maior chapéu, as de forma curva...54

Figura 11- Médias aritméticas e seus desvios padrão das estimativas de categoria numérica em função do comprimento físico para a modalidade sensorial vidente e os níveis do fator forma. As barras verticais representam o desvio padrão da média aritmética. As barras com chapéus menores indicam a situação de forma reta, as de chapéu médio, as de forma em L e as de maior chapéu, as de forma curva.

Figura 12- Média aritmética da estimativa de categoria numérica em função do logaritmo da média geométrica da estimativa de magnitude numérica para os níveis do fator forma e modalidade não vidente.

Figura 13- Média aritmética da estimativa de categoria numérica em função do logaritmo da média geométrica da estimativa de magnitude numérica para os níveis do fator forma e modalidade vidente. 


\section{ÍNDICE DAS TABELAS}

Tabela 1- Correlações de Pearson entre o observador 10 e a média aritmética dos demais participantes, na situação experimental forma curva e modalidade sensorial vidente para estimativas de magnitude.

Tabela 2- Número de igualdades e inversões em cada situação experimental de forma e modalidade sensorial para estimativas de magnitude (EM) e de categoria (EC) numéricas..

Tabela 3- A tabela indica as médias geométricas, os desvios padrão e as amplitudes das estimativas de magnitude numérica para o menor comprimento físico (c1) e para o maior comprimento físico (c13), para as situações de forma: reta (R), em L (L) e curva (C) e de modalidade sensorial: não vidente (NV) e vidente (V). 


\section{RESUMO}

O presente estudo buscou investigar se participantes videntes apresentaram a mesma performance nos julgamentos de comprimentos de linha do que participantes videntes vendados, cujas estimativas foram realizadas através da percepção tato-cinestésica (háptica). Além disso, buscou-se conhecer se esta relação é mantida nas três diferentes formas de comprimentos de linha apresentados: reta, em L e curva e na utilização de dois métodos psicofísicos diferentes: estimação de magnitude e estimação de categoria. A amostra foi constituída por 120 participantes com visão normal, de ambos os sexos, com idade entre 18 e 35 anos, divididos em dois grupos de acordo com a modalidade sensorial: vidente e não vidente (vidente vendado). Os experimentos consistiram em: 1. estimação de magnitude visual; 2. estimação de magnitude não-visual; 3. estimação de categoria visual e 4. estimação de categoria não-visual. Trinta participantes se submeteram a cada um destes experimentos, divididos em três grupos de 10, de acordo com a forma dos comprimentos. Análises estatísticas permitiram concluir que: 1) comprimentos de linha diferentes foram percebidos como diferentes em todos os grupos; 2) a forma dos comprimentos de linha não interferiu nos julgamentos dos participantes; 3) a modalidade sensorial não interferiu nos

julgamentos de comprimentos de linha dos participantes e 4) a relação entre o comprimento físico e a estimativa foi mantida em ambos os métodos utilizados, estimação de magnitude e estimação de categoria. 



\begin{abstract}
The present study aimed to investigate if sighted participants presented the same performance in the judgements of length of line as blindfolded sighted participants, whose estimates were performed through the touch-cinestesic (haptic) perception. Besides, it aimed to know if this relation is kept in the three different shapes of line length presented: straight; L-shaped and curved and in the use of two different psychophysics methods: magnitude estimation and category estimation. The sample was composed by 120 participants with normal sight, of both sexes, aged between 18 and 35, divided into two groups according to the sensorial mode: sighted participants and blindfolded sighted participants. The experiments consisted in: 1. visual magnitude estimation; 2. non-visual magnitude estimation; 3 . visual category estimation and 4. non-visual category estimation. Thirty participants were submitted to each of them, divided into three groups of ten, according to the shape of the lengths. Statistic analysis allowed to conclude that: 1) different line lengths were perceived different in all the groups; 2) the shape of the line lengths did not interfere in the judgements of the participants; 3) the sensorial mode did not interfere in the participants' judgements of line lengths; 4) the relation between physical length and estimate was kept in the use of both methods: magnitude estimation and category estimation.
\end{abstract}





\section{INTRODUÇÃO}

\section{I.1. Percepção}

A percepção consiste em um processo que, na presença de um estímulo, capta as informações através de receptores sensoriais distribuídos ao longo do organismo, enviando-as para o sistema nervoso central, resultando no reconhecimento e identificação do objeto. Este processo depende de uma série de fatores como intensidade do estímulo, representação mental do estímulo, interpretação, experiência emocional e condições ambientais, podendo sofrer grandes interferências e até prejudicar os sinais de respostas do sujeito. Sternberg (2000) define percepção como o conjunto de processos pelos quais reconhecemos, organizamos e entendemos as sensações recebidas dos estímulos ambientais.

\section{I.2. Percepção visual}

Percepção visual é o processo de construção de uma representação interna do ambiente local, baseada nos padrões de luz refletida de objetos e superfícies na cena. Isto é conveniente para categorizar as operações que contribuem para a percepção visual de acordo com a influência relativa de informação bottom-up, como as propriedades dos estímulos, e de informação top-down, como memória e expectativa, sobre seu funcionamento normal (Yantis, 1998).

A visão primitiva refere-se ao funcionamento da retina e áreas corticais primitivas em resposta aos padrões de claro e escuro que variam sobre espaço e tempo. A visão de alto nível está preocupada com operações complexas, tais como reconhecimento de faces e 
objetos, imagem mental e outras formas de cognição visual; estas operações interagem excessivamente com a memória e o conhecimento (Yantis, 1998).

Entre a visão primitiva e a visão de alto nível está a visão intermediária. Dentre as operações deste nível do sistema visual estão os processos de organização perceptual e atenção. A organização perceptual se refere àquelas operações responsáveis por unir fragmentos de imagens que são criadas pela obstrução parcial de um objeto por outro (Kellman \& Shipley, 1991). A atenção visual se refere àquelas operações perceptuais responsáveis por selecionar objetos relevantes ou importantes para a tarefa, a fim de favorecer o processamento visual detalhado como a identificação. A seleção é solicitada para minimizar a interferência entre diferentes operações de identificação (Tsotsos, 1990).

\section{I.3. Percepção tato-cinestésica (háptica)}

O toque (tato) permite a percepção de objetos próximos quando a visualização não é possível e nos informa sobre propriedades do objeto e eventos (por ex.: aqueles sinalizados por vibrações) inacessíveis a outros sentidos. A percepção cinestésica consiste naqueles casos de percepção do tato, na qual variações na estimulação cutânea, como contato rígido ou falta de contato entre a superfície da pele e o estímulo externo, informam suas propriedades, espacial ou de textura, ao observador (Owem \& Brown, 1970).

Do ponto de vista funcional, a sensibilidade cutânea proporciona qualidade de estimulação externa à superfície do corpo por meio de receptores dentro da pele e associados ao sistema nervoso. Enquanto a sensibilidade cinestésica proporciona ao observador a qualidade da postura do corpo estática e dinâmica, como o posicionamento relativo da cabeça, torso, membros e efetores através de: a) informação aferente originada 
dentro do músculo, das articulações e pele e b) cópia eferente, a qual é correlacionada com a informação do músculo eferente para altos centros nervosos (Owem \& Brown, 1970).

A percepção "háptica" refere-se à percepção do tato na qual ambas as sensibilidades, do tato e cinestésica, levam informações significativas sobre o objeto distal e eventos. A maioria das nossas percepções táteis diárias e tarefas controladas pelo tato pertencem a esta categoria (Loomis \& Lederman, 1986).

O tato difere da visão por ser uma modalidade de contato cujos receptores estão espalhados por todo o corpo. Como resultado, o campo da percepção tátil é consistentemente menor do que o campo perceptual visual. Considerando este campo visual, isto é, a porção do espaço que ativa os processos neurais em um dado momento e tem forma e tamanho estáveis (um alongamento horizontalmente e uma elipse incompleta), a forma e o tamanho do campo perceptual tátil varia de acordo com o modo de exploração adotado pelo observador. Na percepção tátil passiva, onde não existe movimento, este campo é muito pequeno, visto que ele é limitado pela superfície da pele em contato com objetos. Embora algumas discriminações são possíveis nesta situação, habilidades perceptuais táteis são limitadas pela ausência de movimento (Gentaz \& Hatwell, 2004).

$\mathrm{Na}$ maior parte do tempo, movimentos voluntários devem ser realizados. A amplitude destes movimentos, requerida por tocar o objeto todo, varia em relação ao tamanho do objeto a ser percebido. Nesta percepção háptica (tato-cinestésica), o tamanho do campo perceptual varia de acordo com o segmento do corpo ativado (um dedo, uma mão inteira, duas mãos associadas com movimentos dos braços etc). Quando apenas um dedo está em ação, dicas de referência externa são drasticamente reduzidas, considerando que dicas egocêntricas (dicas centradas no corpo do observador) permanecem úteis e podem atuar como uma forma de referência eficiente. A exploração com as duas mãos livres aumenta o campo perceptual háptico e facilita a percepção de dicas contextuais 
(Millar, 1994, Millar \& Al-Attar, 2000, 2002). Entretanto, aumentar o campo perceptual háptico pela ativação de todos os dedos não significa que todos os dados sensoriais fornecidos são processados simultaneamente (Gentaz \& Hatwell, 2004).

Devido à exploração manual confiar nos movimentos intencionais especializados de acordo com a propriedade dos objetos a serem percebidos (Lederman \& Klatzky, 1987, 1993), a percepção háptica espacial pode ser incompleta ou menos estruturada do que a percepção visual. Embora movimentos exploratórios sejam necessários na visão também, a exploração e o processamento hápticos são consistentemente mais seqüências do que são os visuais. Conseqüentemente, a memória de trabalho é excessivamente carregada e uma síntese mental é necessária para obter uma representação unificada do objeto (Revesz, 1950).

O papel central desempenhado pelos movimentos significa que as áreas mais móveis e as áreas mais dotadas de receptores sensoriais são as mais eficientes no domínio tátil. Portanto, as mãos, ou mais especificamente, o sistema mão-braço são os mais eficientes. Devido à percepção háptica manual prover informações relacionadas às propriedades espaciais do ambiente, ela é grandemente redundante em relação à visão. Sob certas condições, isto permite acesso às propriedades espaciais de textura, forma, tamanho, localização (direção e distância), orientação e assim por diante. Entretanto, em muitas circunstâncias, ela é menos eficiente do que a visão no domínio espacial, porque o percepto tátil final depende da qualidade dos movimentos exploratórios conduzidos, o modo no qual o input é processado e a síntese mental feita no final da exploração (Gentaz \& Hatwell, 2004).

Em síntese, Lederman, Browse e Klatzky (1988) consideram algumas diferenças notáveis entre o sistema visual e háptico: 1) Os dois sistemas não são igualmente sensitivos para todas as formas de energia física, nem são processos prováveis para os mesmos 
atributos de objetos e superfícies; 2) A retina é uma superfície estendida que movimenta como uma unidade, enquanto que a mão apresenta uma estrutura livre com cinco apêndices, a qual pode ser movimentada semi independentemente durante a exploração e 3) Enquanto o sistema háptico utiliza a informação aferente obtida diretamente de uma seqüência de contatos, a visão usualmente tem disponível a informação para o processamento dentro da imagem da retina singular.

\section{I.4. Ilusões visuais e hápticas geométricas}

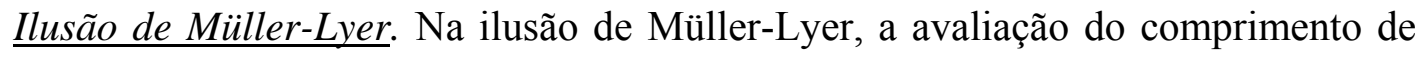
um segmento de linha é modificada de acordo com a orientação das setas situadas em ambos os finais do segmento. O comprimento do segmento de linha com setas apontando para dentro é superestimado quando comparado com outro, de mesma extensão, com setas apontando para fora. O procedimento que permite a avaliação da presença e da intensidade desta ilusão é geralmente o seguinte: os dois segmentos são apresentados lado a lado; um deles é o padrão e seu comprimento é fixo, considerando que o comprimento do outro pode variar; o ângulo formado por cada seta e o segmento horizontal varia de acordo com a pesquisa, mas são mais freqüente $45^{\circ}$ ou $30^{\circ}$. Na visão, as duas figuras são desenhadas num papel preto ou branco e na modalidade háptica elas estão em relevo. O relevo linear é obtido por linhas de pontos elevados ou barras pequenas tridimensionais (Gentaz \& Hatwell, 2004).

Ilusão horizontal-vertical. $\mathrm{Na}$ ilusão vertical-horizontal, o comprimento do segmento vertical é superestimado quando comparado com o mesmo segmento em uma orientação horizontal. Esta ilusão pode ser decomposta em duas ilusões: a ilusão vertical observada em formas de L (a ilusão vertical-horizontal pura) e a ilusão de bisseção 
observada quando um segmento é bissecionado enquanto o outro não é, como na figura $T$ invertido (Gentaz \& Hatwell, 2004). Por contrate, os fatores responsáveis pela presença da ilusão vertical são específicos para cada modalidade. Na visão, numerosos estudos têm mostrado que o erro é devido a uma anisotropia do campo visual (Prinzmetal \& Gettleman, 1993). Na anisotropia do espaço percebido, as dimensões percebidas se diferenciam em magnitude de acordo com a direção visual da dada dimensão física. Ou seja, uma mesma extensão observada na horizontal é percebida diferentemente desta mesma extensão em outra orientação espacial, por exemplo, na vertical (Verrillo \& Irvin, 1980). Por causa da forma da retina, o campo visual é uma elipse orientada horizontalmente. Assim, linhas verticais geralmente serão mais estreitas ao limite do campo visual do que serão as linhas horizontais, portanto, linhas verticais parecerão mais longas. Por outro lado, na modalidade háptica, estudos têm mostrado o papel dos movimentos exploratórios, ressaltando o papel da direção do movimento (Day \& Avery, 1970, Deregowski \& Ellis, 1972, Wong, 1977).

A implicação teórica destas ilusões encontradas em vários estudos consiste em um fator comum, a bisseção, que afeta as modalidades, visual e háptica, no mesmo modo. Mas ao contrário da ilusão Müller-Lyer, existem também fatores específicos para cada sistema. Os movimentos exploratórios afetam apenas a ilusão háptica, assim como a anisotropia do campo visual tem um efeito apenas na visão. A presença da ilusão vertical na modalidade háptica, incluindo sua presença no cego precoce, invalida as explicações exclusivamente visuais deste erro. Realmente, esta ilusão é devido a um fator perceptivo comum para as duas modalidades (bisseção), visto que fatores específicos de modalidades, resultando em erros análogos, são também responsáveis pela ilusão em cada sistema (Gentaz \& Hatwell, 2004). 


\section{I.5. Estudos sobre percepção de comprimento de linha}

A existência de diferenças individuais em julgamentos psicofísicos é bem conhecida (Johnson, 1945). Reproduções ou bisseções de linhas visuais podem diferir consideravelmente entre participantes (Fischer, 1994). Estas diferenças podem depender da comparação de comprimentos em tais tarefas. Erros em julgamento comparativo são chamados erros espaciais quando eles dependem da posição diferente no espaço do estímulo comparado (Guilford, 1954).

Verrillo e Irvin (1980) desenvolveram um estudo para determinar o comprimento subjetivo de linhas através do método de estimação de magnitude absoluta, isto é, sem um padrão ou uso de um módulo. Eles pretendiam averiguar mudanças no comprimento percebido, as quais ocorrem como funções da orientação e da polaridade de contraste. Os experimentos consistiram em: Experimento 1A: para determinar se a Ilusão VerticalHorizontal podia ser obtida pelo método de estimação de magnitude, no qual os participantes estimaram os comprimentos de segmentos de linhas pretas verticais e horizontais de figuras em forma de $\mathrm{L}(1,2,4,11,22,40$ e $110 \mathrm{~cm})$. Julgamentos verticais e horizontais foram feitos nas mesmas sessões; experimento 1B: os participantes avaliaram ou linhas pretas verticais ou linhas pretas horizontais $(1,4,2,8,5,0,13,0,26,0,52,0$ e 132,5 $\mathrm{cm}$ ). Para cada participante, um período mínimo de um mês separou as duas sessões experimentais para reduzir a possibilidade dos participantes utilizarem números com base na memória; experimento 1C: 9 linhas verticais e 9 linhas horizontais brancas de comprimentos diferentes foram utilizadas para os julgamentos realizados em um quarto totalmente escuro, por 11 participantes que participaram de duas sessões experimentais separadas, no mínimo, por um mês. Os resultados mostraram que linhas brancas e pretas de comprimento físico igual foram julgadas como iguais perceptivelmente; linhas verticais 
foram julgadas como perceptivelmente maiores do que linhas horizontais, quando avaliadas separadamente (1B) ou dentro do contexto de Ilusão Vertical-Horizontal (1A) e que as diferenças virtualmente desaparecem quando linhas são avaliadas separadamente na ausência de dicas contextuais (no escuro).

Massin (2002) conduziu dois experimentos para testar se diferenças individuais em erros espaciais para comprimentos de linha ocorrem e se essas diferenças persistem. O experimento 2 foi uma repetição do experimento 1 . Vinte e cinco estudantes universitários com visão normal ou corrigida participaram de ambos os experimentos, com um intervalo entre os experimentos 1 e 2 de aproximadamente dois meses. Os estímulos apareceram na tela de um computador fronte-paralela ao participante, em uma distância de $35 \mathrm{~cm}$. Os estímulos eram duas linhas pretas simultâneas apresentadas por $50 \mathrm{~ms}$. As linhas eram verticais, uma na esquerda e a outra na direita, ou horizontais, uma acima e a outra abaixo do cruzamento, cujo centro era colinear com os centros das linhas apresentadas. A fixação do cruzamento aparecia primeiramente e em seguida os estímulos eram apresentados, perfazendo um total de 50 reproduções de duas linhas verticais e 50 reproduções de duas linhas horizontais. As séries destes 100 estímulos eram mostradas uma vez com os estímulos em ordem randômica. Os participantes tinham que focalizar no cruzamento e relatar verbalmente, para cada estímulo, qual das linhas pareciam maiores ou se elas pareciam iguais. Antes de cada experimento, era dito aos participantes que os comprimentos em cada par de linhas eram escassamente discrimináveis. Houve 24 erros espaciais significativos no experimento 1, e 26 erros no experimento 2. Os resultados de ambos os experimentos mostraram que $24 \%$ dos participantes compararam linhas corretamente; $32 \%$ superestimaram o comprimento da linha na esquerda; 30\% superestimaram o comprimento da linha na direita; $28 \%$ superestimaram o comprimento da linha no topo e $10 \%$ superestimaram o comprimento da linha localizada abaixo. 
Aproximadamente metade dos participantes que superestimou o comprimento da linha na esquerda também superestimou o comprimento da linha no topo. Para alguns participantes não ocorreu erro espacial, enquanto para outros participantes erros espaciais ocorreram apenas na horizontal, apenas na vertical ou ambos nas dimensões horizontal e vertical do campo visual. Para $72 \%$ dos participantes não ocorreu erro espacial ou o mesmo erro espacial ocorreu em ambos os experimentos. Para o restante dos participantes erros espaciais diferiram nos dois experimentos. $\mathrm{O}$ autor concluiu que diferenças individuais em erros espaciais ocorreram e que a maioria dessas diferenças persistiram sobre um período de cerca de dois meses, revelando a necessidade de análises entre-grupos e intra-grupos em estudos de julgamento comparativo.

\section{I.6. Estudos sobre percepção visual e háptica}

Durante séculos, ilusões perceptuais (então chamadas ilusões ópticas geométricas) eram pensadas dizer respeito apenas ao sistema visual e serem devidas a algumas propriedades específicas deste sistema (Eagleman, 2001). A questão se estas ilusões também ocorrem no tato foi investigada na primeira metade do século 20 , em particular pelos psicólogos da Gestalt. Estes pesquisadores defenderam que os erros sistemáticos em relação à estimação do tamanho ou da forma de certas figuras não estavam ligados a um sentido particular, mas eram resultados do funcionamento do próprio sistema nervoso, particularmente das interações (chamadas efeitos de campo) entre as diferentes partes da figura. Visto que, de acordo com os psicólogos da Gestalt, os mesmos controles de processamento são condições em todas as modalidades perceptuais, ilusões análogas à visão devem ser também apresentadas no tato. Na verdade, isto foi observado por Revesz (1934) e Bean (1938), que encontraram que quase todas as ilusões visuais existiam na 
modalidade tátil. Entretanto, desde os anos 60, estudos adicionais com melhor controle metodológico produziram algumas vezes resultados contraditórios (Gentaz \& Hatwell, 2004).

De acordo com Gentaz e Hatwell (2004), a presença ou ausência de ilusões visuais na modalidade háptica pode ser entendida através de três características especiais relativas ao modo pelo qual um objeto é explorado e, conseqüentemente, o modo como o input háptico é codificado:

1) Durante a exploração, o tamanho do campo perceptual varia dependendo se o participante usa a face interna de um dedo indicador apenas, a mão toda ou ambas as mãos. No primeiro caso, as linhas que induzem o erro visual não devem ser percebidas pela mão e a ilusão háptica não deve aparecer;

2) A intervenção da informação cinestésica resultante dos grandes movimentos exploratórios, isto é, quando o sistema mão- braço está envolvido na percepção de um grande estímulo, poderia produzir distorções espaciais (Faineteau, Gentaz \& Viviani, 2003);

3) As dicas gravitacionais geradas pelas forças antigravidade permitindo que o braço seja mantido no ar podem prover dicas de referência não apresentadas na ilusão visual (Gentaz \& Hattwell, 1996, 1998, 1999).

Em uma série de publicações, Gibson $(1962,1963,1966)$ descreveu informalmente uma tarefa comparando forma global através da modalidade cruzada visual-háptica e concluiu que um observador, após muito pouca prática, é capaz de distinguir entre os objetos tangíveis e compará-los às suas réplicas visíveis com pouco erro. Admitindo esta conclusão, isto sugere diretamente que as duas modalidades sensoriais diferentes ou dividem uma representação de alto nível de forma ou têm representações de forma 3- D 
com formatos suficientemente similares para comparações efetivas (Norman, Norman, Clayton, Lianekhammy \& Zielke, 2004).

A crença de Gibson (1962, p. 489) na "equivalência dos dois modos de percepção" (isto é, visão e tato) tem sido sustentada por estudos mais recentes. Além disso, estudos confirmam que o reconhecimento háptico de objetos, semelhante ao visual, pode de fato ser realizado rápido e acuradamente. Klatzky, Lederman e Metzger (1985), por exemplo, mostraram que a identificação háptica de um objeto 3- D tipicamente ocorre dentro de 1- 2 segundos e que $94 \%$ dos reconhecimentos corretos ocorreram dentro de 5 segundos ou menos.

Garbin (1990), ao investigar a equivalência perceptual visão-tato em crianças através de técnicas escalares multidimensionais, comparada aos resultados de um grupo de adultos, verificou que tanto as crianças como os adultos basearam seus julgamentos na largura e forma dos estímulos tridimensionais. Além disso, ambos os grupos enfatizaram o atributo tamanho na similaridade do julgamento. As comparações das dimensões (complexidade e angulosidade) dos julgamentos táteis de crianças e adultos revelaram que as crianças apresentam uma grande equivalência perceptual entre soluções visual e tátil em relação aos adultos. Visto que as crianças apresentam uma maior tendência em explorar formas de objetos hapticamente do que os adultos, sugere- se que a equivalência perceptual entre o sistema visual e háptico é aumentada pela experiência bimodal.

A ausência de diferenças conforme a condição visual também foi encontrada por Casla, Blanco e Travieso (1999) em adultos cegos e por Hatwell (1960) em crianças cegas, utilizando figuras de Müller-Lyer. Entretanto, quando os participantes eram solicitados a explorarem livremente o estímulo com as duas mãos, Hatwell (1960) obteve uma ilusão mais fraca na modalidade háptica do que na modalidade visual em um grupo misto de crianças totalmente cegas tardia e precocemente. 
Lederman, Klatzky, Chataway e Summers (1990) conduziram uma série de experimentos para investigar o papel da imagem visual no reconhecimento háptico de representações em alto-relevo de objetos comuns, nos quais os participantes exploraram os estímulos com as duas mãos. Ao contrário dos achados citados anteriormente, estes autores encontraram que, observadores videntes vendados apresentaram performance ruim no experimento 1, enquanto outros achados convergiram para indicar que um processo de translação visual foi adotado, incluindo acurácia e velocidade de reconhecimento e performance superior com representações $2 \mathrm{D}$ em relação às $3 \mathrm{D}$, à despeito da equivalência na linha ordenada de complexidade. Observadores cegos congênitos realizaram a mesma tarefa com performances ainda piores, porém elas não diferiram para representações $2 \mathrm{D} x$ 3D, provendo evidência adicional de que translação visual foi usada pelos videntes. Tal performance limitada é contrastada com a habilidade considerável com a qual objetos comuns reais são processados e reconhecidos hapticamente.

Loomis, Klatzky e Lederman (1991) compararam os desempenhos de adultos videntes e videntes vendados na identificação de desenhos em auto-relevo. Na condição háptica, os participantes podiam explorar com um dedo indicador apenas ou com dois dedos indicadores. Na condição visual, os participantes olhavam os desenhos através de um tubo cujo diâmetro igualava o tamanho do campo visual com o tamanho do campo háptico quando um ou dois dedos indicadores eram usados. Resultados mostraram que quando o campo visual correspondia ao campo háptico de um dedo indicador, não haviam diferenças entre as performances visual e háptica. Mas quando o campo visual correspondia ao campo háptico de dois dedos indicadores, performances visuais melhoravam, enquanto performances hápticas não. Isto significa que a capacidade do processamento paralelo do tato nesta tarefa complexa é reduzida para a informação provinda por um dedo indicador apenas. 
Zedu (1991) desenvolveu uma pesquisa para estudar um parâmetro de sensibilidade para percepção visual e háptica de espessura (três amplitudes diferentes) e área em três grupos experimentais: visão, tato induzido (participantes com visão que julgaram os estímulos através da percepção háptica) e tato natural (cegos), através do método psicofísico de estimação de magnitude. Os resultados para julgamento de espessura indicaram uma diferença significativa em relação ao efeito dos grupos experimentais, mas não foi demonstrada uma diferença significativa entre as amplitudes. A interação entre os grupos experimentais e as amplitudes foi significativa. Os resultados para julgamentos de áreas irregulares não mostraram diferença significativa entre as condições experimentais. Comparando os resultados obtidos para ambos os julgamentos, de espessura e de área, verificou- se que o expoente para área visual é significativamente menor que aquele para espessura visual. Analisando os julgamentos hápticos para espessura e área, não foi verificada uma diferença significativa entre os grupos tato induzido e tato natural. Esses dados sugerem que para estimativas visuais existem dois canais visuais distintos: um para julgamento de comprimento (espessura) e outro para julgamentos de área, não ocorrendo o mesmo para julgamentos hápticos, visto que, nestas condições, não houve diferenças significativas entre os julgamentos de espessura e área, sugerindo, portanto, a existência de apenas um canal de transdução sensorial.

Suzuki e Arashida (1992) encontraram que tanto na modalidade visual quanto na háptica o segmento vertical de uma figura T- invertido é percebido como sendo 1,2 vezes maior do que o segmento horizontal.

Millar (1985, 1988, 1994, 2000) propôs que a percepção acurada de comprimento através do tato depende da convergência e congruência das dicas de diferentes fontes, as quais atuam como âncoras de referência para as posições iniciais e finais dos movimentos. Com base nestas considerações, Millar e Al-Attar (2001) investigaram erros sistemáticos 
de distância na leitura de mapas com linhas auto-relevo através do tato e como eles poderiam ser reduzidos. Sua hipótese era que provendo dicas espaciais similares (estrutura quadrada ao redor do mapa e dicas centradas no corpo) também reduziria a ilusão, se isto ocorresse em um contexto de mapa. O material utilizado consistiu em um mapa simplificado, mas real, de uma parte de Oxford, o qual incluiu junções em forma de $\mathrm{T}$ e junções semelhantes à ilusão de Müller-Lyer. Os participantes foram completamente vendados do começo ao fim dos experimentos e eram solicitados a interromper a exploração com a ponta dos dedos no ponto no qual eles julgavam a comparação do comprimento ser igual à distância do comprimento apresentado. O gênero foi um fator em todas as análises, porém não produziu efeitos principais ou de interações. Os autores mostraram que junções de vias em forma de $\mathrm{T}$ produziram os erros típicos devido a superestimação do comprimento da via de bisseção comparada à via bissecionada. $\mathrm{O}$ erro não foi reduzido quando a localização do alvo foi marcada inicialmente por um símbolo. No entanto, isto foi eliminado pelas instruções para usar ambas as mãos de forma concorrente para examinar a rota relativa para uma estrutura quadrada externa ao redor do mapa e para a linha mediana do corpo. Junções de vias, as quais se assemelhavam à ilusão de Müller-Lyer, produziram uma superestimação significativa do comprimento de uma via que finalizava em vias de lados divergentes em relação à subestimação de uma seção de via com vias de lados convergentes. Dicas de âncora espacial dos marcos ao longo da rota, sozinhas ou em conjunto com as instruções da estrutura espacial, eliminaram a ilusão igualmente. Este estudo mostrou que ilusões geométricas táteis também ocorrem em contexto de mapas e forneceu novas evidências que sugerem que as ilusões são eliminadas por informação de referência espacial adicional. Os resultados são consistentes com a explicação que a percepção acurada de comprimento através do tato depende das dicas de referência espacial congruentes para extensões de movimentos. 
Millar e Al-Attar (2002) utilizaram a ilusão Müller-Lyer para investigar fatores na integração do tato, movimento e dicas espaciais na percepção háptica de forma e na similaridade com a ilusão visual. A hipótese do tempo de movimento, sugerindo que o tempo de inspeção das figuras de Müller-Lyer (com setas convergentes tomando menos tempo e setas divergentes mais tempo) também poderia explicar a ilusão háptica (Erlebacher \& Sekuler, 1969), foi refutada. Efeitos de seta característica apoiaram a hipótese de que dicas diferentes contribuem para a ilusão, mas mostraram também que isto depende das condições de modalidade específica e que isto não foi o fator principal. Dicas alocêntricas (informações de referência externa) não reduziram a ilusão háptica. Foram obtidos mais erros negativos para figuras convergentes horizontais e mais erros positivos para figuras divergentes verticais, sugerindo um efeito do movimento da modalidade específica. Mas a ilusão de Müller-Lyer foi altamente significativa para ambas as figuras vertical e horizontal. Entretanto, instruções para usar referência centrada no corpo (egocêntrica) e ignorar as setas reduziram a ilusão háptica para figuras verticais de 12,6\% para 1,7\%. Na condição visual, sem referência egocêntrica explícita, instruções para ignorar setas não reduziram a ilusão à nível próximo, embora dicas externas foram apresentadas. Mas a ilusão visual foi reduzida para o mesmo nível, como no tato, com instruções que incluíram o uso das dicas egocêntricas. Esta evidência mostrou que as mesmas instruções reduziram a ilusão de Müller-Lyer quase para zero em ambos visão e tato, sugerindo que a similaridade da ilusão não é fortuita. Os resultados sobre o tato sustentaram a hipótese de que referência espacial egocêntrica está envolvida na integração de inputs do tato e do movimento para a percepção háptica acurada de comprimento e forma. Os resultados de que a referência egocêntrica explícita teve o mesmo efeito na visão sugerem que isto deve ser um fator comum na integração de inputs diferentes provenientes de fontes multisensoriais. 
Heller, Brackett, Wilson, Yoneyama, Boyer e Steffen (2002) compararam a intensidade da ilusão de Müller-Lyer em videntes vendados, cegos tardios, cegos congênitos e adultos com baixa visão. Os participantes usaram o dedo indicador direito para sentir a figura em auto-relevo e simultaneamente usaram a mão esquerda para fazer estimativas de comprimento, utilizando uma régua com cursor tangível. Os dados mostraram a presença da mesma ilusão de Müller-Lyer háptica nas quatro populações.

Norman e cols. (2004), a partir dos achados experimentais de Caviness e Gibson (1962) e Caviness $(1962,1964)$ à respeito da acurácia razoável de participantes para comparar formas de objeto através da modalidade cruzada visão-tato, conduziram um estudo para avaliar a habilidade de observadores, estudantes universitários, para comparar a forma natural de objetos tridimensionais, usando seus sentidos de visão e tato. No experimento 1 , os observadores hapticamente manipularam um objeto e então indicaram qual, entre doze objetos visíveis, possuía a mesma forma. No segundo experimento, pares de objetos eram apresentados e os observadores indicavam se sua forma $3 \mathrm{D}$ era a mesma ou diferente. Os dois objetos eram apresentados ou de forma unimodal (visão-visão ou háptico-háptico) ou através de modalidades cruzadas (visão-háptico ou háptico-visão). Em ambos os experimentos, os observadores foram capazes de comparar forma 3D através das modalidades com níveis razoavelmente altos de acurácia. No experimento 1, por exemplo, a performance comparada dos observadores aumentou para $72 \%$ de acerto após cinco sessões experimentais. No experimento 2, diferenças pequenas mas significativas na performance foram observadas entre a condição unimodal visão-visão e as duas condições de modalidade cruzada. Tomados juntos, estes resultados sugerem que existem muitas similaridades em como os sistemas, visual e háptico, detectam forma de objeto 3D, mas não necessariamente de forma equivalente. 
Gentaz e Hatwell (2004) conduziram uma revisão da ocorrência, na modalidade háptica, de três ilusões geométricas bem conhecidas na visão e discutiram a natureza dos processos subjacentes a estas ilusões hápticas. Estes autores argumentaram que os resultados aparentemente contraditórios encontrados na literatura em relação a elas podem ser explicados, no mínimo parcialmente, pelas características dos movimentos exploratórios manuais. A ilusão de Müller-Lyer é apresentada na visão e na háptica e parece ser o resultado de processos similares nas duas modalidades. A ilusão verticalhorizontal também existe em visão e háptica, mas é devida parcialmente a processos similares (bisseção) e parcialmente a processos específicos para cada modalidade (anisotropia do campo visual e superestimação dos movimentos exploratórios manuais radiais x tangenciais). A ilusão Delboeuf parece ocorrer apenas na visão, provavelmente devido à exploração pelo dedo indicador que deve excluir o contexto enganador da percepção tátil. O papel destes movimentos exploratórios hápticos pode explicar porque a modalidade háptica é tão sensitiva quanto a visão para certas ilusões e menos sensitiva para outras. Estes resultados favorecem explicações baseadas nas características gerais do funcionamento dos sistemas perceptivos, independente das modalidades sensoriais. Entretanto, estas explicações gerais não necessariamente ocorrem para as mesmas ilusões. Claramente, isto não é suficiente para estudar a visão a fim de entender os outros sentidos e um estudo sistemático de cada modalidade é necessário.

Gentaz, Camos, Hatwell e Jacquet (2004) observaram, em resultados provisórios, uma correlação positiva entre as magnitudes da ilusão de Müller-Lyer nas modalidades visual e háptica quando os mesmos participantes videntes vendados realizaram exatamente a mesma tarefa em ambas as modalidades.

Tomados juntos, estes resultados constituem forte evidência de que a ilusão de Müller-Lyer envolve fatores similares em ambas as modalidades, visual e háptica. Além 
disso, estes achados sugerem a presença de processos hápticos análogos, independente da condição visual dos participantes.

\section{I.7. Algumas evidências neuropsicológicas sobre percepção visual e háptica}

Nós adquirimos representações sensoriais de diferentes modalidades especializadas (por exemplo, visão, tato e audição), ainda que nossa percepção do mundo é altamente integrada e unitária. Apesar de suas capturas independentes, é claro que a informação de um sentido influencia a percepção obtida de outro (Stein \& Meredith, 1993).

A ativação do córtex occipital parece ser funcionalmente relevante para a leitura Braille tátil (Hamilton, Keenam, Catala \& Pascual-Leone, 2000). Este exemplo de processamento de modalidade cruzada não é limitado para condições sensoriais privadas. Estudos em participantes videntes têm demonstrado que áreas corticais occipitais também são empregadas no processamento de informação não visual (Amedi, Jacobson, Hendler, Malach \& Zohary, 2002). A contribuição relativa de cada área cortical deve refletir qual modalidade é mais adaptada teoricamente em prover a informação desejada (Guest \& Spence, 2003).

Usando mapeamento cerebral fMRI, James, Humphrey, Gati, Servos, Menon e Goodale (2002) encontraram que ambas a exploração visual e a háptica de forma de objeto 3D produziram quantidades significativas de ativação no córtex visual extra-estriado humano. Eles concluíram de sua pesquisa que observadores humanos possuem uma representação visual e háptica comum de forma de objeto, sugerindo que um candidato para esta representação comum é a área occipital mediana, a qual se encontra dentro do complexo occipito-temporal lateral. 
Merabet, Thut, Murray, Andrews, Hsiao e Pascual-Leone (2004) investigaram o papel do córtex occipital e somatosensorial em uma tarefa de discriminação háptica. Neste estudo, sujeitos videntes e cegos congênitos avaliaram a textura e a distância espaçada para uma série de padrões de pontos arranjados. Os efeitos diferentes de TMS (MagStim Stimulator) na performance da tarefa e evidência clínica comprovada sugerem que o córtex occipital (visual) está envolvido no processamento de informações táteis que requerem discriminação espacial fina.

A implicação do córtex occipital no processamento tátil deve ser o resultado de inputs especializados mas complementares que convergem para esta região; e é esta sobreposição que provê a redundância de dicas necessárias para organizar estímulos espacialmente através de diferentes modalidades (Johnson \& Hsiao, 1992). Áreas que tipicamente processam uma modalidade sensorial podem contribuir para input obtido de uma outra modalidade. Apesar de representações sensoriais e estratégias de processamento similares, isto não significa que áreas corticais primárias não podem contribuir diferentemente para a representação global ou identificação de um objeto. Deste modo, uma estrutura envolvida num processamento sensorial de modalidade cruzada pode conferir uma vantagem comportamental e ainda ser funcionalmente adaptativa quando uma modalidade sensorial é perdida, por exemplo, a visão (Merabet, Thut, Murray, Andrews, Hsiao \& Leone, 2004).

\section{I.8. Diferenças de gênero na percepção e cognição espacial}

De acordo com a revisão literária, alguns estudos indicam a influência do gênero e de alguns fatores internos ao participante na percepção e cognição espacial, apontando sua 
relevância no julgamento perceptivo. Pesquisas recentes têm examinado tipos diferentes de tarefas espaciais demonstrando diferenças significativas de gênero nos diferentes tipos de tarefas. Algumas tarefas espaciais tendem a favorecer mulheres, enquanto outras favorecem os homens (Alexander, Packard, \& Peterson, 2002; Jacobs, Gaulin, Sherry \& Hoffman, 1990; Kimura, 1999; Kitchin, 1996; McCourt, Mark, Radonovich, Willison \& Freeman, 1997).

Teorias biológicas, ambientais e evolucionistas contemporâneas têm integrado novas formulações teóricas às antigas, a fim de prover explicações para diferenças de gênero em tarefas de percepção visual e espacial (Kimura, 1999; Kitchin,1996; McCourt \& cols., 1997; Silverman \& Phillips, 1993).

\section{I.8.1. Teorias biológicas}

Estudos neurológicos têm mostrado que existem diferenças sexuais no funcionamento cerebral, visto que homens e mulheres são criaturas biologicamente diferentes, apesar de que as diferenças cognitivas não são tão aparentes como as diferenças físicas. A teoria neuropsicológica das diferenças sexuais espaciais está baseada nos achados que sugerem que os cérebros masculinos são funcionalmente lateralizados para um grau maior do que cérebros femininos. Ou seja, as habilidades espaciais, as quais são primariamente incumbências do hemisfério direito, apresentam uma área maior e mais homogênea no homem (Alexander \& cols., 2002; McCourt \& col., 1997; Mc Glone, 1980). McCourt e cols. (1997) notaram que homens se saem tipicamente melhor do que mulheres nas tarefas que focalizam nas funções do hemisfério direito, tais como tarefas de percepção espacial e visual, enquanto mulheres tipicamente se saem melhor em tarefas do hemisfério esquerdo, como tarefas envolvendo habilidades verbais.

No entanto, um dos obstáculos principais para a teoria biológica que tenta explicar 
as diferenças de gênero em certas tarefas espaciais, é que a pesquisa através das culturas não tem consistentemente partido de diferenças de gênero nas várias tarefas espaciais. Feingold (1994) falhou em encontrar evidência fidedigna para a superioridade de gênero na habilidade espacial, verbal e matemática, através das diferenças nacionais de sexo. Uma crítica deste estudo foi que dados recentes não foram usados e medidas espaciais foram amontoadas dentro de uma categoria ao invés de serem desdobradas em várias medidas espaciais para diferentes tarefas espaciais.

\section{I.8.2. Teorias ambientais}

Silverman e Phillips (1993) acreditam que a experiência constitui um papel chave na memória espacial superior. Portanto, diferenças espaciais poderiam ser aprendidas e não necessariamente herdadas. Se uma criança está imersa em um ambiente rico em tarefas orientadas espacialmente, isto deveria torná-la mais capaz nos testes espaciais do que uma criança que não recebeu tanta orientação para tarefas espaciais.

Kitchin (1996) propôs que a atividade de encontrar o caminho, bem como a aquisição de um conhecimento ambiental estão baseados na emoção influenciada pelos sistemas de processamento da memória. Este modelo propõe também que a aprendizagem ambiental influenciada pela emoção inicia com o surgimento de atividades do mundo real. Homens e mulheres provavelmente contam com preferências aprendidas, especialmente na exploração de um ambiente desconhecido. Experiência ambiental primitiva pode, portanto, ser um fator crucial que prepara o sistema de processamento da memória para diferenças de gênero.

Kimura (1999) sugeriu que mulheres devem ter uma desvantagem para tarefas espaciais tais como a tarefa de nível de água, porque elas são mais dependentes nas atividades do que os homens, significando que elas são mais afetadas pelas condições do 
meio ambiente. Isto apóia o fato de que mulheres prestam mais atenção aos detalhes em seu ambiente imediato do que os homens.

\section{I.8.3. Teorias Evolucionistas}

Teorias evolucionistas recentes acerca das diferenças de gênero encontradas em algumas tarefas de percepção e cognição espacial, apresentam as práticas de socialização como o foco destas diferenças (Gaulin \& Fitzgerald, 1986, Greenwood, 1980, Silverman \& Phillips, 1993).

Greenwood (1980) explica as diferenças sexuais espaciais com base nas práticas de acasalamento, cunhando o termo dispersão natal que se refere ao deslocamento de certos animais, como os mamíferos, de seu lugar natal para o lugar de procriação.

O modelo de Gaulin e Fitzgerald (1986) explica as diferenças espaciais entre os sexos considerando que espécies cujas estratégias se relacionam à defesa do companheiro, apresentam maior dispersão do macho e, portanto, apresentam superioridade deste nas habilidades espaciais; enquanto nas espécies que utilizam estratégias de defesa de recursos, ocorre maior dispersão da fêmea, apresentando, portanto, superioridade desta nas habilidades espaciais. Estes autores acreditam que as habilidades espaciais em machos teriam sido selecionadas por espécies poligâmicas, porque machos poligâmicos requerem habilidades de navegação para defender e percorrer grandes territórios, nos quais buscam acasalamentos potenciais e/ou recursos para atrair parceiros. Um estudo mais recente, revelou que na espécie poligâmica, mas não na espécie monogâmica, os machos apresentavam hipocampo proporcionalmente maior do que as fêmeas, devido à sua participação nas funções espaciais (Jacobs \& cols. 1990).

Silverman e Eals (1992) consideram como o fator crítico na seleção para as diferenças espaciais em humanos a divisão sexual do trabalho entre caçar e coletar durante 
a evolução dos hominídeos. Estes autores defendem que os mecanismos cognitivos do homem contemporâneo parecem refletir estas diferenças, como sua maior capacidade para rotação mental, leitura de mapa e aprendizagem de labirinto, todos estes constituindo atributos para o sucesso da caça. Do mesmo modo, as especializações espaciais relacionadas a atividade de coletar, deveriam estar associadas às mulheres, compreendendo habilidades de reconhecer e lembrar configurações espaciais de objetos, bem como sua localização. As vantagens femininas na memória de objetos e de localização podem representar habilidades verbais superiores, especialmente uma capacidade maior para lembrar nomes de objetos. Isto também sugere uma relação com a divisão do trabalho, indicando diferenças sexuais verbais universais e correlações hormonais (Burstien, Bank \& Jarvick, 1980).

Diante da teoria neuropsicológica que admite a existência de diferenças funcionais hemisféricas entre os sexos (Mc Glone, 1980), Silverman e Eals (1992) entendem que cérebros masculinos e femininos se tornaram diferencialmente lateralizados por alguma circunstância não relatada para processos espaciais e diferenças sexuais espaciais, desenvolvidos como um efeito incidental desta divergência. Portanto, o conceito da evolução das diferenças sexuais espaciais encara as diferenças sexuais na lateralização como conseqüências das diferenças sexuais espaciais emergidas da divisão do trabalho.

\subsection{Julgamentos perceptivos em função do gênero}

Verrillo (1979a) encontrou que um grupo pequeno de homens e mulheres não diferiu em suas estimativas de comprimento de linha em seu estudo piloto. Deste modo, o autor conduziu um novo estudo (1982), estendendo seu estudo piloto (1979a) para um número maior de participantes, 26 homens e 26 mulheres, com idade entre 19 e 68 anos, 
usando o método de estimação de magnitude absoluta para determinar se existiam diferenças entre homens e mulheres na magnitude percebida de comprimento de linha. $\mathrm{O}$ procedimento consistiu em linhas pretas horizontais projetadas numa tela branca em uma distância visual de 3,7 metros do participante sentado. Os comprimentos físicos das sete medidas lineares eram: 1,4, 2,8, 5,0, 13,2, 26,6, 53.3, e $132.5 \mathrm{~cm}$. Eles eram apresentados de forma randômica duas vezes para cada participante, com a restrição de que o primeiro estímulo não seria a linha maior nem a menor e que as linhas de mesmo comprimento não apareceriam em sucessão. Os participantes foram instruídos para assinalar um número, sem módulo para cada comprimento de linha, de forma que a magnitude subjetiva do número correspondia à magnitude subjetiva da linha. Resultados mostraram a ausência de diferenças tanto na razão de crescimento da função potência quanto no valor absoluto de números assinalados para representar o comprimento subjetivo das linhas (Verrillo, 1982).

Os achados de Verrillo (1979a/82) confirmam que a estimação de comprimento de linha é um controle conveniente para o uso de números em experimentos de estimação de magnitude envolvendo outras modalidades sensoriais.

\subsection{Julgamentos perceptivos em função da idade}

Muitas mudanças na capacidade sensorial acompanham o envelhecimento. De fato, todos os sistemas sensoriais, com a possível exceção do paladar, sofrem déficits como uma conseqüência da idade. É considerado "normal", por exemplo, pessoas com idade média de 40 anos necessitarem de óculos para leitura e que a sensibilidade de ouvir, especialmente acima de 2,000 Hz, diminui a partir da idade de 20 anos progressivamente, com perdas severas em evidência após os 70 anos de idade. A sensação do tato não é exceção. Estudos recentes sobre o tato têm surgido por uma razão muito prática: o sentido do tato está sendo 
revisto seriamente como um canal substituto de comunicação para compensar déficits em visão e audição (Verrillo, 2000).

Verrillo (1979b/80) conduziu estudos para verificar mudanças na sensibilidade de vibração tátil com participantes agrupados de acordo com as idades de 10, 20, 35, 50 e 65 anos. Os resultados mostraram uma perda dramática de sensibilidade entre as idades de 20 e 65 anos em freqüências acima de $40 \mathrm{~Hz}$, o que não ocorreu em 25 e $40 \mathrm{~Hz}$. Esta perda gradual de sensibilidade nas freqüências mais elevadas se manifesta em algum ponto entre 20 e 35 anos. Limiares nas freqüências mais baixas tendem a permanecerem estáveis com o aumento da idade.

Verrillo (1981) avaliou o efeito da idade sobre a magnitude subjetiva de comprimento de linha em três grupos de participantes com idade de 25, 50 e 68 anos, através do método de estimação de magnitude absoluta. Os resultados não mostraram diferenças significativas entre os grupos, sendo essencialmente os mesmos resultados encontrados em um estudo anterior, com crianças de cinco para seis anos, apesar de uma inclinação levemente mais alta para esta idade.

Alliprandini e Da Silva (2000) verificaram o efeito da idade no expoente da função de potência na percepção, memória e condições experimentais de inferência. A amostra constituiu- se de três grupos para cada condição experimental: grupo I: 17- 35 anos; grupo II: 40- 55 anos e grupo III: 60- 77 anos, com educação variando de segundo grau a graduação. Os observadores estimaram as áreas dos estados brasileiros através do método de estimação de magnitude, considerando o estado de São Paulo como estímulo padrão, recebendo o módulo 100. Na condição perceptiva, o mapa do Brasil foi observado livremente pelos participantes durante os julgamentos das áreas diferentes dos estados e na condição de inferência, os julgamentos dos participantes foram realizados a partir das informações que eles tinham adquirido previamente, considerando as áreas geográficas dos 
estados brasileiros. Portanto, nesta condição considerou- se que as estimativas foram feitas a partir da memória de longo prazo, com intervalos de tempo indefinidos. Na condição de memória, os participantes inicialmente examinaram o mapa do Brasil livremente por 7 minutos para obter uma boa idéia da localização dos estados. Em seguida, eles estimaram as áreas de acordo com os seguintes intervalos de tempo: 2 min., 8, 24, 48 horas ou uma semana (fase de relembrar). Diferenças significativas não foram obtidas para os grupos I, II e III para cada condição experimental, exceto para a condição de memória com o intervalo de 24 horas. Análises para condições experimentais e idades mostraram uma diferença significativa entre a condição perceptiva e cada uma das outras, mas ausência de diferença entre as condições de inferência e de memória. Estes resultados indicaram ausência de perda de informação nos processos de relembrar em função da idade e diferenças nos processos cognitivos como uma função das condições experimentais. Por causa da pequena variabilidade nos expoentes da função potência para os três grupos de idade, pôde- se assumir que isto poderia estar relacionado à educação diferente dos observadores, mostrando a necessidade de mais estudos de idade.

Alliprandini, Kanesiro e Souza (2002) conduziram um estudo para verificar os expoentes da função de potência nas condições experimentais perceptiva e memória para área em 240 observadores, divididos em dois grupos de acordo com a idade, 17 a 30 anos (grupo I) ou 45 a 60 anos (grupo II), com diferentes níveis educacionais (fundamental, básico e universitário). O estímulo usado foi a figura de um carro, ao invés do mapa brasileiro (Alliprandini \& Da Silva, 2000), assumindo que o estímulo poderia interferir nos resultados obtidos. A figura do carro apresentava todas as suas partes divididas com seus nomes e a porta foi considerada como o estímulo padrão, com módulo igual a 100. A tarefa dos participantes foi estimar a área de outras partes do carro, atribuindo valores para cada uma delas, tomando como base a porta do carro. $\mathrm{Na}$ condição perceptiva, os participantes 
observaram a figura do carro livremente durante os julgamentos. Na condição de memória, os participantes inicialmente examinaram a figura do carro livremente por 7 minutos, a fim de obter uma boa idéia da localização das diferentes partes do carro. Após esta aquisição da fase de informação, os participantes estimaram as áreas das partes do carro, de acordo com os seguintes intervalos de tempo: 2 minutos, 24 horas ou 1 semana, sem a figura do carro (fase de lembrar). A condição perceptiva diferiu das condições de memória em todos os intervalos de tempo. Os resultados mostraram que para o grupo I, o nível educacional fundamental diferiu dos níveis básico e universitário. Para o grupo II, os níveis educacionais não mostraram uma diferença significativa. Os achados sugerem que o estímulo julgado por um observador, a idade e o nível educacional são importantes variáveis nos processos mnemônicos. 



\section{JUSTIFICATIVA}

Considerando o envolvimento das habilidades visuais e hápticas na realização de tarefas cotidianas de qualquer ser humano, interessa-nos investigar como estas habilidades se manifestam, através da realização de julgamentos de comprimentos e formas de linha, em participantes videntes (julgamento visual) e participantes não videntes (julgamento háptico).

Haja vista o desenvolvimento cada vez maior de habilidades sensoriais, inclusive da percepção háptica de participantes saudáveis e de deficientes visuais, justifica- se tal investigação, a fim de ampliar o conhecimento acerca dos processos básicos da percepção.

Desde 1800 existe uma vasta literatura sobre percepção visual e os fatores internos aos participantes que nela interferem, porém, só por volta de 1972 é que teve início estudos utilizando a tarefa de apontar na percepção visual dirigida, apresentando vários resultados, como observados nos estudos relatados anteriormente de Kitchin (1996). Por esta razão, modalidades sensoriais diferentes, visual e háptica, serão utilizadas neste estudo, a fim de verificar a performance dos participantes.

Deste modo, esta pesquisa se justifica pela possibilidade de revelar o papel da percepção visual e da percepção háptica em participantes com visão normal, quando submetidos à tarefas que envolvem julgamentos de comprimentos de linhas, apresentados em diferentes formas. Tal conhecimento tornará possível o desenvolvimento de estratégias mais adequadas para lidar com situações práticas no dia- a- dia, como dirigir, atravessar uma rua, andar no escuro ou reconhecer objetos e faces. 



\section{OBJETIVOS E HIPÓTESES}

\section{III.1. Objetivo geral}

O objetivo desta pesquisa é verificar se existem diferenças nos julgamentos, visual e háptico, de comprimentos de linha apresentados em três formas diferentes, comprimento de linha reto, comprimento de linha em L e comprimento de linha curvo, utilizando dois métodos psicofísicos: estimação de magnitude numérica e estimação de categoria numérica.

\section{III.2. Objetivo específico}

Como objetivo específico pretende- se verificar se o grau de incerteza nos julgamentos se mantém em função do método psicofísico utilizado.

\section{II.3. Hipóteses}

Através deste estudo busca- se verificar as seguintes hipóteses: a ausência de diferenças nas estimativas dos participantes nos respectivos níveis para os fatores modalidade sensorial e forma que é submetido.

Um modo descritivo das hipóteses é apresentado a seguir:

1. Para o fator modalidade sensorial: visual $(\mathrm{V})$ e háptica $(\mathrm{H})$, não há diferenças significativas entre as estimativas dos comprimentos nestes níveis $\left(\mathrm{H}_{0}: \mu_{\mathrm{V}}=\mu_{\mathrm{H}}\right)$;

2. Para o fator forma: reta (R), em L (L) e curva (C), não há diferenças significativas entre as estimativas dos comprimentos nestes níveis $\left(H_{0}: \mu_{R}=\mu_{L}=\mu_{C}\right)$.

Outras hipóteses a serem consideradas: 
3. Os métodos psicofísicos utilizados nas estimativas de comprimento de linha, estimativa de magnitude numérica (EM) e estimativa de categoria numérica $(\mathrm{EC})$, não interferem no grau de incerteza dos julgamentos $\left(\mathrm{H}_{0}: \mu_{\mathrm{EM}}=\mu_{\mathrm{EC}}\right)$;

4. Todos os comprimentos de linha são percebidos como diferentes e independentes da modalidade sensorial e forma $\left(\mathrm{H}_{1}: \mu \mathrm{c}_{1} \neq \mu \mathrm{c}_{2} \neq \mu \mathrm{c}_{3} \ldots \mu \mathrm{c}_{13}\right)$. 


\section{I.V. MÉTODO}

\section{IV.1. Participantes}

Participaram desta pesquisa 120 estudantes voluntários de graduação e pósgraduação de diferentes cursos e universidades brasileiras, com idade entre 18 e 35 anos, residentes na cidade de Ribeirão Preto- S.P., no momento da pesquisa. A amostra constituiu- se de 66 mulheres (55\%), com idade média igual a 23,8 anos $\pm 4,07$ e 54 homens (45\%), com idade média igual a 24,5 anos $\pm 3,82$. Estes participantes foram divididos em dois grupos, de acordo com a modalidade sensorial: videntes (V), que realizaram julgamentos visuais e não videntes $(\mathrm{NV})$, participantes videntes que usaram uma máscara isoladora de visão binocular e realizaram julgamentos hápticos de formas e comprimentos de linha diferentes. Todos os participantes tinham visão normal ou usavam lentes corretivas adequadas e não foram informados quanto aos propósitos dos experimentos.

\section{IV.2. Materiais e instrumentos}

Os materiais utilizados nesta pesquisa constituíram de 39 peças retangulares de acrílico fumê, com $6 \mathrm{~mm}$ de espessura e diferentes comprimentos $(2,5,4,5,7,0,12,0,20,0$, $31,0,45,0,55,0,63,0,70,0,83,0,95,0$ e 118,0 cm) com pregos para fixação, sendo 13 comprimentos retos, 13 comprimentos em forma de L e 13 comprimentos curvos; os segmentos dos comprimentos em L eram diferentes e formavam um ângulo de $90^{\circ}$ e os comprimentos curvos eram concêntricos e apresentavam diferentes raios. Um quadro de cortiça com medidas iguais a $120 \mathrm{~cm}$ de largura e $90 \mathrm{~cm}$ de altura, no qual as peças foram 
fixadas e folhas de respostas referentes a cada tarefa experimental, também foram utilizadas pelo pesquisador.

Ao participante, foi entregue um termo de consentimento livre e esclarecido, autorizando sua colaboração na pesquisa e uma folha contendo as instruções específicas para sua tarefa.

\section{IV.3. Procedimentos e experimentos}

Procedimentos. Os participantes foram convidados a participar deste estudo. Mediante sua anuência, receberam um Termo de consentimento livre e esclarecido para o participante (anexo1), contendo informações sobre o estudo, tais como objetivos, natureza do experimento, riscos, forma de divulgação dos resultados e contato com o(s) pesquisador(es), com o qual concordaram e assinaram para participar do estudo. Após a assinatura, o participante recebeu uma folha contendo instruções específicas à sua tarefa (anexos 2, 3, 4 e 5).

A sala experimental foi totalmente isolada, com iluminação adequada. O participante sentou- se em uma cadeira fixa e confortável, situada a $68 \mathrm{~cm}$ de um quadro $(90 \times 120 \mathrm{~cm})$ posicionado à sua frente, onde os estímulos foram apresentados. Os estímulos retos foram fixados horizontalmente no quadro a $98 \mathrm{~cm}$ do chão; os estímulos curvos, fixados com a concavidade para baixo e os estímulos em L foram apresentados de acordo com a configuração da letra L e também fixados no quadro a $98 \mathrm{~cm}$ do chão.

Na condição visual, os estímulos foram fixados à altura dos olhos do participante na região central da sua visão inter-ocular e na condição não visual (háptica), os estímulos foram fixados à altura do ponto de interseção entre o braço estendido horizontalmente do 
participante e o quadro. Tanto o julgamento visual quanto o julgamento háptico foram livres.

A tarefa se iniciou com a apresentação do estímulo padrão (comprimento $=45 \mathrm{~cm}$ ) ao participante. Em seguida, o experimentador apresentou os 13 estímulos, um de cada vez, incluindo o estímulo padrão, enquanto anotava suas respostas. Este procedimento foi feito em duas séries, sendo a primeira série para treino, a fim de calibrar todos os participantes. Foi estabelecida uma ordem aleatória padrão de apresentação dos estímulos para os participantes de cada tarefa experimental.

Os 120 participantes foram submetidos individualmente a quatro experimentos. Metade deles se submeteu ao método de estimação de magnitude, sendo 30 para a condição visual e 30 para a condição não-visual (háptica), enquanto a outra metade foi submetida ao método de estimação de categoria, sendo 30 para a condição visual e 30 para a condição não-visual, sendo que cada 10 participantes destes subgrupos foram submetidos a cada um dos níveis do fator forma ( $R$, em L e C). Ou seja, houve dez participantes em cada uma das possíveis combinações entre os níveis dos fatores modalidade, forma e método, apresentando, assim, doze subgrupos.

Experimentos. A seguir, estão descritos os experimentos realizados nesta pesquisa, bem como os métodos psicofísicos utilizados:

\section{IV.3.1. Experimento 1 - Estimação de magnitude visual (EMV)}

Cada participante realizou 26 estimativas, divididas em duas séries com 13 comprimentos de linha diferentes e aleatórios, através da percepção visual, submetido ao método psicofísico: estimação de magnitude. 
A tarefa dos participantes consistiu em atribuir um número para cada um dos treze comprimentos de linha, que foram previamente selecionados pelo pesquisador. Eles receberam instruções para atribuir a cada comprimento um número que fosse proporcional à sua dimensão aparente, tendo como referência um comprimento de linha denominado estímulo padrão, cujo módulo era igual a 100. Por exemplo, se um participante julgasse que um dado comprimento fosse duas vezes maior do que o estímulo padrão, ele atribuiria um número duas vezes maior. Se ele julgasse que um outro comprimento fosse a metade do estímulo padrão, ele atribuiria um número que fosse a metade deste.

\section{IV.3.2. Experimento 2 - Estimação de magnitude não visual (EMNV)}

Os participantes foram vendados e realizaram 26 estimativas, divididas em 2 séries, com 13 comprimentos de linha diferentes e aleatórios para cada subgrupo, através da percepção háptica, submetidos ao método psicofísico: estimação de magnitude.

A tarefa dos participantes consistiu em estimar treze comprimentos de linha que foram previamente selecionados pelo pesquisador. Eles receberam instruções para estimar os treze comprimentos de linha, estando vendados e podendo deslizar continuamente com dois dedos da mão dominante sobre o estímulo apresentado, por três vezes. Sua tarefa consistiu em atribuir a cada comprimento um número que fosse proporcional à sua dimensão aparente, tendo como referência um comprimento de linha denominado estímulo padrão, cujo módulo era igual a 100. Por exemplo, se um participante julgasse que um dado comprimento fosse duas vezes maior do que o estímulo padrão, ele atribuiria um número duas vezes maior. Se ele julgasse que um outro comprimento fosse a metade do estímulo padrão, ele atribuiria um número que fosse a metade deste. 


\section{IV.3.3. Experimento 3 - Estimação de categoria visual (ECV)}

Cada participante realizou 26 estimativas, divididas em duas séries com 13 comprimentos de linha diferentes e aleatórios, através da percepção visual, submetido ao método psicofísico: estimação de categoria.

A tarefa dos participantes consistiu em atribuir um escore, que variava de 1 a 7 , para cada um dos treze comprimentos de linha, que foram previamente selecionados pelo pesquisador. Eles receberam instruções para atribuir a cada comprimento um escore que fosse proporcional à sua dimensão aparente, tendo como referência um comprimento de linha denominado estímulo padrão, cujo módulo era igual a 4. Por exemplo, se um participante julgasse que um dado comprimento de linha apresentava uma dimensão bem menor que o estímulo padrão, ele atribuiria a este comprimento o escore 1. Caso ele considerasse que um outro comprimento fosse muito maior que o estímulo padrão, ele atribuiria o escore máximo igual a 7. Todos os participantes foram instruídos a utilizar os escores intermediários 2, 3, 4, 5 e 6 para indicar dimensões intermediárias de comprimentos de linha. Assim, se os participantes julgassem que alguns comprimentos de linha apresentavam dimensões similares, eles atribuiriam um mesmo escore a estes comprimentos. O participante utilizou dois dedos da mão dominante para deslizar continuamente sobre o estímulo, podendo percorrer três vezes pelo comprimento apresentado antes de dar sua resposta 


\section{IV.3.4. Experimento 4 - Estimação de categoria não visual (ECNV)}

Os participantes vendados realizaram 26 estimativas de 13 comprimentos de linha diferentes e aleatórios, divididos em 2 séries, através da percepção háptica, submetidos ao método psicofísico: estimação de categoria.

A tarefa dos participantes consistiu em atribuir um escore, que variava de 1 a 7 , para cada um dos treze comprimentos de linha, que foram previamente selecionados pelo pesquisador. Eles receberam instruções para atribuir a cada comprimento um escore que fosse proporcional à sua dimensão aparente, tendo como referência um comprimento de linha denominado estímulo padrão, cujo módulo era igual a 4. Por exemplo, se um participante julgasse que um dado comprimento de linha apresentava uma dimensão bem menor que o estímulo padrão, ele atribuiria a este comprimento o escore 1. Caso ele considerasse que um outro comprimento fosse muito maior que o estímulo padrão, ele atribuiria o escore máximo, igual a 7. Todos os participantes foram instruídos a usar os escores intermediários 2, 3, 4, 5 e 6 para indicar dimensões intermediárias de comprimentos de linha. Assim, se julgassem que alguns comprimentos de linha apresentavam dimensões similares, eles atribuiriam o mesmo escore a estes comprimentos. O participante podia deslizar continuamente com dois dedos da mão dominante sobre o estímulo apresentado, por três vezes. 

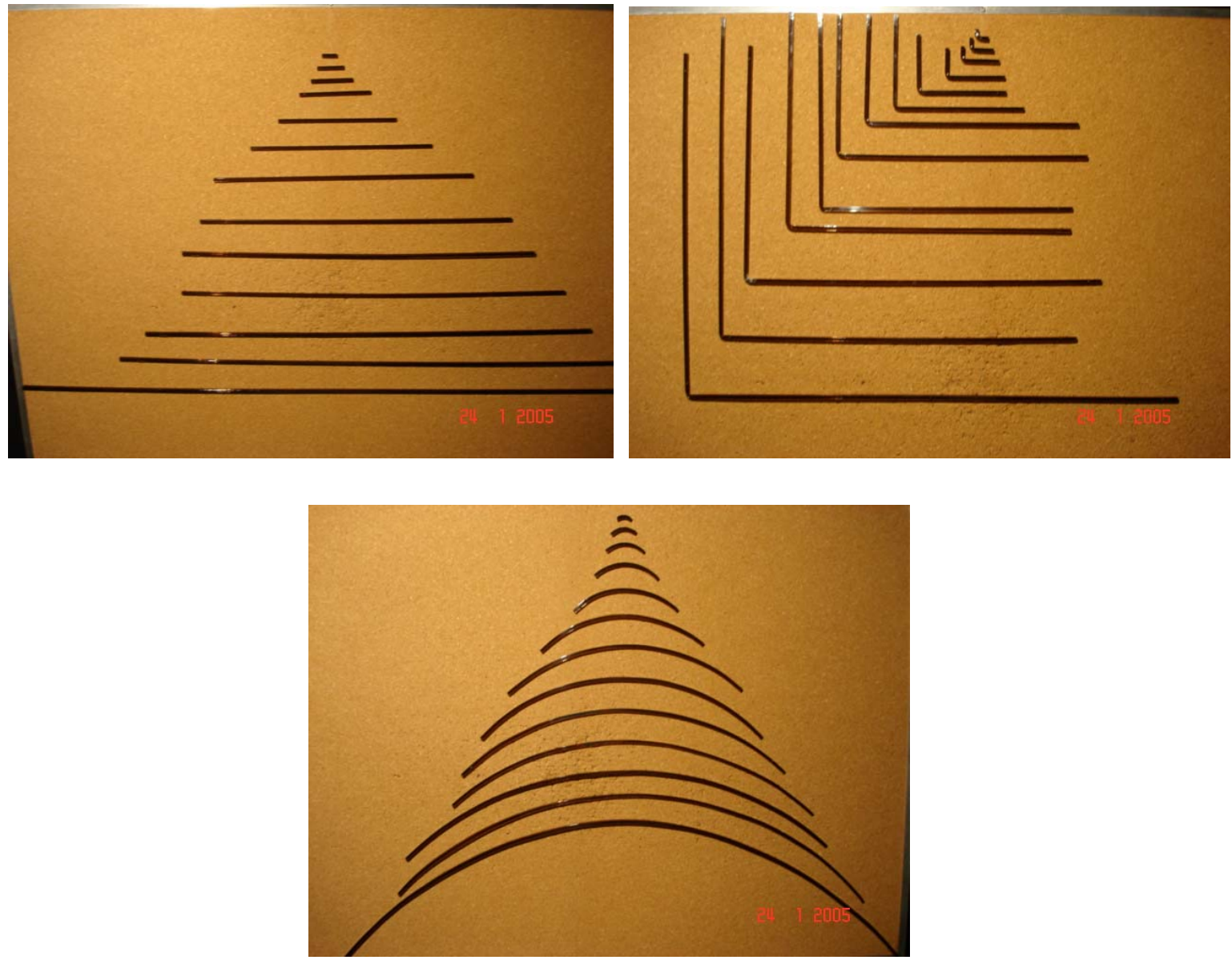

Figura 1- Representação dos 39 estímulos, peças retangulares de acrílico fumê, com $6 \mathrm{~mm}$ de espessura e 13 comprimentos diferentes $(2,5,4,5,7,0,12,0,20,0,31,0,45,0,55,0,63,0$, $70,0,83,0,95,0,118,0 \mathrm{~cm})$, utilizados em cada situação experimental de forma: reta (painel superior à esquerda), em L (painel superior à direita) e curva (painel inferior). 

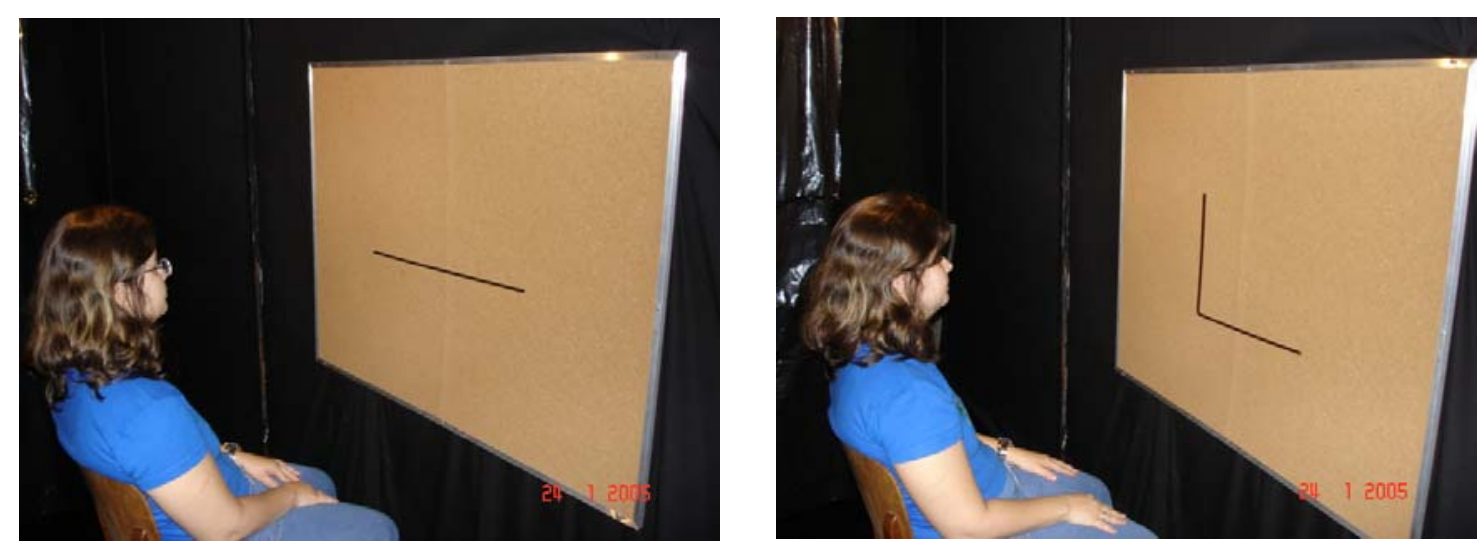

Figura 2- Representação do ambiente experimental. O observador está sentado em uma cadeira fixa, situada a $68 \mathrm{~cm}$ do estímulo apresentado em um quadro $(90 \times 120 \mathrm{~cm})$ posicionado à sua frente, podendo mover a cabeça livremente. $\mathrm{O}$ estímulo foi posicionado à altura dos olhos do observador. Tipo de experimento: Visual Reto (painel à esquerda), Visual em L (painel à direita) .
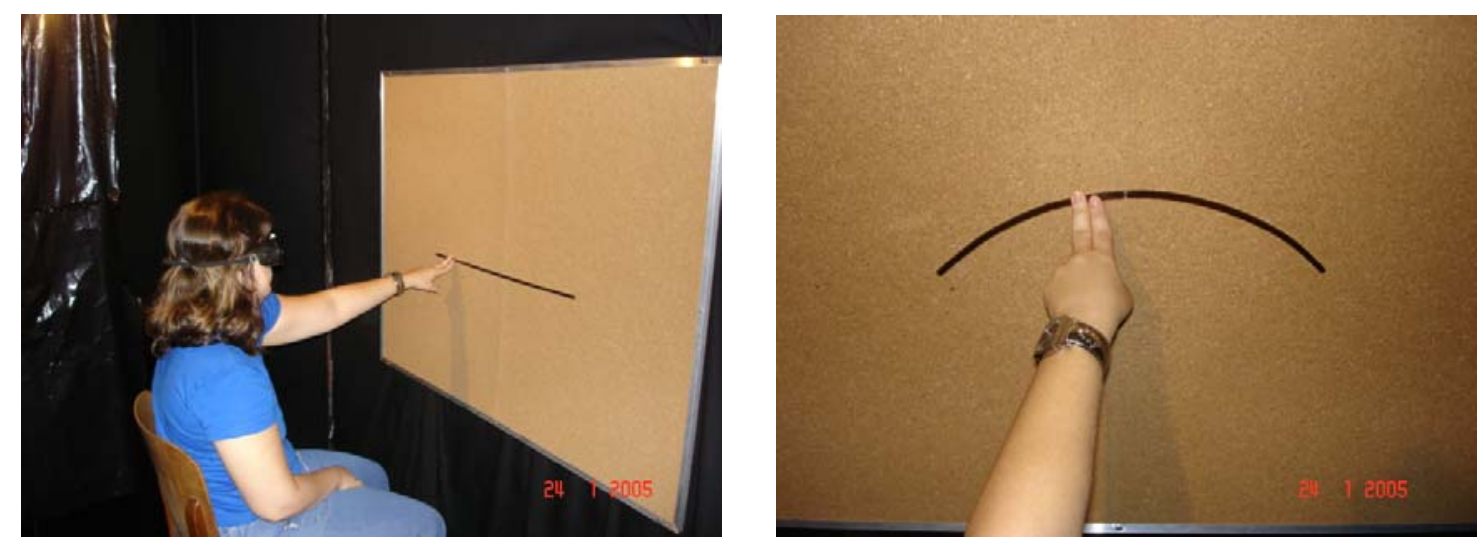

Figura 3- Representação do ambiente experimental. O observador está sentado em uma cadeira fixa, situada a $68 \mathrm{~cm}$ do estímulo apresentado em um quadro $(90 \mathrm{x} 120 \mathrm{~cm})$ posicionado à sua frente, podendo deslizar a ponta de dois dedos até três vezes pelo estímulo. Se necessário, o observador podia deslocar ombros e braços livremente. $\mathrm{O}$ estímulo foi posicionado de acordo com a posição do braço estendido horizontalmente do observador ao atingir o quadro. Tipo de experimento: Não Visual Reto (painel à esquerda), Não Visual Curvo (painel à direita) . 


\section{RESULTADOS}

Nesta seção são apresentados os resultados obtidos através dos dois métodos psicofísicos utilizados, estimação de magnitude numérica e estimação de categoria numérica.

\section{V.1. Análises das estimativas de magnitude numérica}

Os resultados obtidos referentes às estimativas dos participantes para os fatores forma e modalidade sensorial estão sumariados nas Figuras 4 e 5. Nestas Figuras pode- se observar uma pequena variação entre os grupos na modalidade não vidente (Figura 4) nas três situações de forma, enquanto que na modalidade vidente (Figura 5), a forma curva mostra um aumento na variabilidade das estimativas nos comprimentos iguais a 95 e 118 centímetros. Uma baixa variação nas estimativas dos comprimentos pode ser observada nas situações formas reta e curva e modalidade não vidente e forma reta e modalidade vidente. Os resultados resumidos nas figuras permitem uma análise de que há uma tendência à estimativas lineares entre todas as possíveis comparações entre os principais fatores e seus respectivos níveis.

Uma transformação logarítmica das médias geométricas das estimativas de magnitude em função do logaritmo dos comprimentos físicos dos estímulos mostra a tendência dos achados acima comentados, representada nas Figuras 6 e 7 . Uma comparação das estimativas na modalidade vidente em todos os níveis do fator forma segue uma mesma tendência para a curva produzida pelas estimativas, no entanto, na modalidade não vidente esta curvatura é menos acentuada e possivelmente produzida por uma compressão nas estimativas nesta situação experimental. 
A Figura 4 sumaria os resultados relativos às médias geométricas das estimativas e seus desvios padrão em função do comprimento físico em centímetros para a modalidade sensorial não vidente.

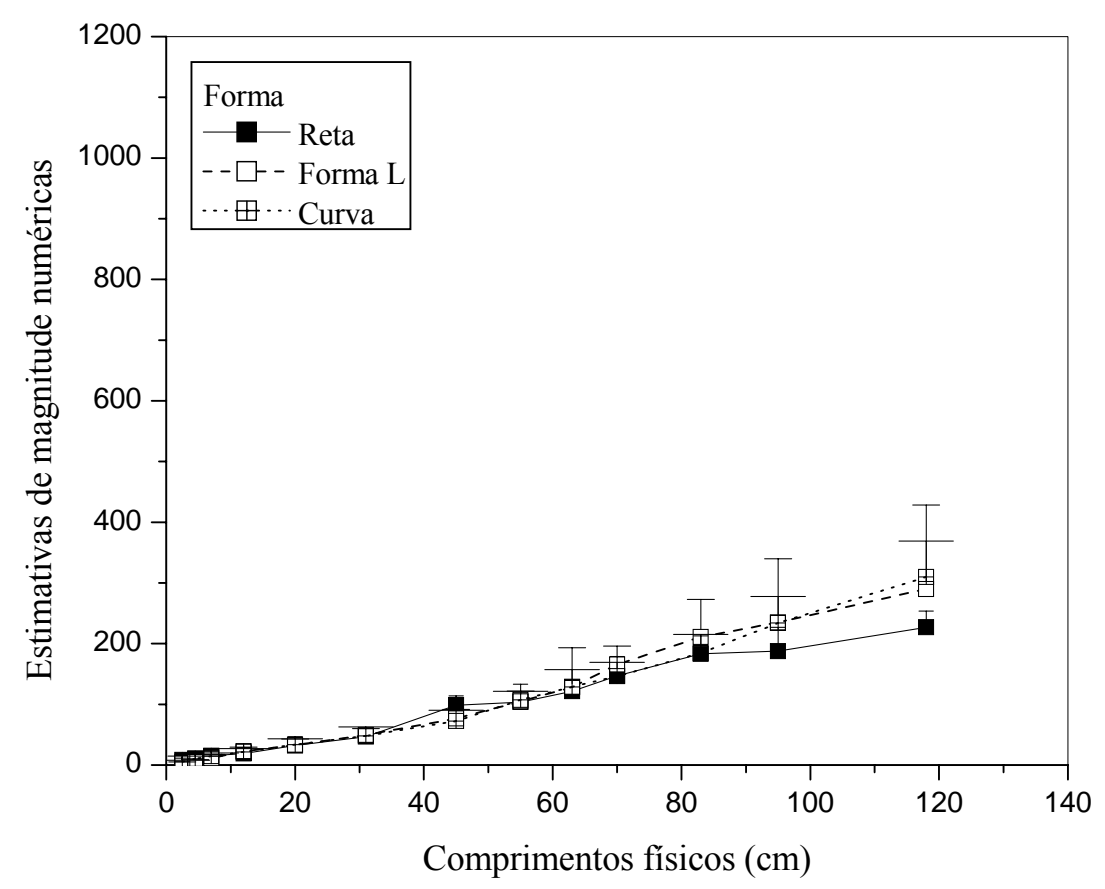

Figura 4- Médias geométricas e seus desvios padrão das estimativas de magnitude numérica para modalidade sensorial não vidente em função do comprimento físico das estimativas para a situação forma, reta x em L x curva. As barras verticais representam o desvio padrão da média geométrica e estão em uma direção por motivos estéticos. As barras com chapéus menores indicam a situação de forma reta, as de chapéu médio, as de forma em L e as de maior chapéu, as de forma curva. 
A Figura 5 sumaria os resultados relativos às médias geométricas das estimativas e seus desvios padrão em função do comprimento físico em centímetros para a modalidade sensorial vidente.

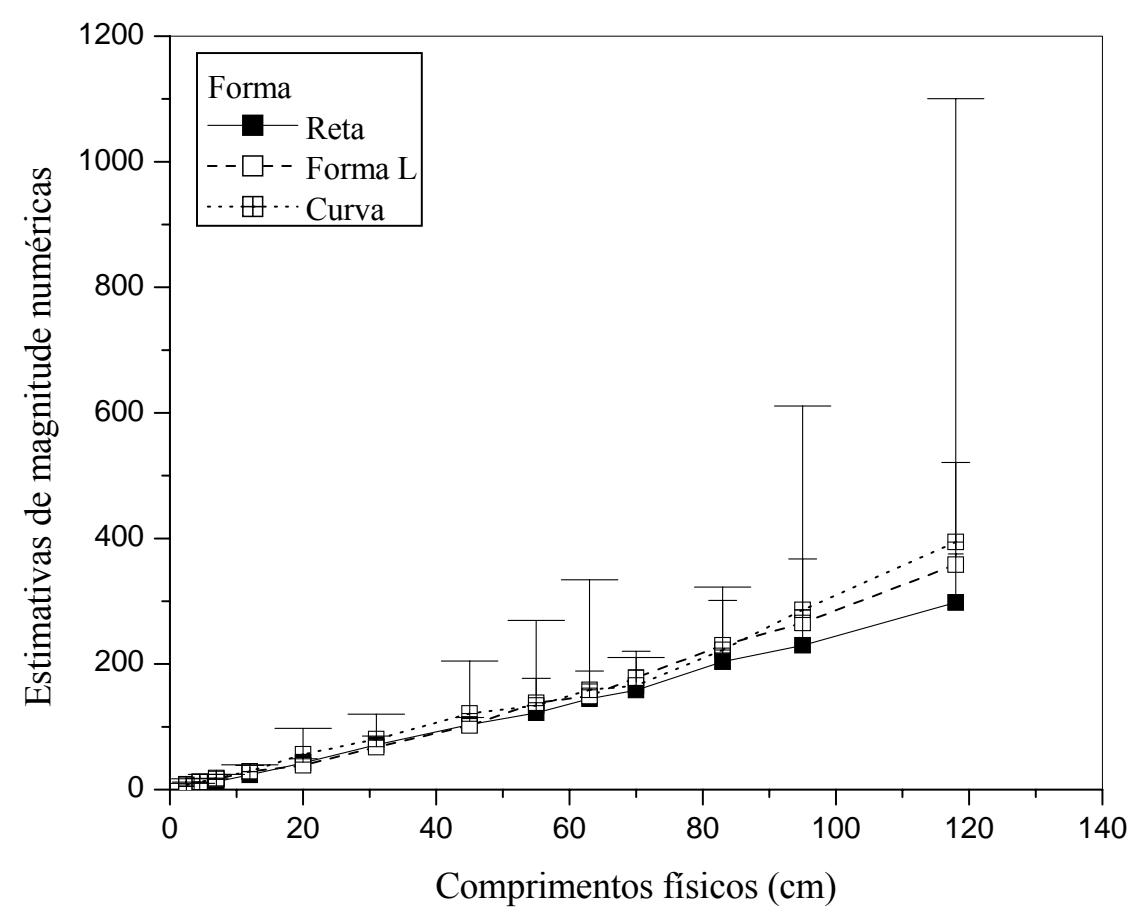

Figura 5- Médias geométricas e seus desvios padrão das estimativas de magnitude numérica para modalidade sensorial vidente em função do comprimento físico das estimativas para a situação forma, reta x em L x curva. As barras verticais representam o desvio padrão da média geométrica. As barras com chapéus menores indicam a situação de forma reta, as de chapéu médio, as de forma em L e as de maior chapéu, as de forma curva. 
As Figuras 6 e 7 sumariam os resultados relativos às médias geométricas das estimativas em função do comprimento físico em centímetros em coordenadas logarítmicas para a modalidade sensorial não vidente e vidente, respectivamente.

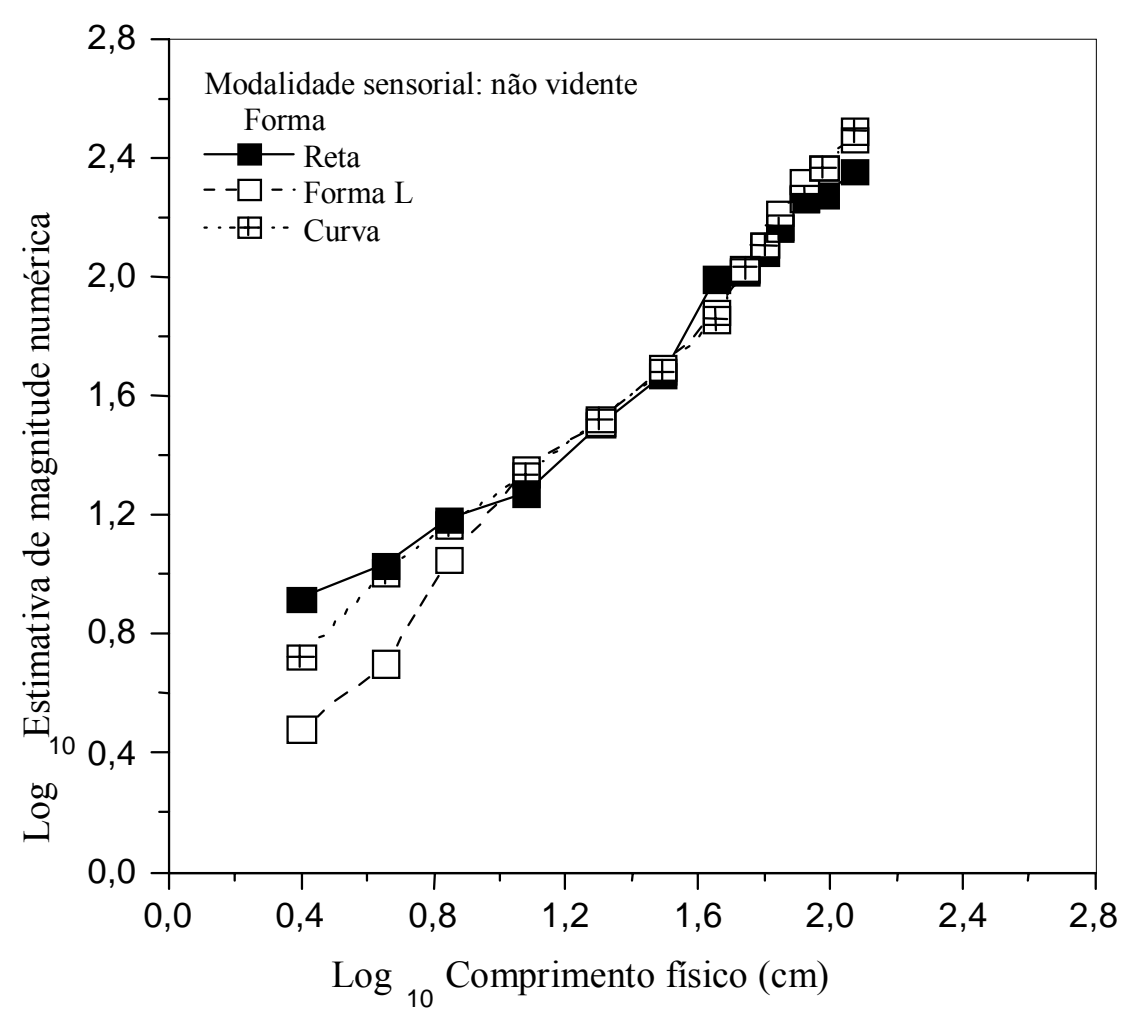

Figura 6- Logaritmo das médias geométricas das estimativas de magnitude numéricas em função do logaritmo dos comprimentos físicos $(\mathrm{cm})$ para os níveis do fator forma para a modalidade não vidente. 


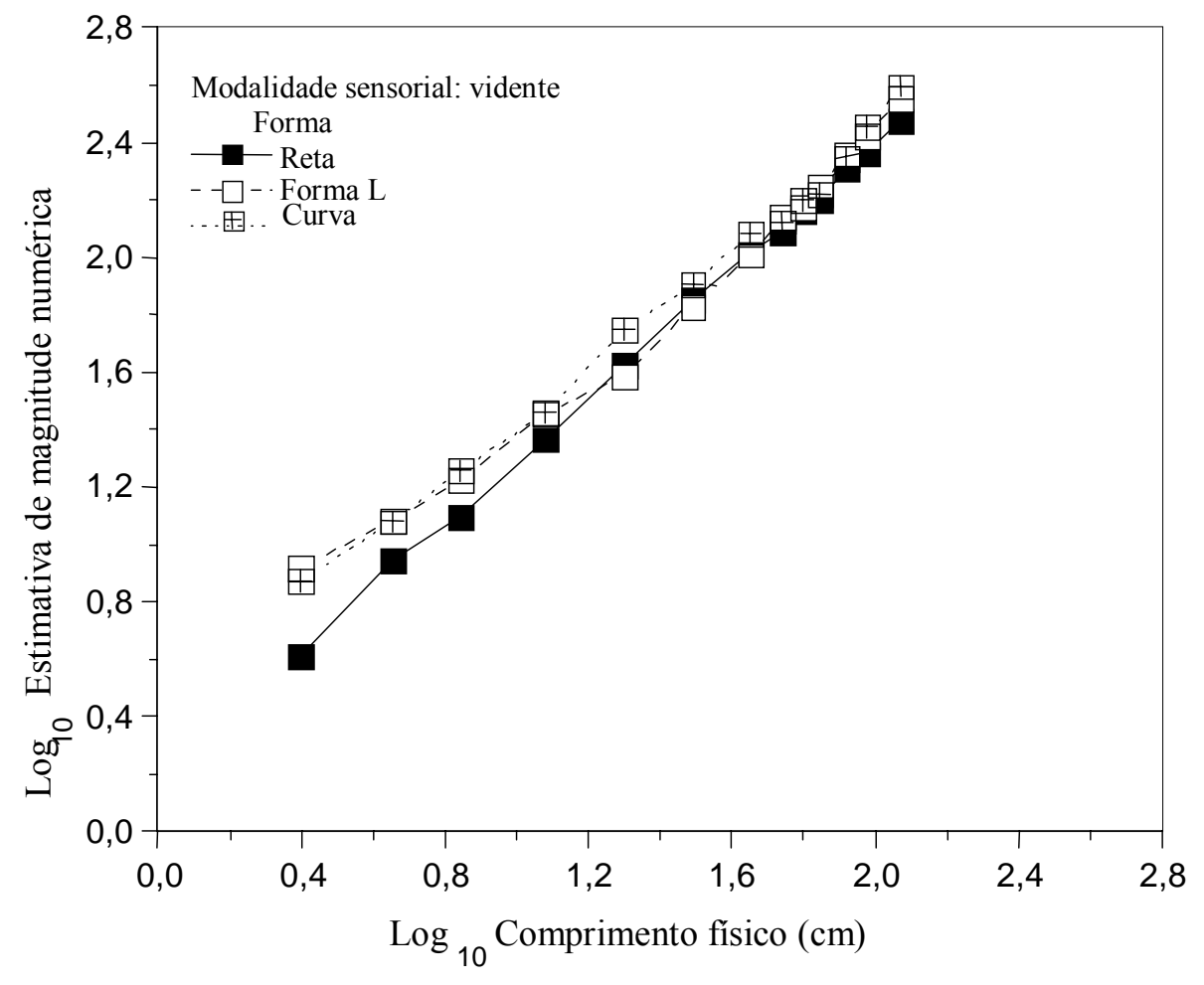

Figura 7- Logaritmo das médias geométricas das estimativas de magnitude numéricas em função do logaritmo dos comprimentos físicos $(\mathrm{cm})$ para os níveis do fator forma para modalidade vidente.

Uma ANOVA para 2 fatores entre-observadores (3 formas x 2 modalidades sensoriais) e 2 fatores intra-observadores (2 séries de estimativas x 13 comprimentos), sobre as estimativas individuais para o método da estimação de magnitude numérica não produziu diferenças significativas para os principais fatores, forma, $\mathbf{F}(2,54)=1,001, \mathbf{p}>0,05$ e modalidade sensorial, $\mathbf{F}(1,54)=2,967, \mathbf{p}>0,05$ e na interação entre os fatores principais, $\mathbf{F}(2,54)<1$. Para os fatores intra-observadores, no fator comprimentos de linha foram encontradas diferenças significativas, $\mathbf{F}(12,648)=33,219, \mathbf{p}=0,000$ e no fator séries de estimativas não foram produzidas diferenças significativas, $\mathbf{F}(1,54)=1,089, \quad \mathbf{p}>0,05$. Nas possíveis interações relativas ao fator séries de estimativas não foram produzidas 
diferenças significativas, séries $\mathrm{x}$ forma, $\mathbf{F}(2,54)=1,529, \mathbf{p}>0,05$, séries $\mathrm{x}$ modalidade sensorial, $\mathbf{F}(1,54)=1,391, \mathbf{p}>0,05$ e séries $\mathrm{x}$ forma $\mathrm{x}$ modalidade sensorial, $\mathbf{F}(2,54)=1,856$, $\mathbf{p}>0,05$. As possíveis interações com o fator comprimento de linha não produziram diferenças significativas entre os demais fatores, comprimento de linha $\mathrm{x}$ forma, $\mathbf{F}(24,648)=1,208, \mathbf{p}>0,05$, comprimento de linha $\mathrm{x}$ modalidade sensorial, $\mathbf{F}(12,648)=1,636$, $\mathbf{p}>0,05$ e comprimento de linha $\mathrm{x}$ forma $\mathrm{x}$ modalidade sensorial, $\mathbf{F}(24,648)=0,659, \mathbf{p}>0,05$. A interação entre os fatores séries de estimativas x comprimentos de linha não produziu diferenças significativas, $\mathbf{F}(12,648)=1,164, \mathbf{p}>0,05$, e nas interações entre séries de estimativas $\mathrm{x}$ comprimentos de linha $\mathrm{x}$ forma, $\mathbf{F}(24,648)=1,196, \mathbf{p}>0,05$, séries de estimativas $\mathrm{x}$ comprimentos de linha $\mathrm{x}$ modalidade sensorial, $\mathbf{F}(12,648)=1,302, \mathbf{p}>0,05 \mathrm{e}$ séries de estimativas $\mathrm{x}$ comprimentos de linha $\mathrm{x}$ forma $\mathrm{x}$ modalidade sensorial, $\mathbf{F}(24,648)=1,238, \mathbf{p}>0,05$.

Os resultados obtidos pelos processos da ANOVA revelam claramente que os fatores principais não produzem diferenças significativas, indicando que as observações realizadas a partir das Figuras 4 e 5 não indicam diferenças entre os fatores e seus níveis. Essas curvas mostram uma tendência a resultados que não diferem entre si, apesar do elevado grau de variabilidade em algumas situações experimentais. Este achado permite supor que o método da estimação de magnitude numérica não discriminou os fatores manipulados neste experimento.

\section{V.1.1. Análise dos expoentes da função de potência}

Com objetivos de obter uma análise em relação ao fenômeno da constância perceptiva para as estimativas de magnitude numérica dos comprimentos submetidos às situações experimentais manipuladas no presente estudo, foram calculados os parâmetros 
da função de potência, que se encontram resumidos nas Tabelas II e III (anexo). Os expoentes individuais obtidos a partir das estimativas de magnitude numérica para as possíveis combinações entre os níveis dos fatores principais, forma e modalidade sensorial, foram emparelhados ao valor de um expoente preditor igual a unidade.

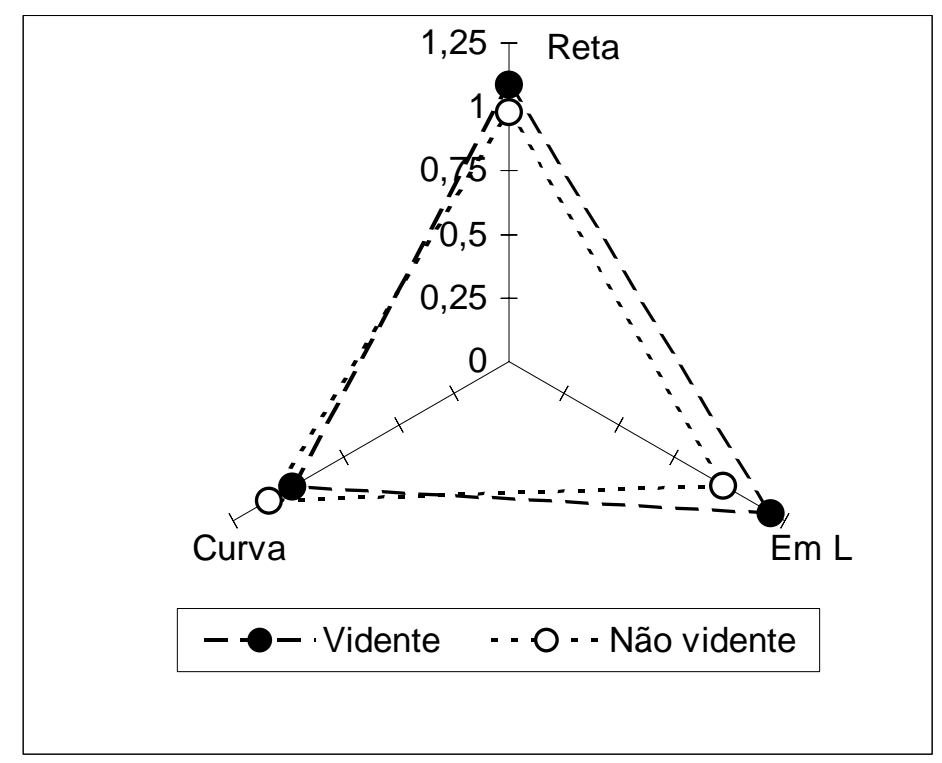

Figura 8- Ilustração dos expoentes médios da função de potência das estimativas de magnitude numérica para os fatores forma e modalidade sensorial.

A Figura 8 ilustra os valores médios dos expoentes da função de potência para os três níveis do fator forma e os dois níveis do fator modalidade sensorial. Pode- se observar uma inversão e uma pequena diferença entre os expoentes quanto aos três níveis do fator forma entre as modalidades vidente e não vidente. 


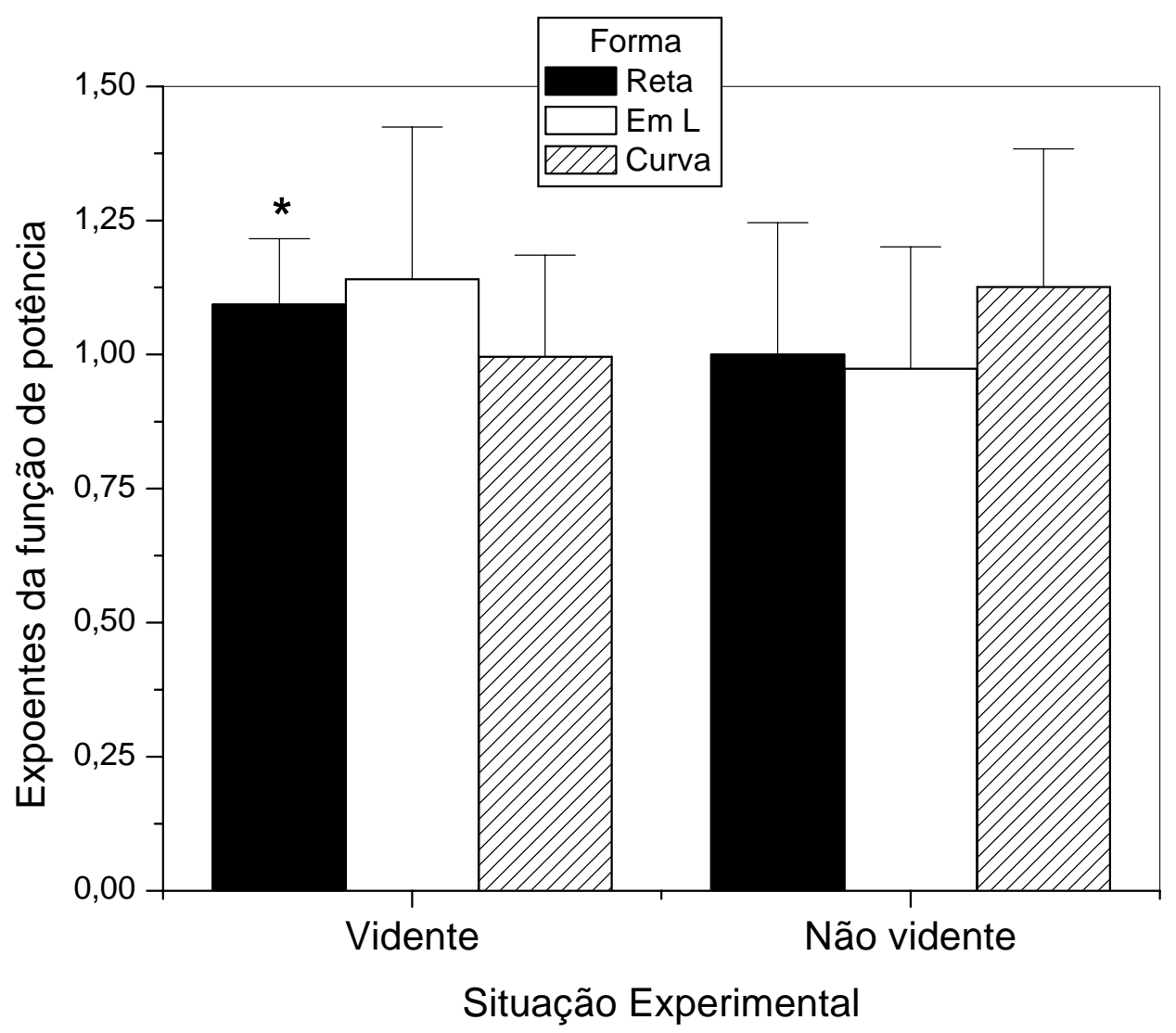

Figura 9- Expoentes médios da função de potência das estimativas de magnitude numérica para os níveis dos fatores modalidade e forma. As barras verticais indicam o desvio padrão da média aritmética e o asterisco $(*)$ indica que o valor do teste $t$ de Student para medidas repetidas do pareamento dos expoentes empíricos e o predito $(1,0)$ foi significativo para $\mathbf{p}$ $\leq 0,05$.

A Figura 9 resume os valores médios e o desvio padrão da média dos expoentes individuais para os fatores e seus níveis. A comparação com o expoente preditor, a unidade, foi significativa para a situação experimental forma reta e modalidade vidente, $\mathbf{t}(9)=2,361, \mathbf{p}=0,042$, para uma prova bilateral e um teste $\mathrm{t}$ de Student para medidas repetidas em ambos os pares. Nesta figura pode- se observar o que está resumido na Figura 8 e uma tendência à menor variabilidade dos expoentes para a situação forma reta em ambas as modalidades sensoriais. A modalidade sensorial não vidente apresenta uma leve 
tendência à estimativas com um indicativo de maior variabilidade dos expoentes, exceto na forma em $\mathrm{L}$.

Uma ANOVA para dois fatores independentes (3 formas x 2 modalidades sensoriais) sobre os valores individuais dos expoentes da função de potência não produziu diferenças significativas para os principais fatores forma, $\mathbf{F}(2,54)<1$ e modalidade sensorial, $\mathbf{F}(1,54)<1$, no entanto para uma possível interação entre ambos os fatores, forma $\mathrm{x}$ modalidade sensorial, foi revelada uma diferença significativa, $\mathbf{F}(2,54)=4,624, \mathbf{p}=0,014$.

\section{V.1.2. O efeito do fator sexo}

Uma nova variável foi introduzida no percurso do experimento, a variável sexo. Os processos de uma ANOVA para três fatores entre-observadores $(2$ sexos x 3 formas x 2 modalidades sensoriais) e dois fatores intra-observadores (2 séries de estimativas x 13 comprimentos), sobre as estimativas de magnitude numérica individuais, não revelaram diferenças significativas para os fatores principais sexo, $\mathbf{F}(1,48)<1$, forma, $\mathbf{F}(2,48)=1,005$, $\mathbf{p}>0,05$ e modalidade sensorial, $\mathbf{F}(1,48)=2,752, \mathbf{p}>0,05$. Todas as possíveis interações entre os fatores entre-observadores não produziram diferenças significativas, $\mathbf{F}(2,48)<1$, $\mathbf{p}$ $>0,05$. Para os dois fatores intra-observadores não foram reveladas diferenças significativas para o fator série de estimativas, $\mathbf{F}(1,48)=1,017, \mathbf{p}>0,05$, e no fator comprimento uma forte diferença significativa foi observada, $\mathbf{F}(12,576)=31,398, \mathbf{p}=0,000$. As demais possíveis interações não produziram diferenças significativas.

\section{V.2. Análises das estimativas de categoria numérica}

Os resultados obtidos referentes às estimativas de categoria numérica dos participantes para os fatores forma e modalidade sensorial estão sumariados na Figuras 10 
(modalidade não vidente) e Figura 11 (modalidade vidente). Pode- se observar a mesma tendência das estimativas médias de categoria numérica comparadas às estimativas de magnitude numérica.

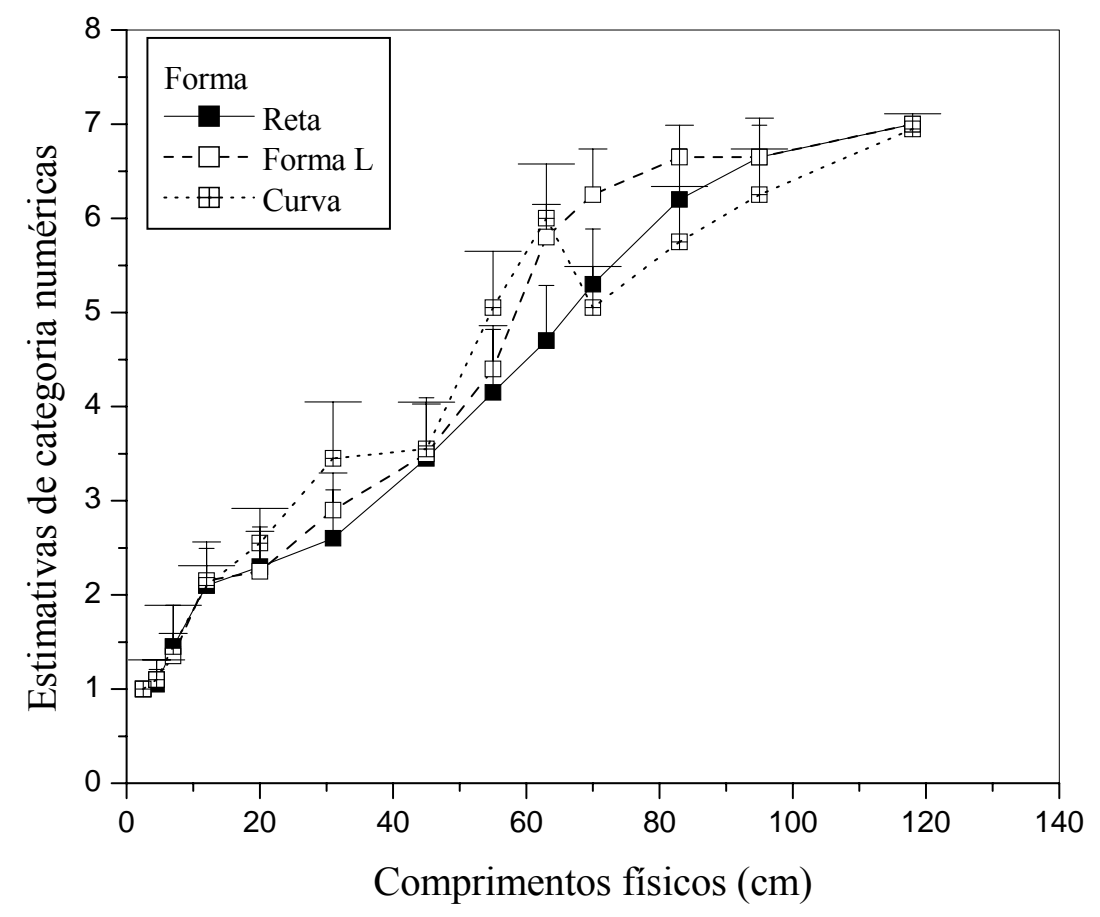

Figura 10- Médias aritméticas e seus desvios padrão das estimativas de categoria numérica em função do comprimento físico $(\mathrm{cm})$ para a modalidade sensorial não vidente e os níveis do fator forma. As barras verticais representam o desvio padrão da média aritmética. As barras com chapéus menores indicam a situação de forma reta, as de chapéu médio, as de forma em L e as de maior chapéu, as de forma curva. 


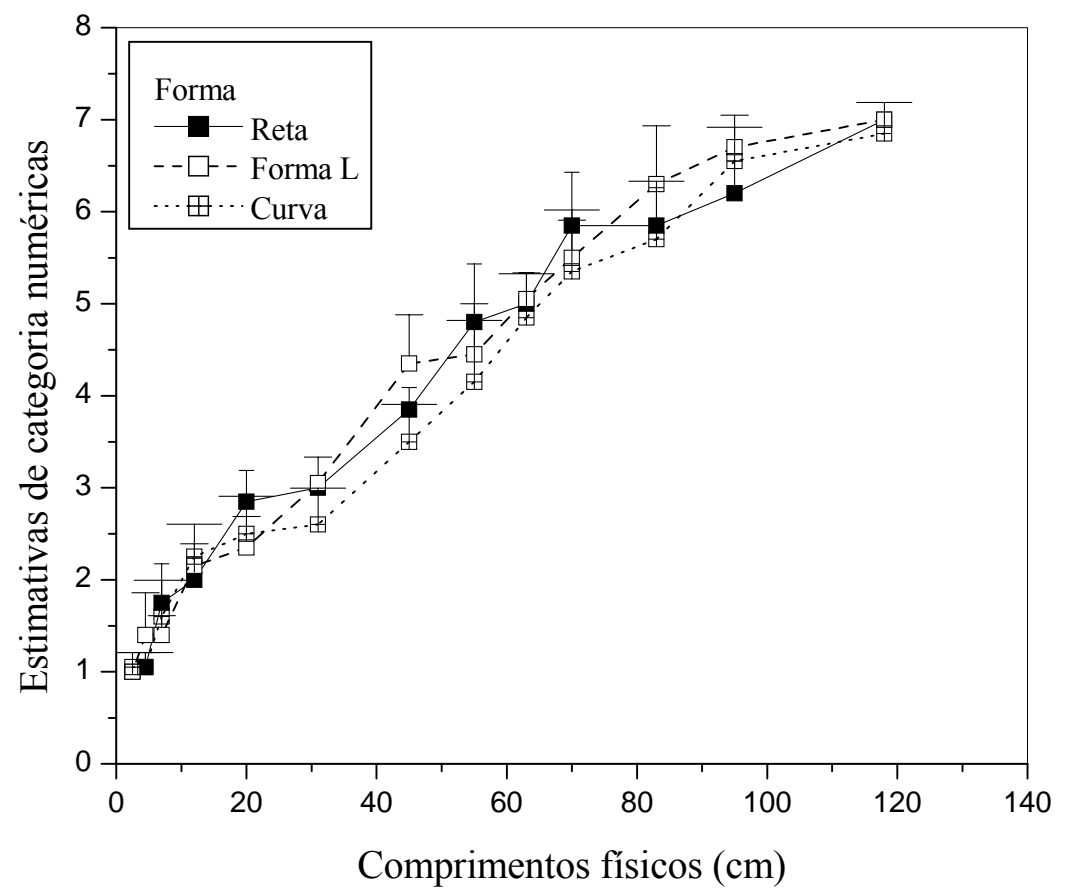

Figura 11- Médias aritméticas e seus desvios padrão das estimativas de categoria numérica em função do comprimento físico para a modalidade sensorial vidente e os níveis do fator forma. As barras verticais representam o desvio padrão da média aritmética. As barras com chapéus menores indicam a situação de forma reta, as de chapéu médio, as de forma em L e as de maior chapéu, as de forma curva.

Uma ANOVA para 2 fatores entre-observadores (3 formas x 2 modalidades sensoriais) e 2 fatores intra-observadores (2 séries de estimativas x 13 comprimentos), sobre as estimativas individuais obtidas pelo método de categoria numérica não produziu diferenças significativas para os principais fatores, forma, $\mathbf{F}(2,54)=2,507, \mathbf{p}>0,05$, e modalidade sensorial, $\mathbf{F}(1,54)<1$, nem para a interação entre os principais fatores, forma $\mathrm{x}$ modalidade sensorial, $\mathbf{F}(2,54)=3,125, \mathbf{p}>0,05$. Para os fatores intra-observadores, no fator comprimento de linha, diferenças significativas foram encontradas, $\mathbf{F}(12,648)=2081,577$, $\mathbf{p}=0,000$ e no fator séries de estimativas não foram produzidas diferenças significativas, $\mathbf{F}(1,54)=2,238, \quad \mathbf{p}>0,05$. Nas possíveis interações relativas ao fator séries de estimativas 
não foram produzidas diferenças significativas, séries $\mathrm{x}$ forma, $\mathbf{F}(2,54)<1$, séries $\mathrm{x}$ modalidade sensorial, $\mathbf{F}(1,54)<1$ e séries $\mathrm{x}$ forma $\mathrm{x}$ modalidade sensorial, $\mathbf{F}(2,54)=2,254$, $\mathbf{p}>0,05$. As possíveis interações com o fator comprimento de linha produziram diferenças significativas entre os demais fatores, comprimento de linha $\mathrm{x}$ forma, $\mathbf{F}(24,648)=5,558$, $\mathbf{p}=0,000$, comprimento de linha $\mathrm{x}$ modalidade sensorial, $\mathbf{F}(12,648)=5,809, \mathbf{p}=0,000$ e comprimento de linha $\mathrm{x}$ forma $\mathrm{x}$ modalidade sensorial, $\mathbf{F}(24,648)=7,241, \mathbf{p}=0,000$. A interação entre os fatores séries de estimativas $\mathrm{x}$ comprimentos de linha produziu diferenças significativas, $\mathbf{F}(12,648)=5,318, \mathbf{p}=0,000$, e nas interações entre séries de estimativas $\mathrm{x}$ comprimentos de linha $\mathrm{x}$ forma, $\mathbf{F}(24,648)=3,215, \mathbf{p}=0,000$, séries de estimativas $\mathrm{x}$ comprimentos de linha $\mathrm{x}$ modalidade sensorial, $\mathbf{F}(12,648)=2,883, \mathbf{p}=0,001 \mathrm{e}$ séries de estimativas $\mathrm{x}$ comprimentos de linha $\mathrm{x}$ forma $\mathrm{x}$ modalidade sensorial, $\mathbf{F}(24,648)=1,869, \mathbf{p}=0,007$.

Pode-se observar que, como para as estimativas de magnitude numérica, os principais fatores não produziram diferenças significativas, bem como o resultado apontado para a interação entre os principais fatores. Quanto aos principais fatores intraobservadores, estes também seguiram os resultados encontrados para estimativas de magnitude numérica; os comprimentos foram estimados como diferentes e o fator principal série de estimativas não revelou diferenças significativas.

\section{V.2.1. O efeito do fator sexo}

Assim como foi analisado no experimento anterior, o fator sexo foi introduzido e submetido aos processos de uma ANOVA para três fatores entre-observadores $(2$ sexos x 3 formas x 2 modalidades sensoriais) e dois fatores intra-observadores (2 séries de estimativas x 13 comprimentos) sobre as estimativas de categoria numéricas individuais, 
não produzindo diferenças significativas para o principal fator sexo, $\mathbf{F}(1,48)=1,507$, $\mathbf{p}>0,05$, para o fator forma, $\mathbf{F}(2,48)=2,392, \mathbf{p}>0,05$ e modalidade sensorial, $\mathbf{F}(1,48)=0,046$, $\mathbf{p}>0,05$. Todas as possíveis interações entre os fatores entre-observadores não produziram diferenças significativas, $\mathbf{F}(2,48)<1, \mathbf{p}>0,05$. Para os dois fatores intra-observadores não foram reveladas diferenças significativas para o fator série de estimativas, $\mathbf{F}(1,48)=2,353$, $\mathbf{p}>0,05$, e no fator comprimento uma forte diferença significativa foi observada, $\mathbf{F}(12,576)=2075,873, \mathbf{p}=0,000$. Para os fatores correlacionados foram reveladas diferenças significativas para as interações série $\mathrm{x}$ sexo, $\mathbf{F}(1,48)=5,106, \mathbf{p}=0,028$ e não foram reveladas diferenças significativas para a interação comprimento $\mathrm{x}$ sexo, $\mathbf{F}(12,576)=$ $1,004, \mathbf{p}>0,05$.

\section{V.3. Comparação entre os métodos psicofísicos: estimativas de categoria numérica $x$ estimativas de magnitude numérica}

Nesta esta etapa buscou- se verificar se ambas as estimativas seguem uma mesma tendência em seus resultados. Uma comparação foi realizada através das Figuras 12 e 13, onde as médias aritméticas das estimativas de categoria numérica foram plotadas em função do logaritmo das médias geométricas das estimativas de magnitude numérica para as modalidades não vidente e vidente, respectivamente. 


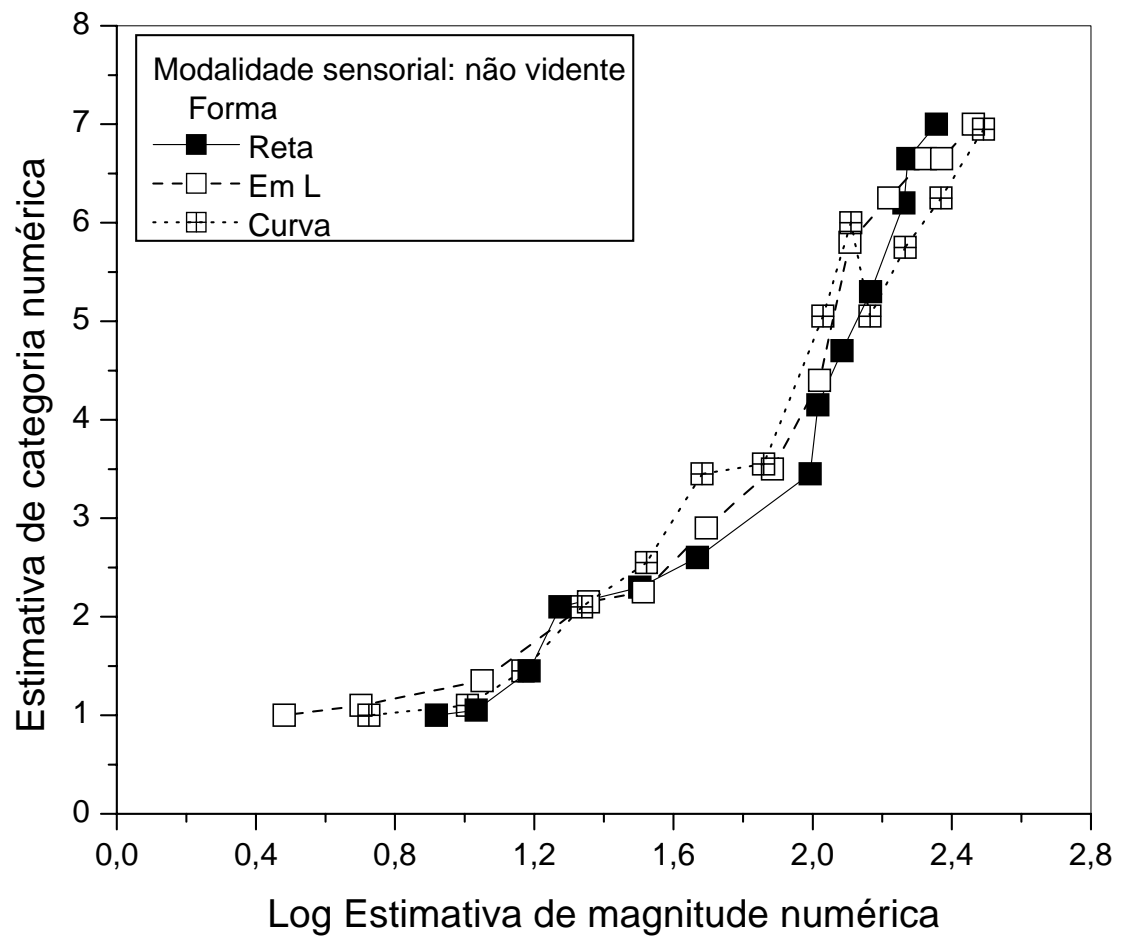

Figura 12- Média aritmética da estimativa de categoria numérica em função do logaritmo da média geométrica da estimativa de magnitude numérica para os níveis do fator forma e modalidade não vidente. 


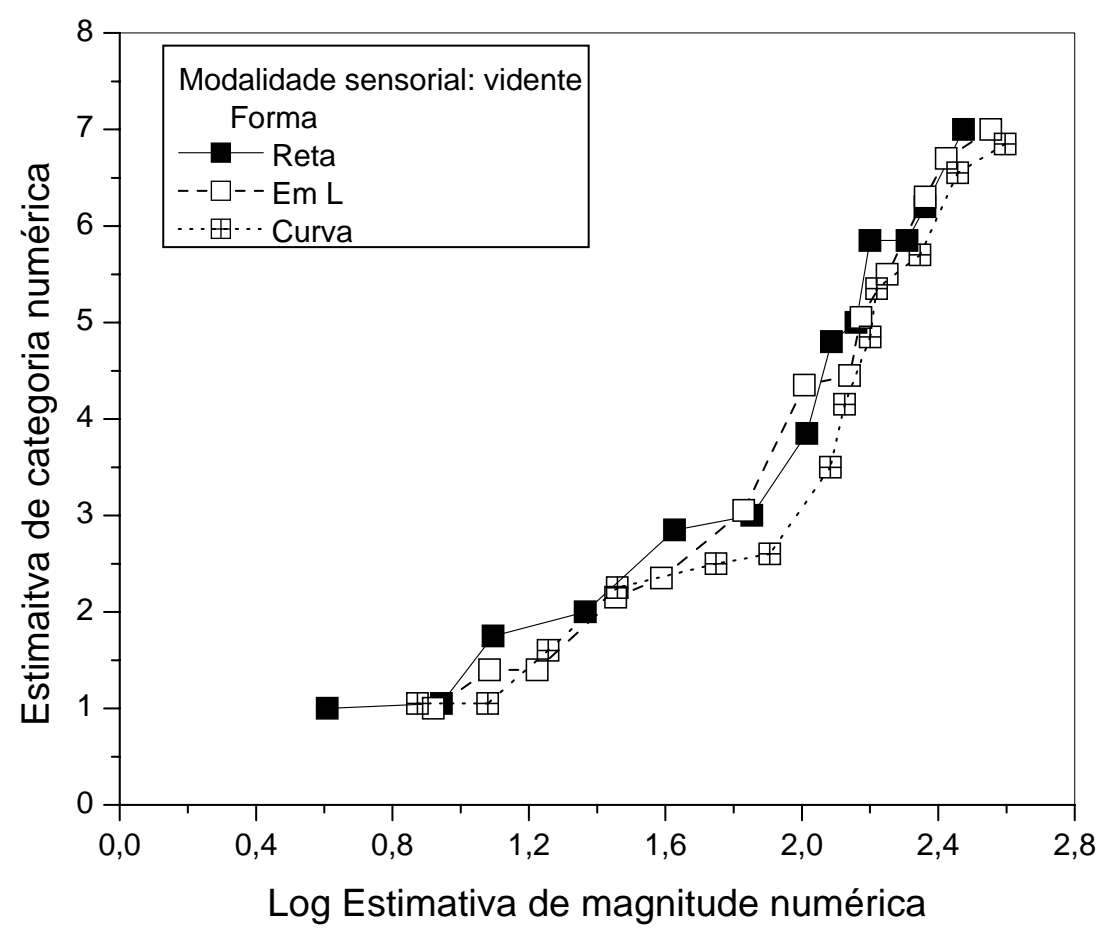

Figura 13- Média aritmética da estimativa de categoria numérica em função do logaritmo da média geométrica da estimativa de magnitude numérica para os níveis do fator forma e modalidade vidente.

Nas Figuras 12 e 13, ao comparar as modalidades sensoriais, não vidente e vidente, pode-se observar um agrupamento nas estimativas de maior comprimento, enquanto que aqueles comprimentos intermediários e inferiores, as estimativas tendem a caracterizar diferenças conforme o fator forma. Pode ser observada uma compressão nas estimativas de forma reta em relação aos demais níveis do fator forma, em L e curva. Esta tendência é menor quando se comparam as formas em L e curva, sendo que a tendência à compressão se dá para o contexto em L. Este achado para a forma curva pode ser observado a partir dos valores menores de comprimento físico em relação às demais formas, permitindo supor estimativas crescentes para esta situação experimental. 
Ainda em relação à situação de forma curva, nota-se uma inversão das estimativas para os comprimentos físicos intermediários, quando comparado o fator modalidade, sendo que o grupo não vidente apresentou estimativas mais elevadas do que o grupo vidente para este nível do fator forma, o que comprova os resultados obtidos para os parâmetros da função de potência, que pôde ser observado nas Figuras 8 e 9 .

Comparações através dos coeficientes de correlação de Pearson estão resumidas nas Tabelas VI, VII e VIII (anexo). Os valores encontrados para a comparação aos pares das médias aritméticas dos níveis dos fatores forma e modalidade sensorial, tanto para estimativas de magnitude numérica quanto para estimativas de categoria numérica, indicaram uma forte correlação positiva e altamente significativa para todos os pares possíveis em uma prova bilateral ou bicaudal, resumidos nas tabelas VI e VII (anexo), respectivamente. Os valores encontrados para a correlação de Pearson entre ambos os procedimentos psicofísicos, estimação de categoria numérica e estimação de magnitude numérica, também foram elevados e de mesma direção. Este achado é confirmado através do valor referente ao coeficiente de determinação para a matriz de correlações dos dados apresentados na Tabela VIII (anexo), indicando um alto nível de variância comum entre as correlações obtidas por ambos os procedimentos psicofísicos.

Outras análises de correlação de Pearson e dos parâmetros da regressão linear para comparações entre os resultados de um participante selecionado de modo aleatório e a média aritmética dos demais participantes para estimação de categoria e a média geométrica para estimação de magnitude, em todos os níveis dos fatores de forma e modalidade sensorial, também revelam fortes correlações positivas e significativas, indicando uma variabilidade comum entre as estimativas de magnitude e categoria numéricas, resumidas na Tabela IX (anexo). 
Considerando que apenas um observador realizou estimativas bastante elevadas, na situação experimental de modalidade vidente e forma curva, realizou-se uma análise de correlação de Pearson entre suas estimativas médias aritméticas e as estimativas médias aritméticas dos demais participantes do seu grupo, constatando que, apesar das elevadas estimativas, os resultados indicaram correlações altas e significativas, conforme indicadas na tabela abaixo.

Tabela 1- Correlações de Pearson entre o observador 10 e a média aritmética dos demais participantes, na situação experimental forma curva e modalidade sensorial vidente para estimativas de magnitude.

\begin{tabular}{cc}
\hline & obs10 \\
\hline obs01 & 0,812 \\
obs02 & 0,760 \\
obs03 & 0,745 \\
obs04 & 0,762 \\
obs05 & 0,801 \\
obs06 & 0,859 \\
obs07 & 0,859 \\
obs08 & 0,662 \\
obs09 & 0,880 \\
\hline
\end{tabular}

\section{V.4. Comparação dos comprimentos estimados}

O fator intra-observadores comprimento físico indicou uma forte diferença significativa para ambos os procedimentos psicofísicos, estimação de categoria numérica e estimação de magnitude numérica, indicando que os participantes perceberam os comprimentos como sendo diferentes uns dos outros. No entanto, algumas inversões ou igualdades ocorreram em raríssimas estimativas. Os resultados referentes à ocorrência de igualdades e inversões das estimativas foram resumidos na Tabela 2, apresentada a seguir. 
Tabela 2- Número de igualdades e inversões em cada situação experimental de forma e modalidade sensorial para estimativas de magnitude (EM) e de categoria (EC) numéricas.

\begin{tabular}{c|cccccc}
\hline Método & EM & EM & EM & EM & EM & EM \\
Forma & Reto & Curvo & Em L & Reto & Curvo & Em L \\
Modalidade & Não & Não & Não & Vidente & Vidente & Vidente \\
& Vidente & Vidente & Vidente & & & \\
Igualdades & 13 & 10 & 8 & 2 & 2 & 7 \\
Inversões & 16 & 7 & 6 & 5 & 8 & 8 \\
Método & EC & EC & EC & EC & EC & EC \\
Forma & Reto & Curvo & Em L & Reto & Curvo & Em L \\
Modalidade & Não & Não & Não & Vidente & Vidente & Vidente \\
& Vidente & Vidente & Vidente & & & \\
Igualdades & 50 & 46 & 53 & 44 & 42 & 45 \\
Inversões & 2 & 20 & 5 & 7 & 8 & 7 \\
\cline { 2 - 7 } & & & & & &
\end{tabular}

Os processos da análise de um CHI-QUADRADO $\left(\chi^{2}\right)$, os dados referentes aos dois processos psicofísicos, tomados como linha, e as freqüências dos pares de níveis dos fatores modalidade sensorial e forma, tomados como colunas para as igualdades de estimativas, produziram uma diferença não significativa entre ambos os procedimentos psicofísicos, $\chi^{2}=10,221, \mathrm{p}>0,05$. Para o critério de inversões, a prova do $\chi^{2}$ produziu uma diferença significativa entre as possíveis combinações, $\chi^{2}=17,630 p<0,01$. Este achado mostra que os participantes produziram freqüências de inversões diferentes em todas as combinações possíveis entre os níveis dos principais fatores, principalmente entre os níveis dos procedimentos psicofísicos utilizados no presente experimento. No entanto, em relação às freqüências de igualdades que não diferirem significativamente, este critério mostrou uma conformidade entre os resultados coletados neste estudo experimental. 
Tabela 3- A tabela indica as médias geométricas, os desvios padrão e as amplitudes das estimativas de magnitude numérica para o menor comprimento físico (c1) e para o maior comprimento físico (c13), para as situações de forma: reta (R), em L (L) e curva (C) e de modalidade sensorial: não vidente $(\mathrm{NV})$ e vidente $(\mathrm{V})$.

\begin{tabular}{c|cccccc}
$\begin{array}{c}\text { Forma x } \\
\text { modalidade }\end{array}$ & Média c1 & $\begin{array}{c}\text { Desvio } \\
\text { padrão c1 }\end{array}$ & $\begin{array}{c}\text { Amplitude } \\
\mathbf{c 1}\end{array}$ & Média c13 & $\begin{array}{c}\text { Desvio } \\
\text { padrão c13 }\end{array}$ & $\begin{array}{c}\text { Amplitude } \\
\text { c13 }\end{array}$ \\
\hline $\mathrm{R}^{*} \mathrm{NV}$ & 8,30 & 3,12 & 10 & 226,78 & 27,18 & 60 \\
$\mathrm{~L} * \mathrm{NV}$ & 3,03 & 2,51 & 8,5 & 289,79 & 152,73 & 490 \\
$\mathrm{C} * \mathrm{NV}$ & 5,31 & 2,76 & 8 & 309,66 & 60,26 & 187,5 \\
$\mathrm{R}^{*} \mathrm{~V}$ & 4,06 & 0,96 & 2,5 & 297,94 & 79,28 & 290 \\
$\mathrm{~L}^{*} \mathrm{~V}$ & 8,32 & 4,27 & 15,25 & 358,16 & 175,14 & 560 \\
$\mathrm{C}^{*} \mathrm{~V}$ & 7,47 & 2,38 & 6 & 394,44 & 1327,33 & 4335
\end{tabular}

$\mathrm{Na}$ tabela acima pode ser observado que tanto a amplitude quanto o desvio padrão dos comprimentos físicos maiores apresentam um aumento crescente em relação aos comprimentos menores em todas as situações experimentais. 



\section{DISCUSSÃO GERAL E CONCLUSÕES}

A presente série de experimentos teve como objetivo comparar julgamentos perceptivos visuais e hápticos de participantes quanto à diferentes comprimentos de linha, apresentados em três formas distintas: reta, em L e curva.

Sabe-se que a percepção visual pode ser influenciada por algumas ilusões visuais conhecidas, como a ilusão de Müller-Lyer e a ilusão de linhas verticais e horizontais (Gentaz \& Hatwell, 2004; Prinzmetal \& Gettleman, 1993; Verrillo \& Irvin, 1980). Alguns estudos têm demonstrado que algumas ilusões visuais também podem ocorrer na modalidade háptica (Bean, 1938; Gentaz \& Hatwell, 2004; Prinzmetal \& Gettleman, 1993; Revesz, 1934; Verrillo \& Irvin, 1980), embora haja discordância entre os possíveis fatores específicos de modalidades, responsáveis pela ilusão em cada sistema (Gentaz \& Hatwell, 2004). Gentaz e Hatwell (2004), por exemplo, argumentaram que os resultados aparentemente contraditórios encontrados na literatura em relação às ilusões hápticas podem ser explicados, no mínimo parcialmente, pelas características dos movimentos exploratórios manuais. Além disso, a percepção visual, assim como a percepção háptica, interage com a memória e o conhecimento (Yantis, 1998), considerando ainda as diferenças individuais em julgamentos psicofísicos (Fischer, 1994; Johnson, 1945; Massin, 2002).

A partir dos achados relacionados à percepção de forma de objetos e comprimentos de linha, utilizando a visão ou o tato, os quais têm mostrado resultados contraditórios quanto à similaridade entre estes dois modos sensoriais, foram conduzidos quatro tipos de experimentos, de acordo com os seguintes fatores: modalidade sensorial: vidente e não vidente, forma dos comprimentos: reta, em L e curva e método psicofísico utilizado: estimação de magnitude numérica e estimação de categoria numérica. 
A escolha da amostra $(\mathrm{N}=120)$ obedeceu alguns critérios que favorecem o rigor científico na realização de pesquisas, como número equilibrado de homens e mulheres em cada situação experimental, mesmo nível educacional e restrição da idade (18 a 35 anos) devido à própria natureza da tarefa, já que muitas mudanças na capacidade sensorial acompanham o envelhecimento (Verrillo, 2000).

\section{Análise dos fatores entre-observadores: modalidade sensorial, forma e sexo}

\section{Comparação entre modalidades sensoriais: vidente (V) e não vidente (NV)}

A ausência de diferenças significativas entre as estimativas para as três situações de forma dos comprimentos de linha apresentados: reto, curvo e em L para ambos os grupos, vidente e não vidente, e métodos utilizados, estimação de magnitude e de categoria numéricas, sugere que as modalidades, visão e háptica, são processos similares em tarefas de estimar comprimentos físicos ou forma de objetos. Este resultado apóia os achados de Casla e cols. (1999), Garbin (1990), Gentaz e cols. (2004), Gibson (1962, 1963, 1966), Hatwell (1960), James e cols. (2002), Klatzky, Lederman e Metzger (1985), Loomis, Klatzky e Lederman (1991), Millar e Al-Attar (2002), Norman e cols. (2004), Suzuki e Arashida (1992), ao contrário do estudo de Lederman e cols. (1990). Porém, isto não quer

dizer que áreas corticais primárias não podem contribuir diferentemente para a representação global ou identificação de um objeto, apesar de representações sensoriais e estratégias de processamento similares (Merabet \& cols., 2004, Norman \& cols., 2004, Zedu, 1991).

De acordo com Stein e Meredith (1993), nossa percepção do mundo é altamente integrada e unitária, apesar de suas capturas independentes, sendo subseqüentemente alcançada dentro de áreas associativas multimodais especializadas. A leitura de Braille 
tátil, por exemplo, é um processamento de modalidade cruzada não exclusivo para condições sensoriais privadas, como revelou o estudo de Amedi e cols. (2002), apontando que as áreas corticais occipitais também são empregadas no processamento de informação não visual de participantes videntes. Outro exemplo são os achados de Merabet e cols. (2004) sugerindo que o córtex occipital (visual) está envolvido no processamento de informações táteis que requerem discriminação espacial fina. A contribuição relativa de cada área cortical parece refletir qual modalidade é mais adaptada teoricamente em prover a informação desejada. A contribuição que um sentido faz para o outro depende da natureza da tarefa (Guest \& Spence, 2003, Johnson \& Hsiao, 1992).

Deste modo, algumas possíveis explicações para a similaridade entre as duas modalidades perceptivas estudadas, visão e háptica, na tarefa de estimar comprimentos de linha, apresentados em diferentes formas, do ponto de vista sensorial referem- se a: 1) as áreas envolvidas na percepção de comprimento são as mesmas para visão e háptico; 2) não há ruídos entre o processamento destas duas modalidades, gerando informações integradas quase exatas na tarefa de estimar comprimentos, confirmando a constatação de Da Silva e Macedo (1982) de que o valor do expoente da função de potência (conhecida como Lei de Stevens) para comprimento visual é muito próximo da unidade.

\section{Comparação entre forma dos comprimentos: reta (R), em L (L) e curva (C)}

Os resultados encontrados indicam que o fator forma não interfere nos julgamentos em ambos os grupos NV e V, como pôde ser observado nos dados obtidos das análises de variância e das correlações, ocorrendo diferenças não significativas entre as estimativas de acordo com os níveis deste fator. Maiores variabilidades das estimativas foram encontradas nas situações de forma em L e C, tanto para não vidente quanto para vidente, sendo que a 
curva das estimativas na situação de forma reta diferenciou mais quando comparada com as curvas das situações de forma em L e curva, para os dois níveis do fator modalidade.

Tais resultados corroboram os achados de Verrillo e Irvin (1980), mostrando que diferenças desaparecem quando linhas em forma de L (ilusão vertical-horizontal) são avaliadas na ausência de dicas contextuais e os resultados de Millar e Al-Attar (2002), nos quais erros foram reduzidos com dicas egocêntricas na condição visual, incluindo instruções para ignorar as setas das figuras de Müller-Lyer no tato. Estes achados sustentaram a hipótese de que referência espacial egocêntrica está envolvida na integração de inputs do tato e do movimento para a percepção háptica acurada de comprimento e forma. Também no estudo de Norman e cols. (2004), os observadores foram capazes de comparar forma 3D, através das modalidades cruzadas visão-háptica e háptica-visão com níveis razoavelmente altos de acurácia.

\section{Comparação entre sexos}

Os resultados de todos os experimentos indicando a ausência de diferenças significativas para o fator sexo, corroboram os achados de Verrillo (1979a, 1982) para comprimento de linha e de Millar e Al-Attar (2001) para a leitura de mapas com linhas auto-relevo através do tato, contrariando estudos que têm mostrado diferenças sexuais espaciais, conforme explicações biológicas, ambientais ou evolucionistas (Alexander \& cols., 2002; Kimura, 1999, Kitchin, 1996; McCourt \& cols., 1997, Silverman \& Phillips, 1993). Talvez diferenças sexuais não foram encontradas nas tarefas de estimar comprimentos físicos devido à natureza desta tarefa, confirmando que a estimação de comprimento de linha é um controle conveniente para o uso de números em experimentos 
de estimação de magnitude envolvendo outras modalidades sensoriais (Verrillo, 1979a, $1980,1982)$.

\section{Comparação entre métodos: estimação de magnitude e estimação de categoria}

A partir dos resultados presentes pôde-se observar que a relação entre o comprimento físico e a estimativa é mantida em todos os grupos e formas de comprimentos de linha apresentados.

De acordo com Stevens (1975), quando os valores médios das estimativas de categoria numérica contra os valores médios das estimativas de magnitude numérica dos comprimentos físicos em coordenadas monologarítmicas são representados em um gráfico, a curva da função é representada por uma linha reta. Isto pôde ser observado nas figuras 12 (não vidente) e 13 (vidente), confirmando as características protéticas do contínuo comprimento físico, isto é, atributo com propriedades quantitativas, apesar de serem métodos psicofísicos com características distintas. Isto significa que por alguma razão, as extensões da categoria aumentam quando é movida para cima a escala de categoria; ou seja, isto toma uma diferença maior entre dois estímulos no topo de uma escala do que na base para produzir uma diferença perceptual de uma unidade da escala de categoria. A explicação mais simples deste fenômeno é oferecida por Stevens e Galanter (1957), que argumentam que isto é simplesmente devido à dificuldade crescente de distinguir entre dois estímulos quando suas magnitudes aumentam. Dois estímulos perto na base da escala são relativamente facilmente discriminados e portanto são assinalados diferentes valores de categoria, enquanto dois estímulos igualmente juntos perto do topo do contínuo são facilmente confundidos e portanto tende a ser assinalado o mesmo valor da categoria. 


\section{Análise dos expoentes da função de potência}

A comparação entre os expoentes médios da função de potência e o expoente preditor, cujo valor é igual à unidade, das estimativas de magnitude revelou que o grupo vidente apresentou superconstância perceptiva, ou seja, expoentes maiores que a unidade, apresentando, portanto, aceleração positiva nas estimativas, exceto para a situação de forma curva, que apresentou subestimação das estimativas. O valor obtido para os expoentes individuais quando comparados ao expoente preditor igual a unidade na situação vidente e forma reta foi significativo, indicando que nesta situação não houve constância perceptiva dos julgamentos dos participantes. Este achado possivelmente pode ser devido à maior quantidade de informação nesta situação experimental, considerando todo o contexto de apresentação dos estímulos, podendo gerar maior variabilidade nas estimativas.

Já o grupo não vidente apresentou subconstância perceptiva, isto é, expoentes inferiores à unidade, indicando aceleração negativa nas estimativas, com exceção da situação de forma curva, que apresentou superestimação das estimativas. Estes achados indicam uma tendência de compressão das estimativas na modalidade não vidente, possivelmente devido à confusão de informações gerada pala ausência da visão.

Contudo, as médias dos expoentes de todos os grupos aproximaram da unidade, confirmando a presença de uma constância perceptiva nos julgamentos subjetivos de diferentes comprimentos e formas de linha. 


\section{Análise dos fatores intra-observadores: comprimento físico e série de estimativa}

\section{Comparação entre comprimentos físicos}

Todos os participantes perceberam os comprimentos como sendo diferentes uns dos outros para ambos os métodos psicofísicos utilizados, ocorrendo raríssimas inversões e igualdades das estimativas, como pôde ser observado na Tabela 2, anteriormente. Esta afirmativa segue os achados de Millar e Al-Attar (2001), Suzuki e Arashida (1992), Verrillo, (1982), Verrillo e Irvin (1980).

As inversões e igualdades apresentadas na Tabela 2 ocorreram nas estimativas de comprimentos físicos de maior semelhança. A ocorrência maior de igualdades nas estimativas de categorias (230) comparada às estimativas de magnitude (42) era esperada, devido à limitação das respostas dos participantes na estimação de categoria. $\mathrm{O}$ fato de ocorrer maior número de igualdades (180) e inversões (56) no grupo não vidente em relação ao grupo vidente (142 igualdades e 43 inversões) possivelmente indica um maior grau de incerteza quando os participantes realizam julgamentos sem a visão, como foi observado nos resultados de Lederman e cols. (1990).

Outro resultado interessante é a relação entre as médias geométricas das estimativas de magnitude numérica e seus desvios padrão, representada na Figura 4. Observou-se que a relação é linear, porém, quanto maior a estimativa de magnitude, tanto maior é o desvio padrão da média. Diferentemente, na relação entre as médias aritméticas das estimativas de categoria numérica e seus desvios padrão, representada nas Figuras 10 e 11, as estimativas correspondentes às categorias extremas (1 e 7) geralmente apresentam um desvio padrão da média das estimativas pequeno e as estimativas correspondentes às categorias intermediárias geralmente apresentam desvio padrão constante ou crescente em 
função da categoria média, conforme proposto por Stevens, 1975.

Ao comparar as Figuras 4 e 5, referentes às estimativas médias de magnitude numérica em função dos comprimentos físicos para não vidente e vidente, respectivamente, estes tenderam a apresentar maior variabilidade de respostas, o que pode ser mais destacado para a situação experimental modalidade vidente e forma curva, na qual apenas um observador realizou estimativas bastante elevadas que, no entanto, apresentaram correlações altas e significativas, quando suas estimativas médias foram comparadas com as estimativas médias dos demais participantes do seu grupo. Este achado confirma os resultados encontrados nas análises de correlação de Pearson realizadas para todas as possíveis combinações entre os principais fatores, modalidade e forma, e métodos utilizados, reforçando que estes fatores não interferem nas estimativas subjetivas dos participantes.

A Tabela 3 permitiu visualizar um aumento significativo do desvio padrão e da amplitude das estimativas médias de magnitude correspondentes ao menor e ao maior comprimento físico, em todas as situações experimentais de forma e modalidade sensorial, indicando maior variabilidade de respostas para comprimentos físicos maiores. Os valores altos do desvio padrão e da amplitude das estimativas médias correspondentes ao maior comprimento físico na situação experimental forma curva e vidente são devidos às altas estimativas de um observador deste grupo, porém apresentando forte correlação em relação aos demais, conforme descrito anteriormente.

Pôde-se notar, portanto, a tendência das estimativas não mostrarem o efeito desejado entre os níveis dos fatores forma e modalidade sensorial, o que foi comprovado na ANOVA, indicando que as estimativas numéricas, tanto de magnitude quanto de categoria, aumentaram em função do aumento do comprimento físico, independente da forma e da modalidade sensorial. 


\section{Comparação entre as séries de estimativas}

O fator intra-observadores séries de estimativas não produziu diferenças significativas, sugerindo que não houve efeito de aprendizagem, de memória ou da ordem de apresentação dos estímulos.

Ao comparar os resultados obtidos das análises de variância (ANOVA) das estimativas de ambos os métodos, magnitude e categoria numéricas, para todos os níveis dos fatores, modalidade, forma e posteriormente sexo, com a ANOVA e os resultados dos parâmetros da função de potência dos expoentes das estimativas de magnitude numérica, pôde-se observar a ausência de diferenças significativas nos principais fatores: modalidade, forma e sexo. Este achado foi confirmado pelas elevadas correlações positivas e significativas obtidas das análises de correlação de Pearson e pelo valor referente ao coeficiente de determinação, indicando um alto nível de variância comum entre as correlações obtidas por ambos os métodos psicofísicos.

Em linhas gerais, os resultados encontrados sustentam que tanto julgamentos visuais quanto julgamentos hápticos de diferentes comprimentos de linha, produzem resultados similares e fidedignos, independente do fator forma (reta, curva e em L), em participantes videntes e videntes vendados, homens e mulheres, com idade entre 18 e 35 anos. Além disso, ambos os métodos, estimação de magnitude e estimação de categoria, são validados e adequados para este tipo de tarefa, considerando as limitações específicas de cada método (Stevens, 1975).

Comparando os presentes resultados com a literatura abordada, constata-se a necessidade de investigações futuras referentes ao desempenho de participantes videntes em tarefas cotidianas que envolvem a percepção de comprimento, forma, distância e outros atributos como profundidade e textura, em relação aos participantes com baixa visão ou 
portadores de deficiências visuais. Haja vista que os dados de Heller e cols. (2002), por exemplo, mostraram uma forte presença da ilusão háptica de Müller-Lyer em quatro populações diferentes, videntes vendados, cegos tardios, cegos congênitos e adultos com baixa visão, ao usarem o dedo indicador direito para sentir a figura em auto-relevo e simultaneamente usarem sua mão esquerda para fazer estimativas de comprimento, utilizando uma régua com cursor tangível.

Desta forma, será possível compreender melhor os mecanismos subjacentes à percepção visual e háptica, permitindo não só o desenvolvimento de estratégias mais adequadas para enfrentar as situações cotidianas na ausência de uma modalidade sensorial, por exemplo da visão, como a construção ou melhora de equipamentos ou instalações adaptados para tal deficiência. 


\section{REFERÊNCIAS BIBLIOGRÁFICAS}

ALEXANDER, G. M., PACKARD, M. G., \& PETERSON, B. S. (2002). Sex and spatial position effects on object location memory following intentional learning of object identities. Neurophysics, 40, 1516-1522.

ALLIPRANDINI, P.M.Z. \& DA SILVA, J.A. (2000). Psychophysical power functions for aparent area in perceptive, memory and inference conditions for observers of diferent age groups. Perceptual and Motor Skills, 91, 783-788.

ALLIPRANDINI, P.M.Z., KANESIRO, S.S. \& SOUZA, A. (2002). The effects of age and educational levels in the perceptive and memory processes for estimates of area. Fechner Day 2002, São Paulo: Editora Legis Summa.

AMEDI, A., JACOBSON, G., HENDLER, T., MALACH, R. \& ZOHARY, E. (2002). Convergence of visual and tactile shape processing in the human lateral occipital complex. Cerebral Cortex, 11, 1202-1212.

BEAN, C. (1938). The blind have optical illusions. Journal of Experimental Psychology, 22, 283-289.

BENNETT, G.K., SEASHORE, H.G. \& WESMAN, A.G. (1974). Differential Aptitude Tests. New York: Psychology Corp.

BURSTIEN, B., BANK, L. \& JARVICK, L.F. (1980). Sex differences in cognitive functioning: Evidence, determinants, implications. Human Development, 23, 299313.

CASLA, M., BLANCO, F. \& TRAVIESO, D. (1999). Haptic perception of geometric illusions by persons who are totally congenitally blind. Journal of Visual Impairment \& Blindness, 93, 583-588. 
CAVINESS, J.A. (1962). The equivalence of visual and tactual stimulation for solid shape perception. Unpublished master's thesis, Cornell University.

CAVINESS, J.A. (1964). Visual and tactual perception of solid shape. Unipublished doctoral dissertation, Cornell University.

CAVINESS, J.A. \& GIBSON, J.J. (1962). The equivalence of visual and tactual stimulation for the perception of solid forms. Paper presented at the meeting of the Eastern Psychologycal Association, Atlantic City, N.J.

DA SILVA, J. A. \& MACEDO, L. (1982). A função- potência na percepção: significado e procedimentos de cálculo do expoente. Arquivos Brasileiros de Psicologia, 34, 2745.

DAY, R. \& AVERY, G. (1970). Absence of the horizontal- vertical illusion in haptic space. Journal of Experimental Psychology, 83, 172-173.

DEREGOWSKI, J. \& ELLIS, H.D. (1972). Effect of stimulus orientation upon haptic perception of the horizontal-vertical illusion. Journal of Experimental Psychology, 95, 14-19.

EAGLEMAN, D.M. (2001). Visual illusion and neurobiology. Nature Neuroscience Review, 2, 920-926.

ERLEBACHER, A. \& SEKULER, R. (1969). A conclusion on confusion in the illusion of Müller-Lyer. Proceedings of the Annual Convention of the American Psychological Association, 4, 27- 28.

FAINETEAU, H., GENTAZ, E. \& VIVIANI, P. (2003). The kinaesthetic perception of Euclidean distance; A study of the detour effect. Experimental Brain Research, 152, $166-172$

FEINGOLD, A. (1994). Gender differences in variability in intellectual abilities: a crosscultural perspective. Sex Roles: A Journal of Research, 30, 81-93. 
FISCHER, M.H. (1994). Less attention and more perception in cued line bisection. Brain and Cognition, 25, 24- 33.

GARBIN, C.P. (1990). Visual touch perceptual equivalence for shape information in children and adults. Perception \& Psychophysics, 48 (3), 271-279.

GAULIN, S.J.C. \& FITZGERALD, R.W. (1986). Sex differences inspatial ability: An evolutionary hypothesis and test. American Naturalist, 127, 74-88.

GENTAZ, E., CAMOS, V., HATWELL, Y. \& JACQUET, A.Y. (2004). The visual and haptic Müller-Lyer illusions. Manuscript submitted for publication.

GENTAZ, E. \& HATWELL, Y. (1996). Role of gravitational cues in the haptic perception of orientation. Perception \& Psychophysics, 58, 1278-1292.

GENTAZ, E. \& HATWELL, Y. (1998). The haptic oblique effect in the pereption of rod orientation by blind adults. Perception \& Psychophysics, 60, 157-167.

GENTAZ, E. \& HATWELL, Y. (1999). Role of memorisation conditions in the haptic processing of orientations and the oblique effect. British Journal of Psychology, 90, 377-388.

GENTAZ, E. \& HATWELL, Y. (2004). Geometrical haptic illusions: The role of exploration in the Müller-Lyer, vertical- horizontal and Delboeuf illusions. Psychonomic Bulletim \& Review, 11 (1), 31-40.

GIBSON, J.J. (1962). Observations on active touch. Psychological Review, 69, 477-491.

GIBSON, J.J. (1963). The useful dimensions of sensitivity. American Psychologist, 18, 115.

GIBSON, J.J. (1966). The Senses Considered as Perceptual Systems. Boston: Houghton Mifflin. 
GREENWOOD, P.J. (1980). Mating systems, philopatry and dispersal in birds and mamals. Animal Behavior, 28, 1140- 1162.

GUEST, S. \& SPENCE, C. (2003). Tactile dominance in speeded discriminations of textures. Experimental Brain Research, 150, 201-207.

GUILFORD, J.P. (1954). Psychometric Methods. New York: McGraw- Hill.

HAMILTON, R., KEENAM, J.P., CATALA, M. \& PASCUAL-LEONE, A. (2000). Alexia for Braille following bilateral occipital stroke in na early blind woman. Neuroreport, 11, 237-240.

HELLER, M.A., BRACKETT, D.D., WILSON, K., YONEYAMA, K., BOYER, A. \& STEFFEN, H. (2002). The haptic Müller-Lyer illusion in sighted and blind people. Perception, 31, $1263-1274$.

JACOBS, L.F., GAULIN, S.J.C., SHERRY, D. \& HOFFMAN, G.E. (1990). Evolution of spatial cognition: Sex- specific patterns of spatial behavior predict hippocampal size. Proceedings of the National Academy of Science, USA, 87, 6349- 6352.

JAMES, T.W., HUMPHREY, G.K., GATI, J.S., SERVOS, P., MENON, R.S., \& GOODALE, M. A. (2002). Haptic study of three dimensional objects activates extrastriate visual areas. Neuropsychologia, 40, 1706-1714.

JOHNSON, D.M. (1945). A systematic treatment of judgement. Psychological Bulletin, 42, $193-224$.

JOHNSON, K.O. \& HSIAO, S.S. (1992). Neural mechanisms of tactual form and texture perception. Annual Review of Neurosciense, 15, 227-250.

KELLMAN, P. L. \& SHIPLEY, T. E. (1991). A theory of visual interpolation in object perception. Cognitive Psychology, 23, 141- 221.

KIMURA, D. (1999). Sex and Cognition. Cambridge, MA : MIT Press. 
KITCHIN, R. M. (1996). Increasing the integrity of cognitive mapping research: Appraising conceptual schemata of environment-behaviour interaction. Progress in Human Geography, 20, 56-84.

KLATZKY, R.L., LEDERMAN, S.J. \& METZGER, V.A. (1985). Identifying objects by touch: An “expert system.” Perception \& Psychophysics, 37, 299-302.

LEDERMAN, S.J., BROWSE, R.A. \& KLATZKY, R.L. (1988). Haptic processing of spatially distributed information. Perception \& Psychophysics, 44 (3), 222-232.

LEDERMAN, S.J. \& KLATZKY, R.L. (1987). Hand movements: A window into haptic object recognition. Cognitive Psychology, 19, 342-368.

LEDERMAN, S.J. \& KLATZKY, R.L. (1993). Extracting object properties through haptic exploration. Acta Psychologica, 84, 29-40.

LEDERMAN, S.J., KLATZKY, R.L., CHATAWAY, C. \& SUMMERS, C.C. (1990). Visual mediation and the haptic recognition of two- dimensional pictures of common objects. Perception \& Psychophysics, 47 (1), 54-64.

LOOMIS, J.M., KLATZKY, R.L. \& LEDERMAN, S.J. (1991). Similarity of tactual and visual picture recognition with limited field of view. Perception, 20, 167-177.

LOOMIS, J.M. \& LEDERMAN, S.J. (1986). Tactual perception. In Boff, K., Kaufman, L. \& Thomas, J. (eds.), Handbook of Perception and Human Performance, 2, (pp.1-41). New York: Wiley.

MASSIN, S.C. (2002). Individual differences in space errors. In J. A. Da Silva, E. H. Matsushima e N. P. Ribeiro-Filho (Eds.), Proceedings of the Eighteenth Annual Meeting of the International Society for Psychophysics, (pp. 470-473), Rio de Janeiro: Editora Legis Summa. 
MCCOURT, M. E., MARK, V. W., RADONOVICH, K. J., WILliSON, S. K., \& FREEMAN, P. (1997). The effects of gender, menstrual phase and practice on the perceived location of the midsagittal plane. Neuropsychologia, 35, 717-724.

MCGLONE, J. (1980). Sex differences in human brain asymmetry: A critical survey. Behavioral and Brain Sciences, 3, 215-263.

MERABET, L.; THUT, G.; MURRAY, B.; ANDREWS, J.; HSIAO, S. \& LEONE, A.P. (2004). Feeling by Sight or Seeing by Touch? Neuron, 42, 173-179.

MILLAR, S. (1985). Movement cues and body orientation in recall of locations of blind and sightde children. Quarterly Journalof Experimental Psychology, 37A, 257-279.

MILLAR, S. (1988). Models of sensory deprivation: The nature/nurture dichotomy and spatial representation in the blind. International Journal of Behavioral Development, $11,69-87$.

MILLAR, S. (1994). Understanding and Representing Space: Theory and Evidence from Studies with Blind and Sighted Children. Oxford: Clarendon Press.

MILLAR, S. (2000). Modality and mind: Convergence active processing in interrelated networks as a model of development and perception by touch. Em: M. A. Heller (Ed.), Touch, representation, and blindness (pp. 91-141). Oxford: Oxford University Press.

MILLAR, S. \& AL-ATTAR, Z. (2001). Illusions in reading maps by touch: Reducing distance errors. British Journal of Psychology, 92, 643-657.

MILLAR, S. \& AL-ATTAR, Z. (2002). The Müller-Lyer illusion in touch and vision: Implications for multisensory processes. Perception \& Psychophysics, 64 (3), 353365. 
NORMAN, J.F.; NORMAN, H.F.; CLAYTON, A.M.; LIANEKHAMMY, J. \& ZIELKE, G. (2004). The visual and haptic perception of natural object shape. Perception \& Psychophysics, 66 (2), 342-351.

OWEM, D.H. \& BROWN, D.R. (1970). Vsual and tactual form discrimination: psychophysical comparison within and between modalities. Perception \& Psychophysics, 7, 302-306.

PRINZMETAL, W. \& GETTLEMAN, L. (1993). Vertical- horizontal illusion: One eye is better than two. Perception \& Psychophysics, 53, 81-88.

REVESZ, G. (1934). System der optschen und Hapttischen Raumtãuschungen. Zeitschrift fur Physiologie, 131, 296-375.

REVESZ, G. (1950). Psychology and Art of the Blind. London: Longmans Green.

SILVERMAN, I. \& EALS, M. (1992). Sex Differences in Spatial Abilities: Evolutionary Theory and Data. In: Barkow, J.H., Cosmides, L., Tooby, J. The Adapted Mind. Evolutionary Psychology and the Generation of Culture. New York Oxford. Oxford University Press.

SILVERMAN, I., \& PHILLIPS, K. (1993). Effects of estrogen changes during the menstrual cycle on spatial performance. Ethology and Sociobiology, 14, 257-270.

STEIN, B.E. \& MEREDITH, M.A. (1993). The Merging of the Senses. Cambridge, MA: The MIT Press.

STERnBERG, R. J. (2000). Psicologia Cognitiva. Tradução: M.R.B. Osório. Porto Alegre: Artes Médicas.

STEVENS, S.S. (1975). Psychophysics: Introduction to it Perceptual, Neural and Social Prospects. New York: Wiley.

STEVENS, S.S. \& GALANTER, E. (1957). Ratios scales and category scales for a dozen perceptual continua. Journal of Experimental Psychology, 54, 377-411. 
SUZUKI, K. \& ARASHIDA, R. (1992). Geometric haptic illusions revisited: Haptic illusions compared with visual illusions. Percption \& Psychophysics, 52, 329-335.

TSOTSOS, J. (1990). Analyzing vision at the complexity level. Behavioral and Brain Sciences, 13, 423- 445.

VANDENBERG, S.G. \& KUSE, A.R. (1978). Mental rotations: A group test of threedimensional spatial visualization. Perceptual \& Motor Skills, 47, 599-604.

VERRILLO, R.T. (1979 a). Comparison of vibrotactile threshold and suprathreshold responses in men and women. Perception \& Psychophysics, 26, 20-24.

VERRILLO, R.T. (1979 b). Change in vibrotactile thholds as a function of age. Sensory Processes, 3, 49- 59.

VERRILLO, R.T. \& IRVIN, G. (1980). Absolute estimation of line length as a function of orientation and contrast polaritiy. Sensory Processes, 3 (3), 261-274.

VERRILLO, R.T. (1980). Age- related changes in the sensitivity to vibration. Journal of Gerontology, 35, 185- 193.

VERRILLO, R.T. (1981). Absolute estimation of line length in three age groups. Journao of Gerontology, 36, 625-627.

VERRILLO, R.T. (1982). Absolute estimation of line length as a function of sex. Bulletin of the Psychonomic Society, 19 (6), 334-335.

VERRILLO, R.T. (2000). The Effects of Aging on the Sense of Touch. In: Ronald T. Verrillo. Sensory Research- Multimodal Perspectives. Syracuse University.

WARD, S. L., NEWCOMBE, N., \& OVERTON, W. F. (1986). Turn left at the church, or three miles north. A study of direction giving and sex differences. Environment and Behavior, 18, 192-213. 
WONG, T.S. (1977). Dynamic properties of radial and tangential movements as determinants of the haptic horizontal- vertical illusion with an L figure. Journal of Experimental Psychology: Human Perception \& Performance, 3, 151-164.

YANTIS, S. (1998). Objects, attention and perceptual experience. Em: Rigth, R. D. (Ed.) Vsual Attention. Oxford University Press, New York.

ZEDU, P. M. M. (1991). Escalas perceptivas visual e tatual-cinestésica de espessura e área em observadores normais e cegos. Dissertação de Mestrado não publicada. Universidade de São Paulo, Faculdade de Filosofia, Ciências e Letras de Ribeirão Preto, SP. 



\section{Anexo 1- "Termo de consentimento livre e esclarecido para o participante"}

Concordo em participar de uma pesquisa que está sendo realizada pela aluna Ana Paula Tosetto, da Universidade de São Paulo, cujo orientador é o professor Dr. José Aparecido da Silva. Esta pesquisa tem como objetivo investigar como estudantes universitários avaliam uma série de comprimentos de linha, através de modalidades sensoriais diferentes. A coleta de dados será feita através dos seguintes procedimentos: estimação de magnitude de comprimento visual, estimação de magnitude de comprimento não visual, estimação de categoria de comprimento visual e estimação de categoria de comprimento não visual, em uma sala isolada, apropriada para os experimentos.

Ao decidir participar deste estudo, tomei conhecimento de que:

1) Serei submetido aos experimentos citados acima receberei instruções específicas.

2) Estou ciente de que sou livre para desistir e deixar de participar do trabalho a qualquer momento, se assim o desejar. Caso não me sinta à vontade em algum experimento, poderei deixar de realizá-lo, sem que isso implique em qualquer prejuízo, o mesmo ocorrendo se não concordar em participar desta pesquisa ou interromper minha participação.

3) Sei que as informações que fornecerei poderão, mais tarde, ser utilizadas para trabalhos científicos e que minha identificação será mantida sob sigilo, isto é, não haverá chance de ser identificado meu nome, assegurando meu completo anonimato.

4) Não há nenhum risco significativo em participar deste estudo. Estou ciente de que minha participação nesta pesquisa poderá ampliar o conhecimento científico da área a ser estudada.

5) Minha participação é inteiramente voluntária e depende exclusivamente da minha vontade de colaborar com a pesquisa.

6) Aceito voluntariamente participar desta atividade, não tendo sofrido nenhuma forma de pressão para tanto.

7) Caso queira falar com os pesquisadores, serão fornecidos meios de contatos com os mesmos.

Considerando as observações acima:

$\mathrm{Eu}$, aceito voluntariamente participar deste estudo, estando ciente de que estou livre para em qualquer momento desistir ou interromper minha participação na pesquisa. Eu recebi uma cópia deste termo e a possibilidade de lê-lo.

Ribeirão Preto, de de 
Nome:

Idade: Sexo: ( ) F ( ) M

Data: Curso: Nível: ( ) G ( ) PG

\section{Anexo 2- Tipo de Experimento: Estimação de Magnitude de Comprimento Visual (EMV)}

\section{Instruções}

Este experimento tomará aproximadamente 10 minutos de seu tempo e você estará colaborando com a realização de nossa pesquisa. Um registro dos resultados não identificará qualquer um que dele participar. A tarefa que você irá realizar não é difícil de ser completada. Entretanto, se em algum momento você desejar interromper o experimento, avise- nos e este será interrompido e encerrado.

Estamos interessados em estudar como os estudantes universitários avaliam uma série de comprimentos de linha, através de modalidades sensoriais diferentes.

Sua tarefa será atribuir um número que seja proporcional à dimensão aparente de cada comprimento de linha apresentado, tendo como referência um comprimento chamado de estímulo padrão, cujo módulo é igual a 100. Deste modo, se você julgar que um comprimento de linha é duas vezes maior que o estímulo padrão, então você deverá atribuir a este comprimento um número que seja duas vezes maior que o estímulo padrão (200). Caso você julgar que outro comprimento seja quatro vezes menor que o estímulo padrão, você deverá atribuir um número que seja quatro vezes menor que o estímulo padrão (25).

Assim, você deverá atribuir um número para cada estímulo apresentado, utilizando somente a visão, de modo que este número seja proporcional à dimensão do estímulo padrão, na sua opinião. Você poderá atribuir qualquer número positivo, inteiro, fração ou decimal. Suas respostas deverão seguir na ordem em que elas forem requisitadas pelo experimentador.

Está claro para você qual é a sua tarefa? Alguma questão? Sinceramente, muito obrigado pela sua colaboração. 
Nome:

Idade: Sexo: ( ) F ( ) M

Data: Curso: Nível: ( ) G ( ) PG

\section{Anexo 3- Tipo de Experimento: Estimação de Magnitude de Comprimento Não Visual (EMNV)}

\section{Instruções}

Este experimento tomará aproximadamente 10 minutos de seu tempo e você estará colaborando com a realização de nossa pesquisa. Um registro dos resultados não identificará qualquer um que dele participar. A tarefa que você irá realizar não é difícil de ser completada. Entretanto, se em algum momento você desejar interromper o experimento, avise- nos e este será interrompido e encerrado.

Estamos interessados em estudar como os estudantes universitários avaliam uma série de comprimentos de linha, através de modalidades sensoriais diferentes.

Sua tarefa será atribuir um número que seja proporcional à dimensão aparente de cada comprimento de linha apresentado, tendo como referência um comprimento chamado de estímulo padrão, cujo módulo é igual a 100. Deste modo, se você julgar que um comprimento de linha é duas vezes maior que o estímulo padrão, então você deverá atribuir a este comprimento um número que seja duas vezes maior que o estímulo padrão (200). Caso você julgar que outro comprimento seja quatro vezes menor que o estímulo padrão, você deverá atribuir um número que seja quatro vezes menor que o estímulo padrão (25).

Seus olhos serão vendados e você deverá utilizar sua mão dominante para deslizar sobre o estímulo apresentado, podendo percorrer três vezes pelo estímulo, antes de dar sua resposta, que deverá ser proporcional à dimensão do estímulo padrão, na sua opinião. Você poderá atribuir qualquer número positivo, inteiro, fração ou decimal. Suas respostas deverão seguir na ordem em que elas forem requisitadas pelo experimentador.

Está claro para você qual é a sua tarefa? Alguma questão? Sinceramente, muito obrigado pela sua colaboração. 
Nome:

Idade: Sexo: ( ) F ( ) M

Data: Curso: Nível: ( ) G ( ) PG

\section{Anexo 4- Tipo de Experimento: Estimação de Categoria de Comprimento Visual (ECV) Instruções}

Este experimento tomará aproximadamente 10 minutos de seu tempo e você estará colaborando com a realização de nossa pesquisa. Um registro dos resultados não identificará qualquer um que dele participar. A tarefa que você irá realizar não é difícil de ser completada. Entretanto, se em algum momento você desejar interromper o experimento, avise- nos e este será interrompido e encerrado.

Estamos interessados em estudar como os estudantes universitários avaliam uma série de comprimentos de linha, através de modalidades sensoriais diferentes.

A tarefa de estimação é bastante fácil. Serão apresentados uma série de comprimentos de linha, um a um, aleatoriamente à você. Sua tarefa será atribuir um escore, que variará de 1 a 7 , a cada comprimento de linha apresentado, tendo como referência um comprimento chamado de estímulo padrão, cujo módulo é igual a 4. Se você achar que um dado comprimento de linha apresente uma dimensão bem menor que o estímulo padrão, você deverá atribuir a este comprimento o escore 1. Caso você ache que outro comprimento seja muito maior que o estímulo padrão, você deverá atribuir o escore máximo, 7.Você deverá usar os escores intermediários 2, 3, 4, 5 e 6 para indicar dimensões intermediárias de comprimentos de linha. Por favor, tente utilizar todos os escores e evidentemente, se você achar que alguns comprimentos de linha tenham dimensões similares, julgue estes comprimentos com um mesmo escore.

Assim, você deverá atribuir um escore para cada comprimento de linha apresentado, utilizando somente a visão, de modo que este escore seja proporcional à dimensão do estímulo padrão, na sua opinião. Suas respostas deverão seguir na ordem em que elas forem requisitadas pelo experimentador.

Está claro para você qual é a sua tarefa? Alguma questão? Sinceramente, muito obrigado pela sua colaboração. 
Nome:

Idade: Sexo: ( ) F ( ) M

Data: Curso: Nível: ( ) G ( ) PG

\section{Anexo 5- Tipo de Experimento: Estimação de Categoria de Comprimento Não Visual (ECNV) \\ Instruções}

Este experimento tomará aproximadamente 10 minutos de seu tempo e você estará colaborando com a realização de nossa pesquisa. Um registro dos resultados não identificará qualquer um que dele participar. A tarefa que você irá realizar não é difícil de ser completada. Entretanto, se em algum momento você desejar interromper o experimento, avise- nos e este será interrompido e encerrado.

Estamos interessados em estudar como os estudantes universitários avaliam uma série de comprimentos de linha, através de modalidades sensoriais diferentes.

A tarefa de estimação é bastante fácil. Serão apresentados uma série de comprimentos de linha, um a um, aleatoriamente à você. Sua tarefa será atribuir um escore, que variará de 1 a 7 , a cada comprimento de linha apresentado, tendo como referência um comprimento chamado de estímulo padrão, cujo módulo é igual a 4. Se você achar que um dado comprimento de linha apresente uma dimensão bem menor que o estímulo padrão, você deverá atribuir a este comprimento o escore 1. Caso você ache que outro comprimento seja muito maior que o estímulo padrão, você deverá atribuir o escore máximo, 7.Você deverá usar os escores intermediários 2, 3, 4, 5 e 6 para indicar dimensões intermediárias de comprimentos de linha. Por favor, tente utilizar todos os escores e evidentemente, se você achar que alguns comprimentos de linha tenham dimensões similares, julgue estes comprimentos com um mesmo escore.

Seus olhos serão vendados e você deverá utilizar sua mão dominante para deslizar sobre o estímulo apresentado, podendo percorrer três vezes pelo estímulo, antes de dar sua resposta. Você deverá atribuir um escore para cada comprimento de linha apresentado que deverá ser proporcional à dimensão do estímulo padrão, na sua opinião. Suas respostas deverão seguir na ordem em que elas forem requisitadas pelo experimentador.

Está claro para você qual é a sua tarefa? Alguma questão? Sinceramente, muito obrigado pela sua colaboração. 


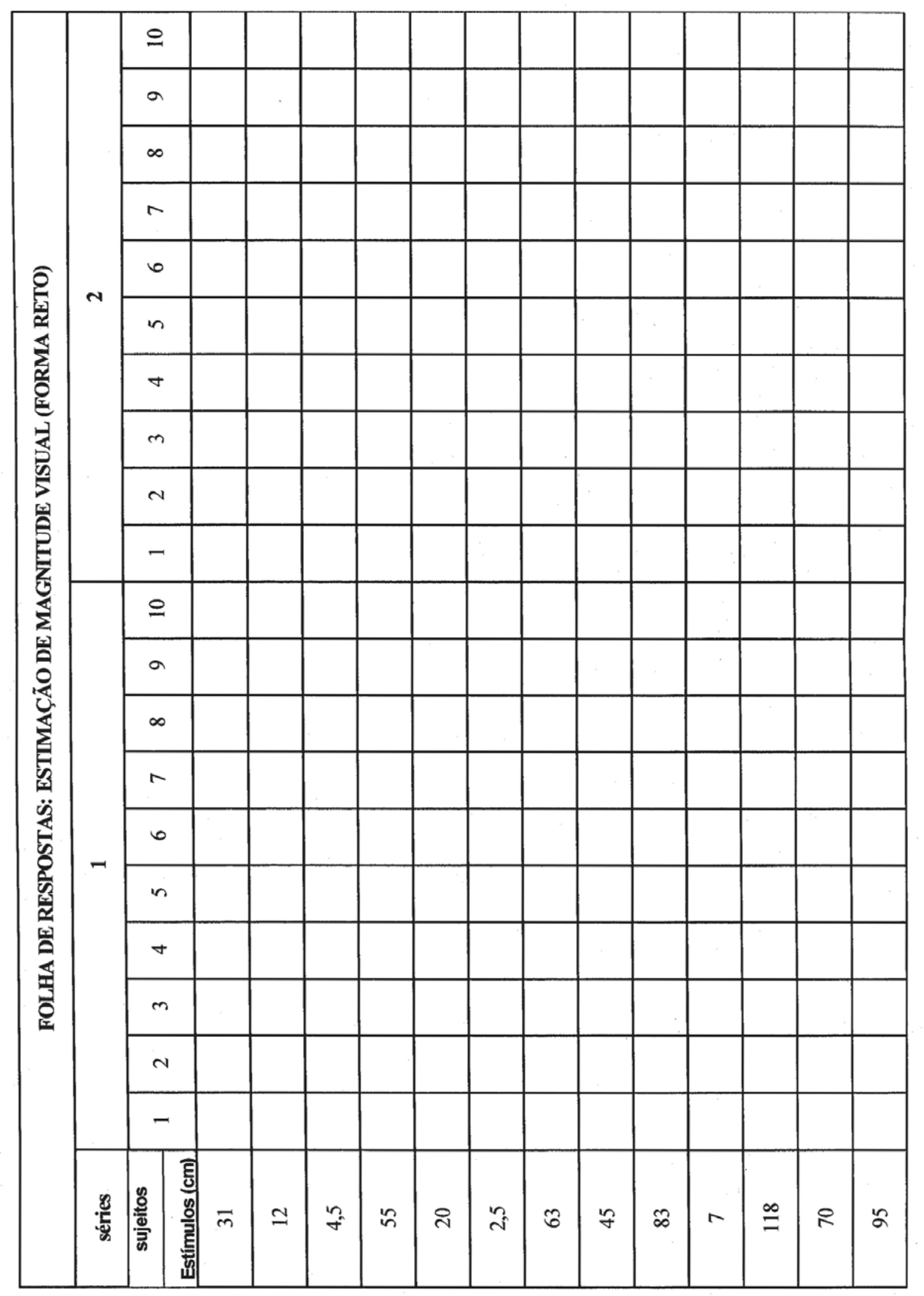


Tabela I- A tabela indica as médias aritméticas e o desvio padrão das estimativas de magnitude numérica para cada comprimento físico nas situações experimentais de forma (reta, curva e em L) e modalidade sensorial (não vidente e vidente).

\begin{tabular}{|c|c|c|c|c|c|c|c|c|c|c|c|c|}
\hline Forma & Reta & & Curva & & Em L & & Reta & & Curva & & Em L & \\
\hline Modalidade & N Vidente & & N Vidente & & N Vidente & & Vidente & & Vidente & & Vidente & \\
\hline Comprimento & MA & DP & MA & DP & MA & DP & MA & DP & MA & DP & MA & DP \\
\hline 2,50 & 8,75 & 3,12 & 5,93 & 2,76 & 3,95 & 2,51 & 4,18 & 0,96 & 7,85 & 2,38 & 9,98 & 4,27 \\
\hline 4,50 & 12,50 & 7,63 & 11,20 & 4,89 & 6,65 & 4,64 & 9,15 & 2,78 & 13,15 & 5,44 & 14,39 & 6,77 \\
\hline 7,00 & 17,15 & 7,97 & 15,70 & 5,31 & 13,05 & 7,17 & 12,95 & 3,84 & 19,20 & 6,46 & 19,35 & 8,42 \\
\hline 12,00 & 20,85 & 10,63 & 22,25 & 5,46 & 23,75 & 6,69 & 23,75 & 5,56 & 30,60 & 11,22 & 30,35 & 10,61 \\
\hline 20,00 & 36,00 & 16,76 & 34,75 & 10,44 & 34,25 & 10,61 & 43,50 & 9,52 & 66,75 & 49,53 & 40,15 & 10,88 \\
\hline 31,00 & 48,50 & 13,80 & 50,00 & 15,14 & 50,50 & 10,59 & 71,75 & 7,46 & 87,00 & 42,64 & 69,75 & 18,31 \\
\hline 45,00 & 99,50 & 15,71 & 74,25 & 18,34 & 78,00 & 15,17 & 103,75 & 9,66 & 136,75 & 94,30 & 102,50 & 12,96 \\
\hline 55,00 & 107,25 & 30,33 & 108,00 & 14,23 & 106,00 & 17,29 & 123,00 & 16,11 & 168,25 & 171,14 & 142,50 & 40,43 \\
\hline 63,00 & 122,75 & 17,77 & 131,50 & 28,78 & 139,00 & 70,78 & 146,00 & 24,27 & 206,00 & 227,96 & 154,00 & 40,69 \\
\hline 70,00 & 150,00 & 32,81 & 148,00 & 23,21 & 168,25 & 31,00 & 161,50 & 32,30 & 170,75 & 45,81 & 182,50 & 43,29 \\
\hline 83,00 & 185,25 & 29,78 & 187,00 & 31,11 & 218,75 & 64,09 & 204,50 & 21,88 & 239,00 & 107,98 & 239,50 & 74,70 \\
\hline 95,00 & 191,25 & 40,02 & 237,75 & 44,88 & 250,00 & 111,23 & 235,50 & 58,19 & 383,75 & 435,39 & 279,00 & 107,21 \\
\hline 118,00 & 228,25 & 27,18 & 315,25 & 60,26 & 319,00 & 152,73 & 305,50 & 79,28 & 741,50 & 1327,33 & 385,25 & 175,14 \\
\hline
\end{tabular}

Tabela II- Valores descritivos dos parâmetros da função de potência para as situações experimentais estimativas de magnitude numérica nos níveis da modalidade sensorial vidente.

\begin{tabular}{|c|c|c|c|}
\hline Parâmetros da & \multicolumn{3}{|c|}{ Forma } \\
\cline { 2 - 4 } função de potência & Reta & Em L & Curva \\
\cline { 2 - 4 } e o coeficiente de & \multicolumn{3}{|c|}{ Modalidade sensorial: vidente } \\
\hline determinação & 1,08462 & 1,18808 & 0,981137 \\
& $(0,113351)$ & $(0,274851)$ & $(0,174308)$ \\
\hline Conpoente & 1,769146 & 1,461289 & 2,996112 \\
& $(0,626472)$ & $(1,227241)$ & $(1,722383)$ \\
\hline Coeficiente de & 0,987907 & 0,96488 & 0,973418 \\
determinação (r) & $(0,004003)$ & $(0,019193)$ & $(0,016294)$ \\
\hline
\end{tabular}

Nota: os valores entre os parênteses indicam o desvio padrão da média aritmética. 
Tabela III- Valores descritivos dos parâmetros da função de potência para as situações experimentais estimativas de magnitude numérica nos níveis da modalidade sensorial não vidente.

\begin{tabular}{|c|c|c|c|}
\hline Parâmetros da & \multicolumn{3}{|c|}{ Forma } \\
\cline { 2 - 4 } função de potência & Reta & Em L & Curva \\
\cline { 2 - 4 } e o coeficiente de & \multicolumn{3}{|c|}{ Modalidade sensorial: não vidente } \\
\cline { 2 - 4 } determinação & 0,97695 & 0,973494 & 1,08869 \\
Expoente & $(0,200109)$ & $(0,225131)$ & $(0,240353)$ \\
\hline Constante escalar & 3,052434 & 3,694263 & 1,970968 \\
& $(2,689497)$ & $(1,942865)$ & $(1,257047)$ \\
\hline Coeficiente de & 0,962263 & 0,956567 & 0,940454 \\
determinação (r $\left.\mathbf{r}^{2}\right)$ & $(0,015189)$ & $(0,025095)$ & $(0,052574)$ \\
\hline
\end{tabular}

Nota: os valores entre os parênteses indicam o desvio padrão da média aritmética.

Tabela IV- Médias dos expoentes das estimativas de magnitude numérica de cada situação experimental emparelhadas com o expoente preditor da constância perceptual $(n=1,0)$ através do teste $t$ Student.

\begin{tabular}{ccccc}
\hline Pares & Expoente preditor & $\mathrm{t}$ & $\mathrm{gl}$ & $\mathrm{p}$ \\
\hline Não vidente reto & 1 & 0,364 & 9 & 0,724 \\
Não vidente em L & 1 & 0,372 & 9 & 0,718 \\
Não vidente curvo & 1 & 1,167 & 9 & 0,273 \\
Vidente reto & 1 & 2,361 & 9 & $\mathbf{0 , 0 4 3}$ \\
Vidente em L & 1 & 2,164 & 9 & 0,059 \\
Vidente curvo & 1 & 0,342 & 9 & 0,740 \\
\hline
\end{tabular}


Tabela $V$ - A tabela indica as médias aritméticas e o desvio padrão das estimativas de categoria numérica para cada comprimento físico nas situações experimentais de forma (reta, curva e em L) e modalidade sensorial (não vidente e vidente).

\begin{tabular}{|c|c|c|c|c|c|c|c|c|c|c|c|c|}
\hline Forma & Reta & & Curva & & Em L & & Reta & & Curva & & Em L & \\
\hline Modalidade & N Vidente & & N Vidente & & N Vidente & & Vidente & & Vidente & & Vidente & \\
\hline Comprimento & MA & DP & MA & DP & MA & DP & MA & DP & MA & DP & MA & DP \\
\hline 2,50 & 1,00 & 0,00 & 1,00 & 0,00 & 1,00 & 0,00 & 1,00 & 0,00 & 1,05 & 0,16 & 1,00 & 0,00 \\
\hline 4,50 & 1,05 & 0,16 & 1,10 & 0,21 & 1,10 & 0,21 & 1,05 & 0,16 & 1,05 & 0,16 & 1,40 & 0,46 \\
\hline 7,00 & 1,45 & 0,44 & 1,45 & 0,44 & 1,35 & 0,24 & 1,75 & 0,42 & 1,60 & 0,39 & 1,40 & 0,21 \\
\hline 12,00 & 2,10 & 0,39 & 2,10 & 0,21 & 2,15 & 0,41 & 2,00 & 0,24 & 2,25 & 0,35 & 2,15 & 0,24 \\
\hline 20,00 & 2,30 & 0,42 & 2,55 & 0,37 & 2,25 & 0,42 & 2,85 & 0,34 & 2,50 & 0,41 & 2,35 & 0,34 \\
\hline 31,00 & 2,60 & 0,52 & 3,45 & 0,60 & 2,90 & 0,39 & 3,00 & 0,00 & 2,60 & 0,39 & 3,05 & 0,28 \\
\hline 45,00 & 3,45 & 0,64 & 3,55 & 0,50 & 3,50 & 0,53 & 3,85 & 0,24 & 3,50 & 0,41 & 4,35 & 0,53 \\
\hline 55,00 & 4,15 & 0,67 & 5,05 & 0,60 & 4,40 & 0,46 & 4,80 & 0,63 & 4,15 & 0,67 & 4,45 & 0,55 \\
\hline 63,00 & 4,70 & 0,59 & 6,00 & 0,58 & 5,80 & 0,35 & 5,00 & 0,33 & 4,85 & 0,47 & 5,05 & 0,28 \\
\hline 70,00 & 5,30 & 0,59 & 5,05 & 0,44 & 6,25 & 0,49 & 5,85 & 0,58 & 5,35 & 0,67 & 5,50 & 0,41 \\
\hline 83,00 & 6,20 & 0,54 & 5,75 & 0,59 & 6,65 & 0,34 & 5,85 & 0,41 & 5,70 & 0,63 & 6,30 & 0,63 \\
\hline 95,00 & 6,65 & 0,34 & 6,25 & 0,49 & 6,65 & 0,41 & 6,20 & 0,35 & 6,55 & 0,37 & 6,70 & 0,35 \\
\hline 118,00 & 7,00 & 0,00 & 6,95 & 0,16 & 7,00 & 0,00 & 7,00 & 0,00 & 6,85 & 0,34 & 7,00 & 0,00 \\
\hline
\end{tabular}

Tabela VI- Correlação de Pearson para comparação aos pares das médias aritméticas dos níveis dos fatores forma e modalidade sensorial para estimativas de magnitude numéricas.

\begin{tabular}{|c|c|c|c|c|c|c|}
\hline & EMNVR & EMNVL & EMNVC & EMVR & EMVL & EMVC \\
\hline EMNVL Corr. Pearson & 0,985 & 1,000 & & & & \\
\hline EMNVC Corr. Pearson & 0,975 & 0,996 & 1,000 & & & \\
\hline Corr. Pearson & 0,991 & 0,994 & 0,993 & 1,000 & 0,995 & \\
\hline Corr. Pearson & 0,980 & 0,996 & 0,998 & 0,995 & 1,000 & \\
\hline Corr. Pearson & 0,876 & 0,925 & 0,950 & 0,927 & 0,948 & 1,000 \\
\hline
\end{tabular}

Tabela VII- Correlação de Pearson para comparação aos pares das médias aritméticas dos níveis dos fatores forma e modalidade sensorial para estimativas de categoria numéricas.

\begin{tabular}{llllllll}
\hline & & \multicolumn{1}{l}{ ECNVR } & ECNVL & ECNVC & ECVR & ECVL & ECVC \\
\hline ECNVL Corr. Pearson & 0,988 & 1,000 & & & & \\
ECNVC Corr. Pearson & 0,969 & 0,977 & 1,000 & & & \\
ECVR & Corr. Pearson & 0,987 & 0,985 & 0,979 & 1,000 & & \\
ECVL & Corr. Pearson & 0,992 & 0,985 & 0,973 & 0,987 & 1,000 & \\
ECVC & Corr. Pearson & 0,997 & 0,988 & 0,974 & 0,990 & 0,990 & 1,000 \\
\hline
\end{tabular}


Tabela VIII- Coeficientes da correlação de Pearson entre os níveis dos fatores forma e modalidade sensorial das estimativas de categoria numérica e estimativas de magnitude numérica.

\begin{tabular}{|c|c|c|c|c|c|c|c|}
\hline \multirow{2}{*}{$\begin{array}{c}\text { Estimativas de } \\
\text { categoria numérica }\end{array}$} & \multicolumn{6}{|c|}{ Estimativas de magnitude numérica } \\
\cline { 3 - 8 } \multicolumn{2}{|c|}{} & Reto & Em L & Curvo & Reto & Em L & Curvo \\
\cline { 3 - 8 } & Reto & 0,965 & 0,943 & 0,825 & 0,977 & 0,949 & 0,938 \\
\hline \multirow{3}{*}{ Vidente } & Em L & 0,974 & 0,950 & 0,826 & 0,987 & 0,958 & 0,945 \\
\cline { 2 - 8 } & Curvo & 0,978 & 0,961 & 0,848 & 0,985 & 0,971 & 0,961 \\
\hline \multirow{2}{*}{$\begin{array}{c}\text { Não } \\
\text { vidente }\end{array}$} & Reto & 0,982 & 0,966 & 0,847 & 0,991 & 0,977 & 0,964 \\
\cline { 2 - 8 } & Em L & 0,956 & 0,932 & 0,791 & 0,973 & 0,948 & 0,930 \\
\cline { 2 - 8 } & Curvo & 0,951 & 0,925 & 0,819 & 0,952 & 0,928 & 0,923 \\
\hline
\end{tabular}

Nota: todos os coeficientes das correlações de Pearson são significativos para um valor de $\mathbf{p}=0,000$.

Tabela IX- Coeficientes da correlação de Pearson, do $\mathrm{R}^{2}$ e dos parâmetros da regressão linear para comparações entre os resultados de um participante selecionado de modo aleatório e a média aritmética dos demais participantes para estimação de categoria e a média geométrica para estimação de magnitude.

\begin{tabular}{|l|c|c|c|c|}
\hline \multirow{2}{*}{ Grupo } & \multirow{2}{*}{ Pearson } & \multicolumn{3}{c|}{ Parâmetros da regressão linear e o R ${ }^{2}$} \\
\cline { 3 - 5 } & & $\mathrm{R}^{2}$ & Interseção & Inclinação \\
\hline & & & & \\
\hline EC + Não vidente + Reto & 0,993964 & 0,987964 & 0,291442 & 0,930763 \\
\hline EC + Não vidente + Em L & 0,989271 & 0,978657 & 0,663251 & 0,90035 \\
\hline EC + Não vidente + Curvo & 0,979914 & 0,960231 & 0,244108 & 1,03367 \\
\hline EC + Vidente + Reto & 0,99542 & 0,990861 & $-0,00894$ & 1,006769 \\
\hline EC + Vidente + L & 0,981492 & 0,963326 & $-0,07447$ & 0,950026 \\
\hline EC + Vidente + Curvo & 0,9795 & 0,959557 & 0,267497 & 0,829566 \\
\hline EM+ Não Vidente + Reto & 0,975961 & 0,952499 & $-3,79178$ & 0,814284 \\
\hline EM+ Não Vidente + L & 0,988392 & 0,976918 & 0,389403 & 0,768516 \\
\hline EM+ Não Vidente + Curvo & 0,995536 & 0,991091 & 5,986932 & 0,827863 \\
\hline EM+ Vidente + Reto & 0,994796 & 0,989619 & 3,346846 & 0,848359 \\
\hline EM+ Vidente + L & 0,989137 & 0,978393 & $-3,72406$ & 1,403707 \\
\hline EM+ Vidente + Curvo & 0,977946 & 0,95637 & 1,840225 & 1,509774 \\
\hline
\end{tabular}

Nota: Os valores do nível de significância para as razões $F$ da função linear $y=a+b x$ foram significativos $(p=0,000)$ em todas as situações experimentais. 
Of.CEtP/063/13.08.2004

Senhor(a) Pesquisador(a):

Comunicamos a V. Sa. que o trabalho intitulado "PeRcepção VISUAL E hÁPtica de COMPRIMENTOS DE LINHA EM TRÊS CONTEXTOS DIFERENTES" foi analisado pelo Comitê de Ética em Pesquisa da FFCLRP-USP, e enquadrado na categoria: APROVADO, de acordo com o Processo CEP-FFCLRP n 142/2004 - 2004.1.746.59.8

Aproveitamos a oportunidade para apresentar nossos protestos de estima e consideração.

Atenciosamente,

Profa. Dra. Eucia Beatriz Lopes Petean Coordenadora do CEP/FFCLRP

Ilustríssimo(a) Senhor(a)

ANA PAULA TOSETTO

Departamento de Psicologia e Educação - FFCLRP-USP

C.C. Prof. Dr. JOSÉ APARECIDO DA SILVA 